\title{
J. GABEREL
}

Ancien pasteur

(1857)

\section{VOLTAIRE \\ ET LES GENEVOIS}

Un document produit en version numérique par Gustave Swaelens, bénévole, Journaliste belge à la retraite, Suisse Courriel: gjswaelens@bluewin.ch

Dans le cadre de la collection: "Les classiques des sciences sociales"

Site web: http://www.uqac.ca/Classiques_des_sciences_sociales/

Une collection développée en collaboration avec la Bibliothèque Paul-Émile-Boulet de l'Université du Québec à Chicoutimi

Site web: http://bibliotheque.uqac.ca/ 
Cette édition électronique a été réalisée par Gustave Swaelens, bénévole, Journaliste belge à la retraite, Suisse. Courriel: gjswaelens@bluewin.ch

à partir de :

\section{J. Gaberel (ancien pasteur)}

\section{Voltaire et les Genevois (1857)}

Paris-Genève : Joel Cherbliez, Libraire-Éditeur, Deuième édition revue et corrigée, 1857, 169 pages.

Polices de caractères utilisée :

Pour le texte: Times New Roman 14 points.

Pour les citations : Times New Roman 12 points.

Pour les notes de bas de page: Times New Roman 12 points.

Édition électronique réalisée avec le traitement de textes Microsoft Word 2004 pour Macintosh.

Mise en page sur papier format : LETTRE (US letter), 8.5’’ x 11’’)

Édition complétée le 23 avril 2007 à Chicoutimi, Ville de Saguenay, province de Québec, Canada.

\section{Fait avec}




\section{Table des matières}

Avertissement à l'édition électronique des Classiques des sciences sociales, par Gustave Swaelens, avril 2007.

Avant-propos de l'auteur, 7 octobre 1856.

I. Voltaire à Genève.

II. Voltaire à Lausanne.

III. Voltaire à Ferney.

IV. Bienfaisance de Voltaire. -- Voltaire et le clergé catholique.

V. Moeurs et usages genevois à l'arrivée de Voltaire.

VI. Voltaire et le théâtre à Genève.

VII. Continuation de la lutte avec Voltaire.

VIII. L'Église de Genève et l'Encyclopédie.

IX. Voltaire et la liberté de conscience.

X. Voltaire et M. Moultou.

XI. La presse voltairienne à Genève.

XII. Résistance des Genevois aux idées voltairiennes.

XIII. Les philosophes genevois et Voltaire.

XIV. Résistance des pasteurs genevois à la presse voltairienne.

XV. Voltaire et le ministre Jacob Vernes. -- Mort de Voltaire. 


\section{J. Gaberel \\ Ancien pasteur \\ VOLTAIRE ET LES GENEVOIS}

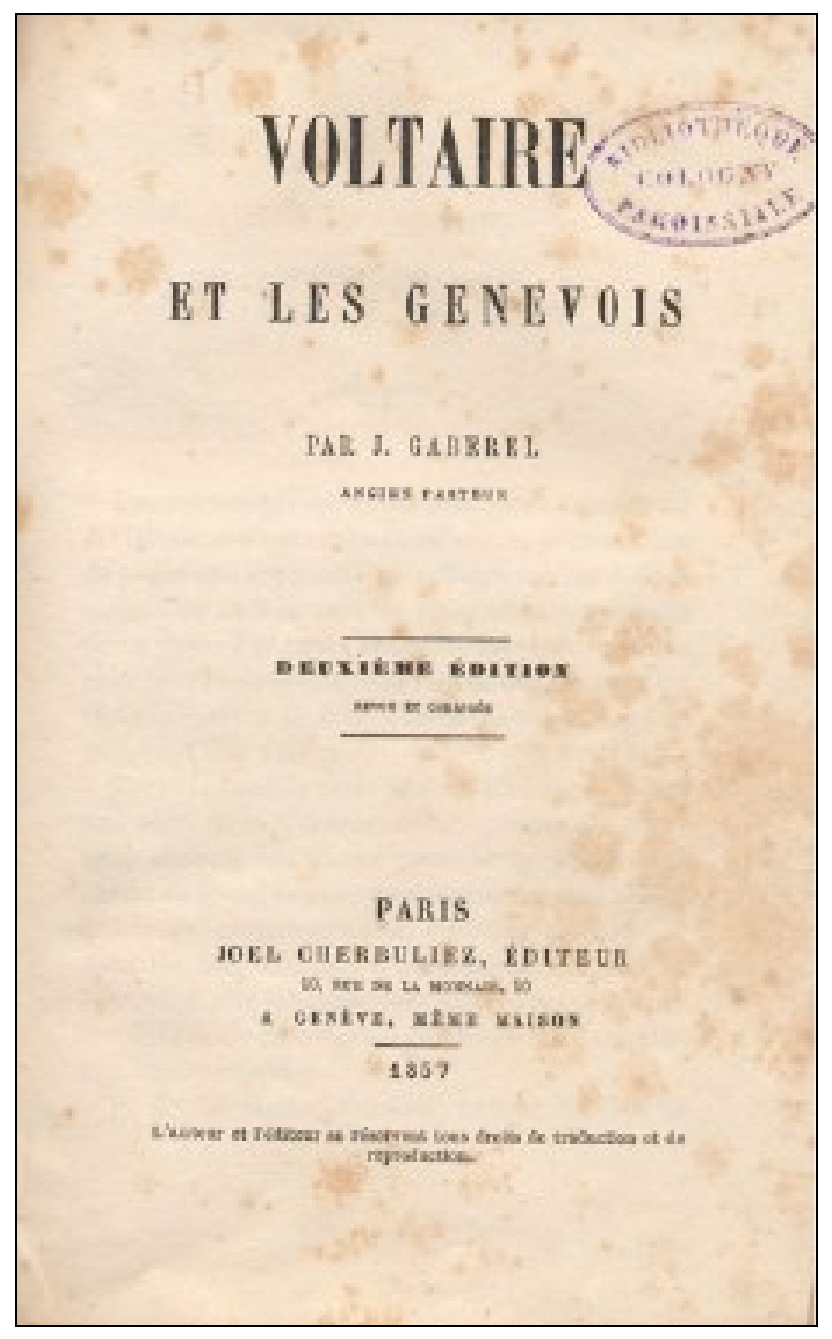

Paris-Genève : Joel Cherbuliez, Editeur, 1857. Deuxième édition, revue et corrigée. 
VOLTAIRE ET LES GENEVOIS

\section{Avertissement}

à l'édition numérique

par Gustave Swaelens, bénévole, Suisse, avril 2007

«Voltaire et les Genevois » est un témoignage sur le quart de siècle passé par Voltaire dans la région lémanique. Dans un avant-propos, l'auteur, J. Gaberel, fait état de nombreuses sources privées suisses contemporaines auxquelles il a eu accès. L'ouvrage traite entre autres des démêlés de Voltaire, avec les autorités religieuses, calvinistes et catholiques, des deux côtés de la frontière franco-suisse, de sa vie quotidienne et de ses interventions dans plusieurs affaires judiciaires (Calas, Sirven, etc.). Il aborde également les relations de Voltaire avec Jean-Jacques Rousseau (auquel J. Gaberel a consacré un autre ouvrage - « Rousseau et les Genevois » - également disponible sur ce site dans la collection «Les auteurs classiques»). 


\title{
VOLTAIRE ET LES GENEVOIS
}

\section{Avant-propos}

\author{
Octobre 1856
}

$\underline{\text { Retour à la table des matières }}$

Les auteurs qui ont écrit l'histoire de Genève au XVIIIe siècle n'ont consacré qu'un très petit nombre de pages aux rapports que Voltaire soutint durant vingt-cinq années avec la population protestante de ce pays. J'ai voulu combler cette lacune et décrire les relations de divers genres que les amis du christianisme à Genève durent soutenir avec le philosophe de Ferney.

Pour recomposer cette période historique, je me suis servi de la Correspondance générale de Voltaire. Mais, à ces lettres connues du public, j'ai ajouté un grand nombre de documents inédits et de brochures contemporaines, enfouies aujourd'hui dans les bibliothèques d'antiquaires. En voici la liste, et je prie les personnes qui me les ont communiquées de recevoir ici l'expression de ma sincère reconnaissance.

De Mme Strekeisen-Moultou. Lettres inédites de Voltaire à son grandpère, le ministre Moultou, au sujet des persécutions religieuses et de la liberté de pensée.

De M. le Dr Coindet. Lettres inédites de Voltaire et brochures contemporaines.

De M. le pasteur Vaucher-Mouchon. Correspondance hebdomadaire entre $M$. Mouchon de Genève et son frère Pierre Mouchon, pasteur à Bâle. 
De M. Vernes-Prescott. Mémoires manuscrits et souvenirs du pasteur Jacob Vernes, son aïeul.

Notes de M. le pasteur Gaberel père, recueillies dans les conversations de M. de Roches, professeur de théologie (1794).

Lettres de Charles Bonnet, collationnées par M. Edouard Humbert, professeur d'esthétique à Genève.

Collections de brochures religieuses et politiques, communiquées par MM. Lullin-Dunant, Gaullieur, professeur, Pictet-de la Rive, professeur, Chaponnière, docteur, et Gustave Moynier.

Anecdotes communiquées par MM. Picot, professeur, Edouard Mallet, Pictet de Sergy, Alphonse de Candolle, professeur, L'hardi, doyen de Neuchâtel.

Extraits des registres des Conseils, du Consistoire et de la Vénérable Compagnie des Pasteurs de Genève (de 1754 à 1778).

Lettres concernant la mort de Voltaire. Extraits de la collection Tronchin, que je dois à l'obligeance de M. le professeur Edmond Scherer.

Lettres et Mémoires du professeur Jacob Vernet. Après avoir extrait de ces documents les faits qui m'ont paru offrir le plus d'intérêt, j'ai donné, durant l'hiver de 1856, un cours public sur les rapports de Voltaire avec les Genevois.

Ce travail livré à l'impression a rencontré beaucoup de bienveillance, et la première édition étant épuisée, $M$. Cherbuliez en publie une seconde où nous avons fait quelques changements autorisés par des documents récemment venus à notre connaissance.

Genève, 7 octobre 1856. 


\section{Voltaire et les Genevois}

$\underline{\text { Retour à la table des matières }}$ 


\section{I \\ Genève et la philosophie du XVIIIe siècle. -- Raisons qui déterminèrent Voltaire à choisir la vallée du Léman pour sa demeure définitive.}

Lorsqu'un peuple adopte un principe généreux, il doit s'attendre infailliblement à susciter une lutte acharnée de la part des adversaires de cette idée. Genève a fait une rude expérience de cette vérité. Au XVIe siècle, notre ville entreprit de protéger la liberté de conscience telle qu'elle pouvait être comprise à cette époque, en même temps que la foi chrétienne réformée devenue celle de ses enfants. Une aussi noble mission, dont l'ultramontanisme saisit dès l'abord la vaste portée, ligua contre elle de redoutables ennemis. Rome, Madrid et Turin voulurent détruire une cité qui, sans territoire, sans richesses, sans armée, osait défendre avec succès les principes de la réforme et ses soldats persécutés 1

1 Les correspondances diplomatiques échangées au XVIIe siècle entre Rome, Madrid et Turin, établissent ce fait d'une manière évidente: il fallait à tout prix que Genève, refuge de l'hérésie, fût convertie ou détruite. 
Cette lutte dura plus de deux siècles. Aussi lorsque vers l'année 1760, les philosophes français proclamèrent la doctrine de la tolérance religieuse. Genève s'associa de coeur au mouvement qu'ils déterminèrent, et se réjouit de voir son plus précieux privilège s'étendre sur les nations voisines. Toutefois cet accord entre les libres penseurs français et la cité de Calvin ne put être complet, car Genève, en repoussant le despotisme romain, avait toujours entendu garder la foi chrétienne dans son intégrité, tandis que les philosophes voulaient envelopper dans la même ruine le fanatisme religieux et la religion elle-même. Genève fut donc obligée de séparer sa cause de celle des hommes qui refusaient à la Divinité toute part dans le gouvernement du monde, et proclamaient qu'en morale la liberté pour chacun de faire ce que bon lui semble est la règle unique de la conscience humaine. Grâce à sa puissante organisation religieuse, notre cité fut longtemps préservée de l'incrédulité française; elle sut déployer contre ces doctrines nouvelles l'énergie qu'elle avait manifestée autrefois envers les vieilles superstitions romaines. Les magistrats, les savants et les pasteurs genevois s'unirent étroitement pour préserver leur ville d'un matérialisme grossier, et leurs efforts furent couronnés de succès positifs. Mais la position des amis du christianisme devint bien difficile à Genève, lorsqu'en 1755 Voltaire résolut de se fixer dans la vallée du Léman.

Le philosophe, devenu vieux, désirait trouver le calme et l'indépendance sur la terre classique du protestantisme, mais son esprit essentiellement dominateur voulut bientôt imposer ses vues et ses tendances aux hommes qui lui donnaient l'hospitalité. Il forma le plan de transformer Genève à l'image de la société française, et, durant vingt années, il multiplia ses efforts et ses travaux, afin, disait-il, " de pervertir cette cité pédante qui conservait un bon souvenir de ses réformateurs, se soumettait aux lois tyranniques de Calvin et croyait à la parole de ses prédicants. »

Voltaire avait soixante et un ans lorsqu'il choisit la Suisse romande pour y venir établir sa demeure. A cette époque, sa gloire remplissait le monde entier, son esprit ne connaissait pas de rival, et comme poëte il était arrivé à se faire placer par ses contemporains bien près de Corneille et de Racine. Une faveur, fort rare au commencement du XVIIIe siècle, s'attachait à sa personne: il avait maintes fois, dans ses 
poésies et dans ses drames, attaqué le fanatisme, et les Français qui acceptaient sans remords le sanglant souvenir de la Saint-Barthélemy, et qui n'éprouvaient que la plus tranquille indifférence pour les derniers bannissements de la Révocation ou les massacres du Désert, applaudissaient à ces beaux vers dans lesquels Voltaire flétrissait la tyrannie religieuse, et sentaient quelques idées vagues de tolérance se glisser et germer dans leurs coeurs.

Néanmoins, en même temps, Voltaire se faisait d'ardents ennemis, ses adversaires multiplièrent leurs efforts pour lui nuire et malheureusement, ce qui rendit les attaques plausibles, c'est qu'il ne sut ou ne voulut point séparer l'Évangile, des crimes commis par les passions humaines armées en son nom. En effet Voltaire confondit toujours la loi de Jésus-Christ avec les misères de la superstition et les cruautés du fanatisme, et cette erreur, involontaire ou raisonnée, lui aliéna les hommes sincèrement religieux; toutefois, ceux qui crièrent le plus fort furent les gens qui faisaient de dévotion métier et marchandise, et qui cherchèrent à venger leur cause personnelle et leur domination temporelle fort compromises par les attaques du philosophe satirique. Ces dévots adversaires étaient si puissants à Paris, que malgré les triomphes intellectuels de Voltaire malgré l'enthousiasme universel excité par la Henriade, Mérope, Zaïre et Mahomet, lorsqu'en 1746 il fut question de recevoir le grand poëte à l'Académie française, ses partisans durent amadouer le parti des jésuites, et Voltaire lui-même dut écrire une lettre où il protestait de son respect envers la religion en général et de son attachement pour les jésuites en particulier. Le philosophe Condorcet, qui approuve toutes les actions de Voltaire, ne peut s'empêcher de dire que, malgré l'adresse avec laquelle sont ménagées les expressions dans cette lettre, il eût mieux valu renoncer à l'Académie que d'avoir la faiblesse de l'écrire. Il est vrai de dire que ces sortes de palinodies ne coûtaient guère au philosophe, et nous aurons plus loin plus d'une occasion de le montrer à nos lecteurs.

Bientôt après sa réception à l'Académie française, Voltaire se rendit en Prusse, sur l'invitation pressante de Frédéric le Grand. Il y resta jusqu'en 1753: à cette époque, il fut obligé de quitter Berlin, où un plus long séjour lui était devenu impossible par suite de son inépuisable malice; Frédéric lui-même était outré de plaisanteries par trop acérées à l'endroit de ses royales poésies. Peu soucieux de revenir en 
France, où il savait que ses ennemis ne manqueraient pas de l'entourer d'intrigues et d'embarras de tout genre, sachant d'ailleurs que l'impression de ses ouvrages s'exécuterait difficilement à Paris, il songeait déjà à la Suisse, lorsqu'il fut visité, à Colmar, par Gabriel Cramer, libraire genevois, qui lui proposa de publier à Genève quelques-uns de ses travaux. -- " Vous êtes imprimeur ? lui dit Voltaire dans sa première visite, -- je vous aurais pris pour un maréchal de camp, » et tout de suite il se prit d'une vive affection pour ce libraire d'apparence si distinguée. Fortifié encore dans sa première idée par les encouragements d'un Vaudois, M. de Polier, le poëte philosophe vint faire d'abord quelque séjour à Pragins, puis, en 1755, il résolut de partager son temps entre Lausanne et Genève. Les registres du Conseil genevois portent en date du 1er février 1755: «On a lu une lettre de M. de Voltaire adressée à noble Tronchin, par laquelle il prie ${ }^{2}$ Messieurs de lui permettre d'habiter le territoire de la république, alléguant l'état de santé et la nécessité où il est de se rapprocher de son médecin, Spectable Tronchin: l'avis a été de permettre audit sieur de Voltaire d'habiter le territoire de la République sous le bon plaisir de la seigneurie. »

2 Terme honorifique s'adressant aux magistrats de Genève. 


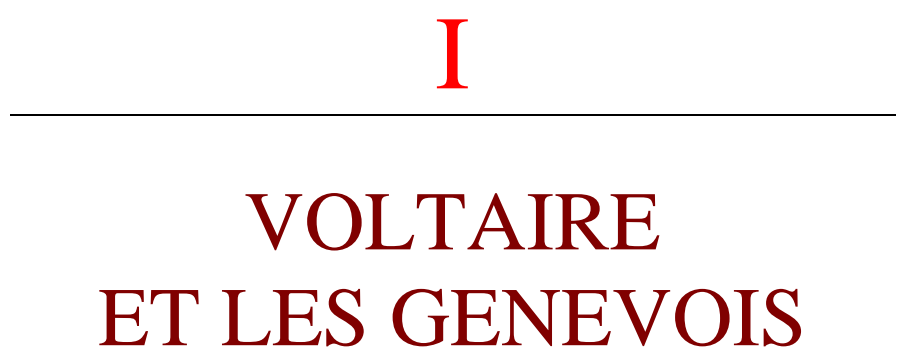

Genève et la philosophie du XVIIIe siècle. -- Raisons qui déterminèrent Voltaire à choisir la vallée du Léman pour sa demeure définitive.

$\underline{\text { Retour à la table des matières }}$

Les catholiques ne pouvant, à l'époque dont nous parlons, acquérir des propriétés à Genève, un négociant fort connu de notre ville, M. Labat, acheta le plateau de Saint-Jean pour le compte de Voltaire, et celui-ci s'empressa d'y construire une somptueuse demeure. En attendant qu'elle fût prête, il acquit à Montrion, près d'Ouchy, une maison d'hiver; en outre, il acheta un magnifique hôtel à Lausanne, rue du Grand-Chêne, no 6; enfin il fit l'acquisition de deux terres en France, dans le voisinage immédiat de la frontière genevoise, l'une à Ferney, l'autre à Tournay (Pregny). Voici comment Voltaire s'exprime au sujet de ces propriétés:

«Toutes ces résidences me sont nécessaires. Je suis charmé de passer facilement d'une frontière à l'autre: si je n'étais que Genevois, je dépendrais trop de Genève; si je n'étais que Français, je dépendrais trop de la France. Je me suis fait une destinée à moi tout seul: j'ai un drôle de petit royaume dans un vallon suisse. Je suis comme le Vieux de la Montagne: avec mes quatre propriétés je suis sur mes quatre pat- 
tes; Montrion est ma petite cabine, mon palais d'hiver à l'abri du cruel vent du nord; puis je me suis arrangé une maison à Lausanne, on l'appellerait palais en Italie, jugez-en: quinze croisées donnent sur le lac, à droite, à gauche et par devant; cent jardins sont au-dessous de mon jardin, le bleu miroir du lac les baigne; je vois toute la Savoie au delà de cette petite a mer, et, par delà la Savoie, les Alpes, qui s'élèvent a en amphithéâtre et sur lesquelles les rayons du soleil forment mille accidents de lumière... Je voudrais, dit-il à d'Alembert, je voudrais vous tenir dans cette demeure délicieuse: il n'y a point de plus bel aspect au monde, la pointe du Sérail à Constantinople n'a pas une plus belle vue... »

La vie matérielle n'était pas moins du goût de Voltaire, et tout en se lamentant, comme il le fit sans cesse, de n'avoir point d'estomac, il pouvait écrire à ses amis: "Allez, nous ne sommes pas bien à plaindre; nous avons le bon vin de la Côte, l'excellent vin de Lavaux, nous mangeons des gelinottes, des coqs de bruyère et des truites de vingt livres. »

Sous le rapport social enfin, Voltaire se montrait également satisfait du séjour de Lausanne. Il ne pouvait se passer d'un peu de philosophie et d'histrionage: entouré d'un cercle nombreux d'hommes de talent et de femmes d'esprit, il leur faisait jouer ses plus récentes créations théâtrales. Les trois pièces qui réussirent le mieux furent: Adélaïde du Guesclin, l'Enfant prodigue et Zaïre; aussi appelait-il ces drames: mes oiseaux du lac Léman. Les acteurs de la noblesse vaudoise lui semblaient parfaits et lui-même se regardait comme un tragédien sans rival: « Je joue le bonhomme Lusignan, et je vous avertis, sans vanité, que je suis le meilleur vieux fou qui soit dans une troupe. Nous avons un très-bel Orosmane, le fils du général de Constant, un Nérestan excellent, un joli théâtre, une assemblée qui fond en larmes; tout le monde joue avec chaleur. Vos acteurs de Paris sont à la glace. Les étrangers accourent de trente lieues à la ronde, et mon beau pays romand est devenu l'asile des arts, des plaisirs et du goût. On croit chez les badauds de Paris que toute la Suisse est un pays sauvage; on serait bien étonné si l'on voyait jouer Zaïre à Lausanne mieux qu'on ne la joue à Paris: on serait bien plus surpris de voir deux cents spectateurs aussi bons juges qu'il y en ait en Europe. Les acteurs se sont formés; ce sont des fruits que les Alpes et le Jura n'avaient point en- 
core portés. César ne prévoyait pas, quand il vint ravager ce petit coin de terre, qu'on y aurait un jour plus d'esprit qu'à Rome. »

Avec le gouvernement bernois, alors maître du canton de Vaud, Voltaire était dans les meilleurs termes, bien qu'il ne se gênât nullement pour railler sans pitié la roideur et la tenue compassée des seigneurs baillis. Il se plaisait en particulier à raconter la conversation suivante: -- « Eh ! que diantre, Monsieur de Voltaire, lui disait un de ces hauts dignitaires, vous faites donc toujours tant de vers? A quoi bon, je vous prie ? Tout cela ne mène à rien... Avec votre talent, vous pouviez cependant devenir quelque chose dans ce pays-ci... Voyez! moi, je suis bailli !...»

Si, au point de vue de la comédie et de la société, les choses marchaient au mieux selon les désirs de Voltaire, à celui de la philosophie, il éprouvait bien certains mécomptes: accoutumé à tout voir fléchir devant ses railleries, traitant les choses religieuses avec une déplorable légèreté, il rencontra chez plusieurs personnes de Lausanne des résistances qui le chagrinaient fort. Le grand Haller surtout lui causait une sorte de frayeur respectueuse: cet homme, unissant une piété profonde à un génie scientifique des plus étendus, lui semblait un phénomène inexplicable; il voulait à tout prix obtenir ses louanges, et le savant bernois conservait une haute franchise qui n'épargnait aucun travers. Un jour Haller vit représenter Zaïre, et comme les spectateurs enthousiasmés lui demandaient son opinion, il leur signala, sans se gêner, un défaut capital dans la pièce: Voltaire, cela ne pouvait manquer, fut instruit séance tenante de la critique du Bernois; sans la relever, il entama bientôt après un magnifique éloge de Haller. "-Eh ! Monsieur de Voltaire, lui dit un auditeur, vous louez bien fort M. de Haller, qui parle de vous sur un ton tout différent ! -- Vous avez raison, mais il se peut bien, au fait, que nous nous trompions tous deux. »

Un autre savant bernois lui inspirait des sentiments très-mélangés; c'était M. Bertrand, pasteur à Yverdon. Tout en le respectant, il ne pouvait s'empêcher de le railler sans pitié, mais Voltaire n'avait pas toujours le meilleur rôle dans la dispute. Le monde savant était alors fort préoccupé de récentes observations faites sur les coquillages fossiles qui se trouvent à de grandes élévations sur les montagnes, et dans 
la présence desquels les géologues suisses voyaient la preuve de la dernière inondation ou déluge qui avait ravagé le globe. Voltaire se moqua à outrance de cette idée et déclara que ces coquillages avaient été certainement semés par les pèlerins qui traversaient les Alpes au moyen âge. M. Bertrand lui ayant montré l'absurdité d'une pareille supposition, le philosophe lui répondit: «Je crois que les Prussiens seraient plus capables de venir en France que les huîtres de Malabar d'être venues sur les Alpes... si les poissons des Indes étaient arrivés chez nous comme nos missionnaires vont chez eux, ils y auraient multiplié et on les trouverait ailleurs que sur nos montagnes. » Ces railleries cachaient mal le dépit de Voltaire, qui était véritablement malheureux lorsqu'il ne pouvait avoir raison des hommes sincèrement attachés aux idées religieuses.

Il eut du reste la satisfaction de pouvoir se dédommager amplement avec un des baillis: c'était celui de Lausanne, froissé de certains rapports qu'on lui faisait touchant des propos tenus par Voltaire, il alla le voir: "Monsieur de Voltaire, on dit que vous écrivez contre le bon Dieu... c'est mal, mais j'espère qu'il vous le pardonnera; on ajoute que vous déblatérez contre la religion... c'est fort mal encore... et contre Notre Seigneur Jésus-Christ lui-même... c'est mal aussi; mais j'espère toutefois que lui aussi vous le pardonnera dans sa grande miséricorde. Mais, monsieur de Voltaire, gardez-vous bien d'écrire contre Leurs Excellences de Berne, nos souverains seigneurs, car vous pouvez bien compter que Leurs Excellences ne vous pardonneraient jamais !... » Lorsque Voltaire avait de nouveaux convives, il ne manquait pas de les régaler de cette anecdote.

Ces habitudes railleuses finirent par troubler son séjour à Lausanne; nombre de ses amis et de ses admirateurs furent blessés de quelques traits par trop rudes, et quelques-uns ne reparurent plus dans son salon. Un autre incident rendit sa position encore plus pénible. Il était lié depuis plusieurs années avec $M$. Polier de Bottens, père de Mlle Isabelle de Montolieu, et pasteur à Lausanne. Il le pria de faire pour l'Encyclopédie l'article Messie. M. Polier accepta, et Voltaire ne doutant pas apparemment que ce morceau ne fût dans le goût des incrédules, écrivit dans un mouvement de joie à d'Alembert: "Les lévites abandonnent l'arche, voici un travail d'un prêtre hérétique de mes amis. » Comme cet article contenait une description simple et positive 
de la personne de Jésus, envoyé divin, il ne plut guère à Messieurs de l'Encyclopédie, qui ne crurent pas toutefois devoir le refuser de la main de Voltaire, et l'article fut imprimé sans modification, bien que Voltaire eût écrit: « Si mon prêtre vous ennuie, brûlez ses guenilles. Il m'a donné un mémoire intitulé Liturgie que j'ai toutes les peines du monde à rendre chrétien. » Ce furent précisément ces peines prises par Voltaire qui commencèrent à le brouiller avec son ami: cette manière de christianiser ses écrits ne pouvait en effet plaire beaucoup à M. Polier. La rupture fut achevée par une autre circonstance qui fait peu d'honneur à Voltaire. On sait qu'un nommé Saurin, parent du célèbre prédicateur et pasteur à Berchier (canton de Vaud), s'enfuit de sa cure et vint à Paris, y fut converti par Bossuet et reçut de Louis XIV une pension de 1,500 livres; comme il était bon géomètre, on le fit entrer à l'Académie des sciences. Plus tard, des hommes impartiaux voulurent savoir la vérité touchant son histoire et les motifs de son changement de religion. Il fut prouvé par les registres de la classe des pasteurs d'Yverdon que ledit Saurin avait quitté son poste afin d'éviter une condamnation pour vol. M. Polier, sachant que Voltaire protégeait beaucoup Saurin, lui communiqua le procès-verbal établissant qu'un jour ce misérable, faisant une prière à la dame du château de Berchier, avait décousu et soustrait les galons d'or du fauteuil de la malade.

Voltaire feignit l'indignation, mais il déchira secrètement le document accusateur. Après la mort de Saurin, une discussion s'étant engagée à son sujet, $\mathrm{M}$. Polier voulut recouvrer les pièces importantes du procès: Voltaire avoua qu'il les avait détruites, et $\mathrm{M}$. Polier rompit toute relation avec le poëte.

Comme la famille Polier tenait un rang élevé dans Lausanne, cette rupture acheva de désorganiser le cercle de Voltaire; des paroles de mauvaise humeur éloignèrent plusieurs dames, et le philosophe, sentant décliner son influence, prit le parti de se défaire de ses propriétés dans le pays de Vaud et de se fixer définitivement à Genève et à Ferney. 
VOLTAIRE ET LES GENEVOIS

\section{III \\ VOLTAIRE À FERNEY}

Voltaire à Ferney. -- Son genre de vie. -- Sa passion de louanges -- Les badauds de Genève. -- Le curé de Saint-Claude. -- Le quatrain de Guibert. -L'empereur Joseph II. -- Le magnat hongrois. -- Le peintre Huber. -- Le quaker Claude Gay.

$\underline{\text { Retour à la table des matières }}$

Voltaire avait acheté la terre de Tournai d'un magistrat de Dijon, le président De Brosses: la correspondance de ces deux personnages dévoile un côté bizarre du caractère du philosophe. Tout poëte qu'il était, Voltaire poussait l'esprit d'ordre jusqu'aux plus minutieux détails; il entendait à merveille les affaires d'intérêt, et soignait sa fortune comme un négociant consommé. 11 acquit Tournai par un marché à vie: la terre rapportant mille écus. Voltaire payait d'avance 24 ans d'intérêts, soit 72,000 francs, et le domaine lui appartenait jusqu'à sa mort; la spéculation était bonne pour l'acheteur, si son existence devait se prolonger au delà du terme de 24 ans. Or il se trouva qu'une forêt indiquée comme devant produire, à la première coupe, environ douze moules de bois, n'en fournit que trois: pour cette somme, s'élevant à peine à cent écus, Voltaire écrivit plus de quarante lettres au président, le chargea d'injures, et remplit sa correspondance générale de doléances à propos de ces bûches. Il avait du temps pour tout ${ }^{3}$.

3 Une famille genevoise, dont l'aïeul était un des conseillers d'affaires de Voltaire, possède une collection de lettres autographes du poëte, où son aptitude aux petite démêlés et son âpreté vis-à-vis de ses voisins se dévoilent de la manière la plus curieuse. 
Une fois établi aux Délices et à Ferney, voici les habitudes intellectuelles qu'adopta Voltaire. Sa célébrité ayant promptement fixé l'attention universelle sur sa somptueuse retraite, elle vit affluer bientôt les plus illustres visiteurs. Voltaire se prétendait constamment malade; était-ce pour exciter l'intérêt, nous ne savons; mais nous pensons plutôt que c'était le stratagème à l'aide duquel il pouvait se ménager à volonté des heures de travail, puis étonner le monde par l'abondance des productions émanées d'une tête soi-disant affaiblie par la souffrance; cette petite santé était encore fort utile à Voltaire lorsqu'il voulait se dérober aux importuns: en tout cas, c'est un fait qu'elle ne l'empêchait point, selon Mallet-Butini, son ami et son voisin, de travailler quatorze heures par jour, et de regagner sur ses nuits le temps qu'il consacrait à la société. Son secrétaire, Wagnière, dormait dans un réduit audessus de sa chambre à coucher, et au moindre bruit descendait par une trappe écrire sous sa dictée. Pendant l'été, Voltaire composait en se promenant à l'ombre de ses charmilles; pendant l'hiver, il travaillait dans son lit.

À table, Voltaire faisait les honneurs de sa maison avec une politesse pleine de gaieté: le soir, au salon, il présidait le cercle, regardant le parquet tandis qu'il parlait, puis promenant soudain ses regards de flamme sur ses auditeurs, comme pour s'assurer qu'il était compris; survenait-il un importun, il prenait l'extérieur d'un vieillard maussade et moribond, et si l'étranger montrait qu'il n'était pas indigne d'entendre Voltaire, aussitôt reparaissaient son entrain et sa sérénité. L'esprit railleur du maître de la maison s'exerçait surtout contre ceux qui avaient eu le malheur de lui déplaire, ou le tort bien plus grave encore de blâmer ses écrits: pour eux il était sans pitié, usant de toutes armes, déchirant, calomniant, ne dédaignant même pas des injures qui ne se trouvent ordinairement que dans le langage des halles; plus d'une fois sa verve en ce genre jeta dans un grand embarras ses convives habituels. En effet Voltaire, qui publiait incognito des oeuvres fort licencieuses, pour mieux dissimuler sa paternité, mettait la conversation sur leur chapitre, les blâmant tout le premier: souvent ses interlocuteurs renchérissaient sur sa sévérité; puis les malheureux, pris au piège, se voyaient assaillis des plus piquantes plaisanteries, dont ils saisissaient trop tard le motif. 
Voltaire aimait fort la louange, mais il voulait qu'elle fût exprimée en termes spirituels, ou parût au moins venir d'un sentiment sincère; toutefois ordinairement il contenait sa satisfaction, souvent même il prenait un malin plaisir à déconcerter ses admirateurs. Ainsi sa présence à Genève, où il se rendait toujours dans un carrosse attelé de quatre chevaux, ne manquait jamais d'occasionner beaucoup de rumeurs: une foule nombreuse se précipitait autour de la voiture jusqu'à gêner sa marche; on ne peut douter que cette manifestation ne flattât grandement celui qui en était l'objet, mais il n'en laissait rien voir. Ses visites les plus fréquentes avaient pour but le comptoir de MM. Macaire, banquiers, au bas de la Cité. Un jour, voyant les curieux entassés jusque sur les marches de cette maison, il s'arrêta sur le seuil et s'écria d'une voix tonnante: «Qu'est-ce que vous voulez, badauds que vous êtes ! voir un squelette ?... Eh bien ! en voilà un !... » Puis, écartant les revers de son habit, il exhiba un grand corps efflanqué, et remonta dans son carrosse, au bruit des applaudissements de la foule. -Plus tard, un bon curé de Saint-Claude vint à Ferney et désira lui être présenté: le brave homme expliqua à Mme Denis que, malgré son grand âge, il avait fait à pied cette longue route pour voir celui qui remplissait le monde de son nom. On le fit entrer: à la vue de Voltaire, le pauvre ecclésiastique demeure tout à fait interloqué et finit par balbutier timidement: "Monseigneur, quand je vous vois, je vois la grande chandelle qui éclaire l'univers. » -- « Madame Denis, réplique vivement le poëte, allez vite chercher des mouchettes. » Et à une dame qui l'avait interrompu pour lui dire: "Ah ! Monsieur, vous avez bien travaillé pour la postérité ! »-- « Oui, Madame, j'ai planté quatre mille pieds d'arbres dans mon parc. »

La louange la plus extraordinaire et la plus scandaleuse qu'il ait eu l'occasion d'entendre lui fut administrée par Guibert, auteur d'une tragédie intitulée: le Connétable de Bourbon. Guibert avait passé huit jours à Ferney sans parvenir à voir le maître du logis: en partant il pria un domestique de remettre à Voltaire les vers suivants:

« Je croyais voir ici le vrai dieu du génie, L'entendre, lui parler, l'admirer en tout point;

Mais, tout semblable au Christ en son Eucharistie, On le mange, on le boit et l'on ne le voit point. » 
À peine Voltaire a lu, qu'il fait atteler son carrosse, court après Guibert, le rejoint, l'embrasse et le ramène: il le garda longtemps auprès de lui.

Cette soif d'admiration causa souvent d'amers désappointements au grand poëte; le plus cruel fut le procédé de Joseph II, empereur d'Autriche, fils de Marie-Thérèse. Ce jeune souverain devant parcourir la Suisse, sa mère lui avait expressément recommandé de visiter $M$. de Haller à Lausanne, mais d'éviter M. de Voltaire. Joseph II vint effectivement de Lausanne à Genève, sans se détourner à Versoix pour passer chez Voltaire, quoiqu'un poteau placé à l'angle du chemin portât en lettres énormes ROUTE DE FERNEY 4

Voltaire avait calculé le moment où l'empereur d'Autriche devait arriver chez lui, et invita tous les habitants riches des environs pour assister à l'entrevue: il était lui-même au salon dans sa plus splendide toilette... Une heure, deux heures se passent... Point d'empereur. La conversation commençait à languir lorsque survient un ami venant de Genève et qui ne sachant pas le but de la réunion, dit dès l'abord: « Il y a bien du mouvement dans la ville: Joseph II vient d'arriver; tout le peuple est amassé devant son auberge; mais il part demain matin. » Chacun se regarda interdit, Voltaire sort à pas de loup; au bout de quelques instants, pâle, en robe de chambre et bonnet de nuit, on le voit entr'ouvrir la porte; puis d'une voix cassée: «Qu'est-ce que tous ces importuns font là ? dit-il. « Ne laissera-t-on pas mourir en paix un pauvre vieux malade comme moi ?»

Tout le monde n'était pas comme Joseph II, et l'empressement que mettaient certains étrangers à visiter Voltaire donna lieu souvent à des scènes plaisantes. Un jour un inconnu demande à le voir. -- « Dites que je n'y suis pas. -- Mais je l'entends, dit l'étranger. -- Dites que je suis malade. -- Je lui tâterai le pouls, a je suis du métier. -- Dites que je suis mort. -- Je l'enterrerai: ce ne sera pas le premier, je suis médecin. -- Voilà un mortel bien opiniâtre... qu'il entre !Š Eh ! Monsieur, vous me prenez donc pour une bête curieuse ? -- Oui, Monsieur, pour

4 Dans une lettre à son ami Haller, Bonnet ajoute que Voltaire avait eu l'attention de faire enlever toutes les pierres sur la portion de route qui joint Versoix à Ferney. 
le phénix. -- Eh bien, sachez donc qu'il en coûte douze sols pour me voir ! -- En voilà vingt-quatre et je reviendrai demain. » -- Voltaire fut désarmé et combla son interlocuteur de politesses.

Les Genevois qui fréquentaient Voltaire étaient très scrupuleux sur le choix des personnes qu'ils présentaient à Ferney. Un magnat hongrois, homme de fort peu d'esprit, tourmentait ses relations pour en obtenir la faveur d'une visite. Afin de débarrasser leurs parents de ses obsessions, les jeunes Chauvet se chargèrent de satisfaire le magyar. Un soir, on le conduit à la campagne dans un carrosse fermé: les arrivants sont reçus par deux laquais à la livrée de Voltaire; l'étranger, introduit dans un salon où règne une clarté douteuse, distingue sur un sofa un vieillard enveloppé d'une robe de chambre et la figure abritée par une immense perruque, lequel toussant creux et parlant à demivoix, reçoit l'étranger fort poliment, lui fait raconter ses voyages, lui débite quelques gaies anecdotes. Le magyar lui demande de si les papiers qu'il voit sur la table ne sont pas quelque chef-d'oeuvre nouveau. « Moins que rien..., un faible enfant de ma vieillesse !... une tragédie. -- Peut-on en savoir le titre ? -- Oh ! ma tragédie est un sujet cher aux enfants de Genève: c'est l'histoire du fameux Empro Giraud; les principaux personnages sont ses non moins célèbres compagnons, Carrain, Carreau, Dupuis, Simon, etc. ${ }^{5}$ "

Puis il déclame quelques vers du chef-d'oeuvre nouveau... La visite terminée, le Hongrois enthousiasmé mit une large offrande dans la main des laquais, frères et amis du pseudo-Voltaire; la mystification continua aux dépens du magyar, car avec son or ses perfides amis lui offrirent un souper où, devant un cercle nombreux, ils lui firent narrer son aventure dans tous ses détails. -- Lorsque Voltaire apprit cette plaisanterie, il voulut voir son Sosie costumé et lui dit: « Je partagerais bien volontiers ma gloire avec vous, si vous vous chargiez de la moitié de mes admirateurs. »

Voltaire avait une grande répugnance à se laisser peindre, et gardait à ce sujet une sérieuse rancune contre le Genevois Huber, artiste distingué et homme de beaucoup d'esprit, qui savait en un instant croquer la physionomie du poëte. Il avait même imaginé une plaisanterie

5 Ces mots forment un jeu familier aux écoliers genevois. 
fort désagréable à Voltaire; il aplatissait un large morceau de mie de pain, et, le faisant mordre à son chien, il dirigeait si adroitement les dents de l'animal que le fragment qui lui restait entre les doigts représentait fidèlement le profil du philosophe de Ferney. Celui-ci finit cependant par prendre son parti des opérations du malicieux peintre et l'invita souvent à dîner., La scène suivante, qui se passa devant l'artiste genevois, lui fournit le sujet d'une de ses meilleures compositions.

Un quaker de Philadelphie, nommé Claude Gay, passa quelques jours à Genève: entendant vanter sa science et sa simplicité, Voltaire désira le voir; le quaker s'en défendit; enfin il accepta une invitation à dîner. Charmé d'abord de la belle et calme figure de son hôte, le philosophe se regarda bientôt comme piqué au jeu par sa sobriété; l'Américain le laissa rire avec le plus grand sang-froid. Puis la conversation tourna sur les premiers habitants de la terre et sur les patriarches, et Voltaire de lancer quelques épigrammes contre les preuves historiques de la révélation, Claude Gay discuta sans s'émouvoir: irrité par sa froideur, la vivacité de Voltaire devint de la colère, si bien qu'à la fin le quaker, se levant de table, lui dit: "Ami Voltaire, peut-être un jour tu entendras mieux ces choses: en attendant, trouve bien que je te quitte. Dieu te conserve et surtout te dirige... " puis il partit sans écouter aucune excuse, Voltaire, honteux de lui-même, prétexta un travail pressé et se retira dans son appartement. -- Hubert dînait ce jour-là à Ferney: il esquissa la scène dont il n'avait rien perdu, mettant en opposition le calme du quaker et la violence du philosophe. Ce tableau, qui portait comme légende: les Adieux de Claude Gay, eut un succès des plus populaires. 


\section{IV \\ Bienfaisance de Voltaire -- Voltaire et le clergé catholique}

Bienfaisance de Voltaire. -- Les agriculteurs de Ferney. -- MM. De Prez de Crassier. -- Les dragées d'Arnaud. -- La malle de Thiriot. -- Mlle Corneille. -- Sévérité du clergé savoisien à l'égard de Voltaire. -- Mahomet et les faucheurs. -- Communion de Voltaire. -- Son sermon dans l'église de Ferney. -- Lettre de l'évêque d'Annecy. -- Voltaire capucin. -- Ferney décrit par un auteur ultramontain.

Voltaire avait un grand plaisir à faire du bien; il donnait beaucoup, faisait un noble usage de sa fortune (deux cent mille francs de rente), et ses générosités étaient rehaussées par des paroles et des procédés empreints d'une spirituelle délicatesse. Un jour on l'informa qu'un laboureur de Ferney était en prison pour une dette de 7,500 fr. Voltaire donna l'ordre de payer cette somme, et comme on lui représentait que ce pauvre homme n'ayant pour tout bien qu'une nombreuse famille, cet argent serait entièrement perdu: " Tant mieux, dit-il, on ne perd point quand on rend un père à sa famille, un citoyen à l'État. » -- Une autre fois, une veuve des environs, mère de deux enfants, étant poursuivie par ses créanciers, eut recours à Voltaire, qui, non seulement lui prêta l'argent sans intérêt, mais encore l'aida à remettre son bien en 
valeur. Ce fonds étant plus tard vendu, Voltaire le racheta beaucoup plus cher qu'il ne valait réellement et remit la différence à la veuve. -Un habitant du village, qui lui devait 600 livres, perdit ses bestiaux: Voltaire lui envoya deux belles vaches et la quittance de sa dette. -Un agriculteur, ayant perdu un procès et se trouvant ruiné, alla trouver le seigneur de Ferney et lui conta ses malheurs: celui ci fit examiner son affaire par des légistes genevois, qui déclarèrent que la condamnation était injuste; lorsque le pauvre homme vint reprendre ses papiers, Voltaire les lui rendit, enveloppant une somme de mille écus, et lui dit: « Voilà, mon ami, de quoi réparer les torts de la justice. Un nouveau procès ne serait qu'un a tourment: ne plaidez plus, et si vous voulez vous établir sur mes terres, je m'occuperai de votre sort. » -- Les jésuites d'Ornex voulaient agrandir leur territoire en acquérant à vil prix un bien de mineurs engagé pour 15,000 francs et valant quatre fois cette somme. La ruine des possesseurs, la famille De Prez de Crassier, était inévitable, lorsque Voltaire fournit les 15,000 livres pour dégager leur bien, et leurs affaires furent depuis si bien dirigées qu'à l'époque de l'expulsion de l'ordre des jésuites, ce furent précisément les De Prez qui purent acheter tous les immeubles de ces religieux.

C'était surtout quand il s'agissait d'hommes de lettres que Voltaire savait entourer ses dons de procédés qui ajoutaient encore au prix du service. Un auteur, Arnaud de Baculard, jeune homme fort pauvre, reçut de grosses sommes de la main du poëte, qui voulait l'encourager dans ses essais dramatiques. Lorsqu'il obtint ses premiers succès, il voulut rendre cet argent à son protecteur, qui le refusa en disant: «Un enfant ne rend pas les dragées que lui a données son père. » -- Un M. Thiriot, qui avait été clerc de notaire avec lui, se trouvait dans une misère profonde: Voltaire le garda pendant un an à Ferney, puis il lui procura la place de correspondant littéraire du grand Frédéric; enfin, lorsque Thiriot le quitta, Voltaire, tout en l'aidant à faire sa malle, y glissa cinquante louis. -- Le trait le plus remarquable de sa bienfaisance est du reste bien connu: on sait qu'il eut pour objet la nièce du grand Corneille, jeune personne fort pauvre. Voltaire la reçut à Ferney, l'adopta, soigna son éducation, et pour lui faire une dot convenable, il composa une édition des oeuvres de Corneille, accompagnée de remarques de sa main. Le livre se vendit 90,000 francs, et Mlle Corneille fut mariée à un M. Dupuis, du pays de Gex. Dans un moment 
d'embarras, le jeune ménage emprunta 12,000 francs à Voltaire: lors de la naissance du premier enfant, le bienfaiteur vint faire une visite à la jeune femme et laissa sur la table un beau vase d'argent dans laquelle se trouvait la quittance des 12,000 livres.

On sait enfin que Voltaire avait fait bâtir la presque totalité du village de Ferney et entretenait la prospérité chez les habitants, ses voisins, par le mouvement énorme d'étrangers qui affluaient pour le voir.

Malgré tous ces actes de bienfaisance, les attaques incessantes de Voltaire contre la religion soulevaient contre lui le clergé de la vallée, et souvent il put s'apercevoir de la méfiance antipathique que ce clergé inspirait à son égard aux habitants de la campagne: les curés savoyards surtout le représentaient comme l'Antechrist, et faisaient de sa personne, à leurs ouailles, des peintures effroyables, Tout impatienté qu'il était de ces bruits, Voltaire trouva plaisant de leur donner du corps: un jour que des ouvriers du Vuache fauchaient près du château de Ferney, il sort soudain de la charmille, revêtu du costume de Mahomet, et leur lance les imprécations du conquérant. Les pauvres Savoisiens s'enfuirent à toutes jambes,' et dès lors l'identité de Voltaire et de Satan fut très-solidement établie sur la rive gauche du Rhône. Toutefois cette antipathie alla si loin qu'elle lui devint absolument désagréable, et il ne craignit pas d'essayer de la conjurer en jouant, de sa personne, une impie comédie en deux actes: il communia dans l'église de Ferney, et se fit recevoir capucin.

Instruit que l'évêque d'Annecy faisait de sérieuses plaintes contre lui à la cour de France, pour détourner le coup, il décida de faire ses pâques à Ferney. La veille, il se confesse à ce père Adam, son aumônier, duquel il disait: " Il ne faut pas s'y tromper... ce n'est pas le premier homme du monde, ", il signe une profession de foi des plus orthodoxes au point de vue romain, et le matin du jour de Pâques il se rend à l'église, accompagné des gens de sa maison, des paysans portant des hallebardes et des fusils, sans compter les tambours et les trompettes. La messe commence: Voltaire se présente à l'autel d'un air humilié et contrit, et reçoit la communion des mains du curé de la paroisse. Jusque-là tout allait bien, au moins au point de vue extérieur; mais voilà que le moment du prône arrive, le seigneur devance le prêtre, escalade la chaire et commence un sermon sur le vol; quelques 
jours auparavant on lui avait dérobé une vache: croyant découvrir son larron dans l'église, il l'apostrophe, l'engage à se réconcilier avec Dieu et l'exhorte à rendre grâces à la Providence de ce qu'il n'a pas été pendu; il l'engage enfin, si sa confession n'est pas faite encore, à venir au plus tôt la faire à son curé et à lui, M. de Voltaire, son seigneur. Malgré le respect qu'on avait pour lui, cette prédication parut un peu forte; le curé sortit brusquement du temple, une partie des paysans le suivit, et cette manifestation mit fin au scandale. L'évêque d'Annecy écrivit à ce sujet à Voltaire une lettre qui est un modèle de sagesse et de dignité: « Le temps presse, lui dit-il, un corps exténué et déjà abattu sous le poids des années vous avertit que vous approchez du terme où sont allés les hommes fameux qui vous ont précédé, et dont à peine aujourd'hui reste-t-il la mémoire; en se laissant éblouir par une gloire aussi frivole que fugitive, la plupart d'entre eux ont perdu de vue les biens immortels. Fasse le Ciel que, plus prudent et plus sage qu'eux, vous ne vous occupiez plus à l'avenir que de la recherche de ce bonheur souverain, qui seul peut remplir les désirs de l'homme fait à l'image de Dieu. » Cette lettre reçut la réponse suivante: « Ce n'est pas assez d'arracher ses vassaux aux horreurs de la pauvreté, de contribuer autant qu'on le peut à leur bonheur temporel; il faut encore les édifier, et il serait bien extraordinaire qu'un seigneur de paroisse ne pût faire dans l'église qu'il a bâtie ce que font tous les prétendus réformés dans leurs temples à leur manière. » Ce fut pour continuer cette mauvaise plaisanterie qu'il sollicita la faveur d'être admis dans l'ordre des capucins, au couvent de Gex; il se vanta d'avoir reçu de Rome la patente du général de l'ordre. Quand à Paris on apprend cette grosse nouvelle, on témoigne quelque incrédulité: " N'en riez point, écrit-il à la Harpe, je suis capucin, père temporel du couvent de Gex; j'ai le droit de porter l'habit et j'ai reçu la patente de notre révérend père le général d'Allambella. » A Madame de Choiseul il mande: « Je recevrai incessamment le cordon de saint François qui, je le crains, ne me rendra pas la vigueur de la jeunesse: en attendant, daignez agréer le respect paternel et les prières de frère François, capucin indigne. »

Le comte de Saint-Florentin, ministre de Louis XV, lui manda d'être plus circonspect à l'avenir, vu que le roi était très-mécontent de cette affaire; Voltaire lui répondit: «J'édifie les habitants de mes terres et de tous les environs en communiant. Le roi veut qu'on s'acquitte de ses devoirs religieux, non-seulement je les remplis, mais j'envoie 
régulièrement mes domestiques catholiques à l'église et les protestants au temple: je pensionne un maître d'école pour enseigner le catéchisme aux enfants; je fais lire publiquement les sermons de Massillon à mes repas. J'ai soin d'informer $M$. le curé des désordres de sa paroisse, quand je les apprends le premier; je l'invite à y mettre fin par ses remontrances et à inspirer le respect pour la religion et les moeurs. »

Pour résumer cette rapide et malheureusement bien incomplète esquisse du genre de vie adopté par Voltaire, noue citerons quelques lignes de M. Nicolardot, auteur ultramontain, qui a déployé la plus injuste sévérité à l'égard du grand poëte: sa description de Ferney n'en est que plus saillante. « La victoire, dit-il, le commerce et l'opulence ont eu leur métropole; Ferney fut pendant vingt années la capitale de l'esprit: tous les monarques s'empressèrent de reconnaître cette principauté, ils la saluèrent à l'envi comme la reine des peuples, le flambeau de la civilisation. Ce que le roi de la civilisation abhorrait, ils l'abhorraient; ce qu'il aimait, ils l'aimaient; ce qu'il aspirait à détruire, ils s'efforçaient de le détruire. Ils lui envoyaient des courriers presque toutes les semaines; ils donnèrent l'ordre à leurs ambassadeurs de respecter toutes ses fantaisies, de favoriser toutes ses entreprises, d'oublier toutes ses fautes. Les Parlements avaient brûlé d'envie de sévir contre la cour de Ferney, mais la cour de France laissait faire, L'évêque d'Annecy le menaçait de ses foudres, mais la ville aux sept collines, la ville du vicaire de Jésus-Christ tolérait ses insolences continuelles et ses injures grossières... Des flots d'étrangers y affluaient sans cesse, ducs, maréchaux, gentilshommes, académiciens, présidents, coudoyaient l'avocat, l'officier, le prêtre, le robin, le journaliste. Tout chemin conduisait à Ferney comme autrefois à Rome. Se proposait-on de parcourir Venise, Gênes, Florence, Naples, on passait par Ferney. Désirait-on baiser la mule du pape ou les pieds de l'impératrice de Russie, on traversait Ferney. Quel que fût le sujet du départ, amour, intrigue, affaires, guerre, persécution, plaisir, curiosité, santé, on faisait halte à Ferney. C'était la capitale autocratique de l'esprit dans un siècle où tout le monde se piquait d'avoir de l'esprit. »

Ainsi parle l'auteur ultramontain, et nous ajouterons qu'à une lieue de Ferney se trouvaient douze pasteurs huguenots et autant de magistrats religieux qui, considérant comme leur devoir de maintenir la foi 
chrétienne dans la conscience du peuple confié à leurs soins, ne craignirent pas de lutter pendant vingt années avec cette royauté si universellement reconnue de l'esprit et de l'irréligion. Ce sont les détails de cette lutte que nous devons maintenant essayer de retracer. 


\section{$\mathrm{V}$ \\ Moeurs et usages genevois à l'arrivée de Voltaire}

Sous le rapport social et religieux, Genève était organisée de manière à présenter une vigoureuse résistance à l'invasion des nouvelles idées françaises. Quoique, au milieu du XVIIIe siècle, la législation de Calvin eût subi, cela va sans dire, de nombreuses modifications, néanmoins les principales dispositions de ce remarquable ensemble, organisé plus de deux siècles auparavant par la vigoureuse conception du réformateur, étaient encore pleinement appliquées et observées. Un coup d'oeil rétrospectif sur les lois ecclésiastiques de Genève est donc nécessaire pour l'intelligence de la période que nous avons à étudier.

Calvin, en établissant dans Genève la réforme religieuse, avait voulu la rendre sincère, complète et solide, en la plaçant sur sa véritable base, la réforme des moeurs publiques et privées. Suivant donc ce plan avec sa rigoureuse logique, à côté des modifications aux institutions religieuses, il créa tout un système parallèle d'ordonnances, destinées à atteindre et à régler la vie pratique, et frappées au coin d'une exemplaire austérité. Sous sa main puissante, la rigidité du législateur de Sparte, doublée de toute la sévérité morale du christianisme à son premier âge, formèrent, à côté de la constitution républicaine de Genève, un ensemble de lois aussi fondamentales pour ce petit pays, aus- 
si constitutionnelles, en un mot, que sa constitution politique ellemême. C'est ainsi qu'en partant du principe, alors universellement adopté, de la religion d'État, Calvin fonda un État réellement chrétien, parce qu'il força, c'est le mot, chaque citoyen d'être chrétien. Ces lois, dites lois somptuaires, introduisaient une surveillance générale, accompagnée de l'action des tribunaux, dans les plus petits détails de la vie ordinaire; non-seulement, au point de vue social, elles punissaient par l'amende, l'exil ou la prison, les violations des commandements de Dieu, et par conséquent plus d'un délit que ne prévoit pas la législation civile, mais encore elles pénétraient fort avant dans l'existence privée: le logement, la nourriture, les vêtements, les divertissements, la dépense en général, étaient déterminés par des règlements inflexibles. Calvin avait cherché et obtenu, au moyen de la contrainte légale, ce que l'Évangile ne demande qu'au libre exercice de la volonté, et, pénétré des idées de son siècle, il ne croyait point avoir outre passé son mandat en infligeant des châtiments matériels pour des fautes que Dieu jugera sans doute, mais que les lois humaines doivent laisser dans le domaine de cette juridiction divine.

Du reste, si l'action du tribunal moral institué par Calvin, sous le nom de Consistoire, était rude à notre point de vue moderne, ce corps se montrait rigoureusement impartial, ne laissant aucune distinction entre les classes sociales, et censurant ou punissant avec une égale sévérité le premier magistrat et le plus mince bourgeois de millionnaire et le paysan, le chef militaire et le simple soldat.

Cette législation, qui obligeait les citoyens à la plus grande simplicité dans leur genre de vie et réduisait leurs dépenses au strict nécessaire, imprima au caractère genevois une austérité dont on ne retrouve guère l'équivalent que dans l'histoire de Lacédémone ou celle des premiers temps de la république romaine. A Genève, la journée commençait pour tout le monde à six heures en hiver et à quatre heures en été: nos ancêtres paraissent avoir été beaucoup moins sensibles au froid que leurs héritiers actuels, puisqu'un seul feu s'allumait dans chaque ménage quelle que fût la saison, celui de la cuisine; à peine, chez les familles riches une brazière se voyait-elle dans la chambre de réunion. On ne connaissait que les meubles de bois ordinaire. Des fenêtres hermétiquement fermées passaient pour un véritable luxe, et l'on s'inquiétait fort peu en général des larges ouvertures qui donnaient 
passage à la bise. Une grande frugalité s'observait dans les repas, et cette simplicité a survécu un certain temps au naufrage des vieilles coutumes de la Réformation, car la loi portant « de n'avoir sur la table, en jour ordinaire, que deux plats au plus, viande et légume, sans pâtisserie, » est encore de nos jours régulièrement observée dans un grand nombre de ménages genevois. La simplicité des moeurs allait plus loin encore: les habitudes du culte de famille, les conversations sans cesse tournées vers les sujets religieux avaient beaucoup rapproché les maîtres et les serviteurs; elles les réunissaient à la même table, et le plus souvent il n'y avait pas d'autre salle à manger que la cuisine; après les repas, la conversation entre voisins s'engageait dans les cours intérieures des maisons, que maintenant nous jugerions peu confortables pour un semblable usage.

À côté de cette austérité, en même temps morale et matérielle, trouvait place chez les Genevois, et c'est un caractère saillant de l'institution de Calvin, un large développement littéraire et intellectuel. Le collége, où tous les enfants s'instruisaient jusqu'à seize ans, avait considérablement élevé le niveau intellectuel de la nation. Un voyageur du XVIIe siècle, Davily, s'étonne de voir qu'à Genève on fasse des lettrés des fils des plus humbles artisans: "Car chez ce singulier peuple, dit-il, on enseigne le grec et le latin aux gens qui ailleurs ne savent ni A, ni B. »

Ce mélange de simplicité républicaine et de fortes études favorisa certainement les développements du négoce et de l'industrie. Le commerce des soies et des velours fut pour Genève une grande source de richesse durant le XVIIe siècle: de 1700 à 1730, de grandes entreprises commerciales, habilement conduites, ajoutèrent encore à ces féconds résultats. La ville, exténuée et ruinée peu auparavant par les sacrifices qu'elle s'était imposés en faveur des réfugiés de la révocation de l'Edit de Nantes, ne s'en trouva pas moins, à l'époque que nous indiquons, dans la situation la plus prospère.

Les riches Genevois employèrent dès lors une notable partie de leur fortune à renouveler l'aspect de la ville. Habitués que nous sommes aujourd'hui aux belles et solides constructions des quartiers d'en haut, nous pourrions penser qu'il en fut toujours de même; cependant, au fond, c'est aux façades de la Pelisserie et aux baraques du nord de 
l'Ile que nous devrions nous adresser pour trouver dans la ville actuelle des morceaux d'architecture propres à nous donner une idée de l'aspect qu'offrait, avant le XVIIIe siècle, aussi bien la zone élevée de la colline genevoise que sa partie inférieure. Mais en quelques années tout avait changé de face: Beauregard, la Treille, la rue des Granges, celle des Chanoines, la Grand'Rue, la Cité, la rue de l'Hôtel de-Ville, la place Saint-Pierre, la Taconnerie, l'Hôpital, le Temple-Neuf, le Grenier à blé, la façade neuve de la cathédrale, s'élevèrent avec une rapidité que les constructions parisiennes dépassent à peine aujourd'hui.

D'autre part, ce développement de prospérité matérielle ne pouvait manquer d'introduire une profonde modification dans les habitudes sociales: " Nous avons des portes cochères, dit un pasteur, mais par ces portes cochères le luxe entre à deux battants. » En effet, un assez grand nombre de citoyens faisaient de longs séjours à Paris, et ils en revenaient, cela se comprend aisément, fort peu charmés de leur précédente manière de vivre. A des hommes qui venaient de briller sous des habits de velours et de soie, de voir de près les splendeurs de la cour et les magnificences du théâtre, de jouir du charme des conversations et de l'esprit de ces admirables causeurs du XVIIe siècle, il faut avouer que la puritaine Genève devait paraître bien sombre et bien froide. Il était dur de renfermer, de par la loi, les habits brodés, les dentelles, les bijoux, pour revêtir la bonne serge et le drap noir, seuls autorisés par les ordonnances. Ces privations excitaient d'amers regrets, et les fêtes, les comédies et les violons de la capitale retentissaient en bruyants souvenirs dans une vie monotone, compassée et plus sévèrement réglée que celle de bien des couvents. Sous cette impression, on lançait des épigrammes d'abord, puis on donnait des fêtes en dépit des amendes et des peines consistoriales; on murmurait, on se révoltait fréquemment de fait contre les ordonnances somptuaires; l'antipathie qu'inspiraient leurs prescriptions surannées ne se donnait pas la peine du raisonnement, et nul, parmi leurs adversaires, ne songeait à se demander si la République pourrait subsister en adoptant le luxe, les usages de la France, et surtout son élégante corruption.

Ainsi, vers le milieu du XVIIIe siècle, la nation genevoise était divisée en deux classes bien tranchées: d'une part, les citoyens invariablement attachés à l'antique simplicité protestante; de l'autre, ceux qui, 
placés sous l'influence immédiate de la civilisation étrangère, se montraient hostiles à des lois qui ne portaient que trop le cachet de leur vieil âge.

Voltaire eut bientôt jugé de l'état des choses et s'empressa de calculer les moyens « de corrompre la pédante ville. » L'établissement d'un théâtre lui parut la mesure la plus urgente pour atteindre ce but; c'est lui-même qui le dit. 


\section{VI \\ VOLTAIRE ET LE THÉÂTRE À GENEVE}

Le théâtre à Genève avant Voltaire. -- Les orages politiques et la comédie. -- Les garçons barbiers jouant la tragédie. -- Représentations dramatiques aux Délices et à Tournay. -- Opposition du Conseil et db Consistoire. -- Lettre de Rousseau contre le théâtre à Genève. -- La comédie à Châtelaine. -Lekain à Ferney et enthousiasme des Genevois pour le célèbre tragédien. -Voltaire dans les coulisses. -- Voltaire et les magnifiques seigneurs qui le sifflent. -- Les Chasse-gueux au théâtre de Châtelaine. -- Opposition des citoyens et incendie du théâtre de Genève. -- Mot de Voltaire: perruques et tignasses.

Dix-huit ans avant l'arrivée de Voltaire à Genève, cette ville avait dû permettre temporairement l'établissement d'un théâtre, et voici quelle occasion fut plus forte que les vieilles prescriptions interdisant « toute représentation comique. »

En 1737, il s'était élevé dans Genève de terribles discordes, dans lesquelles les deux partis politiques en lutte eurent des torts à peu près égaux; le sang des citoyens fut répandu et la ville se divisa en deux camps animés l'un contre l'autre d'une haine implacable. Les cours de France, de Sardaigne et les cantons suisses offrirent leur médiation, qui réussit à ramener dans la République une paix apparente. Les ambassadeurs et leur suite, trouvant fort peu de récréations dans Genève, demandèrent instamment l'établissement d'un théâtre, et, malgré sa répugnance, le gouvernement dut y consentir. Un bâtiment en bois fut 
élevé à côté de la Place-Neuve: le Consistoire adressa, à ce sujet, les plus sérieuses remontrances, et obtint que la permission ne dépasserait point le terme d'un an; ce délai expiré, il réclama la clôture des représentations, et voici les considérants qu'il émettait à l'appui de cette requête: «Il est triste de penser que les comédiens finissent leur campagne en déclarant qu'ils n'ont trouvé à vivre qu'ici et que cette ville est le Pérou. Ils ont raison, car tous frais payés, l'hôpital subventionné, ils emportent 15,000 francs, et malheureusement ce sont les personnes gagnant leur vie qui ont fourni la majeure partie de cette somme. De plus, ce qui doit faire penser que la comédie convient ici moins qu'ailleurs, c'est le goût extraordinaire qu'on a fait paraître pour les plaisirs et le spectacle: ce goût est si prononcé qu'il a eu la force de suspendre l'impression des malheurs publics les plus effrayants. Quand on pense que des visages sur lesquels on voyait la crainte et la douleur empreintes à la suite de nos désastres politiques, ont paru dès le lendemain de la première comédie tout brillants de joie et désireux de se divertir, on ne peut s'empêcher de croire qu'il y a dans cette ville un goût prodigieux pour le plaisir, auquel il est bien important de ne pas fournir de nouveaux aliments. » Le résultat de la démarche du Consistoire fut la fermeture du théâtre, mais les paroles mêmes que nous venons de citer nous dévoilent l'énergie du penchant des Genevois pour ce divertissement et l'impossibilité de conserver, en 1740, la rigueur des coutumes du XVIe siècle. Les faits ultérieurs se chargent bien, du reste, de le prouver à eux seuls. En effet, on transporta dans les maisons particulières des essais dramatiques destinés à remplacer le spectacle, qui n'était plus légalement autorisé, et le Consistoire dut, à maintes reprises, réprimander des citoyens prévenus du délit de " comédie à domicile. " Si nos ancêtres eussent choisi leurs pièces dans les ignobles répertoires de la foire et des carrefours, on pourrait approuver la sévérité ecclésiastique de l'époque; mais l'esprit des Genevois, formé par leurs études du collége au goût de la bonne littérature, se manifestait, d'une manière remarquable dans le choix de leurs récréations dramatiques. La haute comédie et les plus belles tragédies étaient invariablement étudiées par les acteurs bourgeois, et quelle que fût la classe sociale des amateurs, ce fait ne présente aucune exception. Chose singulière, parmi les ouvriers, les gens les plus passionnés pour le drame étaient les garçons barbiers et perruquiers. Voici quels furent, à l'occasion de ce fait, leurs rapports avec le Consistoire. On les mande pour les censurer parce qu'ils ont représenté Polyeucte, Cinna, ou Mahomet 
et le Registre s'exprime en ces termes: "A comparu le sieur Aubert, maître à danser, appelé céans pour avoir prêté territoire aux fins de représenter la tragédie de Mahomet: il avoue qu'il a prêté sa salle et qu'il a dansé en habit de paysanne durant les intermèdes, ce dont il est gravement réprimandé. »

Un autre jour « ont comparu quinze garçons perruquiers et barbiers, appelés pour avoir été acteurs dans la tragédie de la Mort de César, représentée chez le sieur Joubert; ils ont été censurés et exhortés à mieux observer les ordres de leurs supérieurs, et de s'attacher à leur profession sans s'arrêter au jeu ou à d'autres excès. " Ces censures consistoriales, fréquemment répétées, ne corrigeaient du reste personne, et les représentation, dramatiques étaient des plus fréquentes lorsque Voltaire vint s'établir aux Délices.

Nous avons vu les succès qu'il obtint à Lausanne en faisant jouer ses pièces par des acteurs vaudois; Voltaire supposa qu'il recevrait à Genève des encouragements analogues, et son théâtre se trouva prêt avant que la maison fut terminée. Plusieurs familles riches acceptèrent ses invitations, et le poëte n'eut rien de plus pressé que d'organiser des comédies, sur lesquelles il comptait " pour dominer la société genevoise. »

Aussi fut-il grandement irrité lorsqu'il apprit que la majorité du Conseil d'État et le Consistoire blâmaient son entreprise. Voici la délibération qui eut lieu à ce sujet le 31 juillet 1755: «M. le pasteur de Roches a dit, que le sieur Voltaire se dispose à jouer des tragédies chez lui, à Saint-Jean, et qu'une partie des acteurs qui suivent les répétitions sont des particuliers de cette ville: dans ce but, il a fait bâtir un théâtre et préparer des décorations... Le Conseil déclare qu'il maintiendra la défense, qui est la même pour tous, et il invite Messieurs les pasteurs de la ville à visiter les personnes à qui $\mathrm{M}$. de Voltaire distribue des rôles, pour les engager à s'abstenir. »

M. le professeur Tronchin rapporte que, dans une visite qu'il fit quelques jours plus tard à Voltaire, celui-ci lui témoigna « être fort fâché d'avoir donné lieu à quelques plaintes au sujet d'une tragédie qu'on devait représenter chez lui, mais que c'était moins sa faute que celle de ses visiteurs, lesquels ne l'avaient pas averti. Qu'à présent qu'il 
est bien informé, il se donnera garde d'y contrevenir, son intention ayant toujours été d'observer avec respect les sages lois du gouvernement. "

En effet, durant trois années, Voltaire, passant les hivers à Montrion, s'abstint d'organiser aux Délices des représentations théâtrales " avec costumes et décorations. ", Mais ne pouvant se passer de ce plaisir, et la majorité du Conseil demeurant inflexible, il fit construire une salle à Tournay (Pregny), sur la frontière genevoise. Dès lors il avait pleine liberté, et, pour mieux attirer les amateurs, il y fit jouer plusieurs artistes de la Comédie-Française, que le fameux Lekain avait conduits aux Délices auxquels voulurent bien se joindre plusieurs dames genevoises pour compléter la troupe de Tournay. Pour le coup, le scandale parut trop grand; on allait répétant dans les cercles: «A quoi servent les lois si, pendant qu'on nous défend de jouer la comédie dans nos maisons, les dames peuvent la jouer chez M. de Voltaire ? » -- Et la Compagnie des Pasteurs finit par adresser au Conseil une remontrance dont voici la partie la plus saillante: «Il est contre la décence publique et bien affligeant pour tout bon citoyen que des personnes destinées par leur naissance, leur éducation et leurs talents, au gouvernement de l'État se produisent sur un théâtre presque public pour mériter les éloges de vrais comédiens: de jeunes dames, qui devraient donner des exemples de modestie, osent se mettre en quelque sorte au rang des comédiennes, en sorte que le goût pour le théâtre, fait des progrès dangereux et fortifie le penchant, qui ne règne que trop, pour la dissipation, le luxe et la dépense. Ces dissipations influent nécessairement sur les moeurs et font naître des sentiments d'indifférence pour la religion et la patrie. L'exemple des personnes riches peut être suivi par des gens de tout état qui y perdront leur argent et leurs principes. Pour remédier à ce mal, il faut qu'on fasse au sieur de Voltaire une défense expresse de faire jouer ou permettre qu'on joue aucune pièce de théâtre, soit par représentation publique, soit par répétition, pour éviter tout sujet équivoque. Puis le Petit Conseil fera défense expresse à tous sujets de cet État de représenter des pièces, tant sur le territoire que dans les environs. " A la suite de ces observations, le Conseil fit tout ce qu'il pouvait faire: il prit des mesures sévères contre les acteurs de Tournay. 
Voltaire, on le comprend, ne voulut pas laisser au Conseil le dernier mot: « On jouera la comédie aux Délices, s'écria-t-il; on la jouera malgré les perruques genevoises !» Et Lekain lui fut un merveilleux instrument pour déjouer la résistance des magistrats genevois: « J'attends Lekain, écrit-il à d'Argental; il déclamera des vers aux enfants de Calvin: leurs moeurs sont fort adoucies, ils ne brûleraient plus Servet. A propos de Calvin je vais leur jouer un tour dont ils me sauront mauvais gré: je me suis procuré un vieux fauteuil qui servait de chaise ou de chaire à leur réformateur; je l'emploierai dans l'entretien d'Auguste et de Cinna; le beau bruit quand les prédicants le sauront ! »Et, quelques jours plus tard, il peut ajouter: «Eh bien, j'ai réussi; j'ai fait pleurer tout le Conseil de Genève; Lekain a été sublime, et je corromps la jeunesse de cette pédante ville, »

Plût à Dieu que cette corruption se fût bornée à faire entendre Lekain à la jeunesse genevoise !

D'Alembert se trouvait alors aux Délices: il composa, sous la dictée et les inspirations de Voltaire, l'article GENÈVE, qu'il inséra dans l'Encyclopédie, et sur lequel nous reviendrons plus tard à un autre point de vue. Voici le passage qu'il y consacre au théâtre: «On ne souffre point de comédie à Genève: ce n'est pas qu'on y désapprouve les spectacles en eux-mêmes, mais on craint le goût de la parure, la dissipation, le libertinage que les troupes de comédiens apportent avec elles. Cependant ne serait-il pas possible de remédier à cet inconvénient par des lois sévères et bien exécutées sur la conduite des comédiens. Par ce moyen Genève aurait des spectacles et conserverait ses moeurs: les représentations théâtrales formeraient le goût des citoyens, leur donneraient une finesse de tact, une délicatesse de sentiments qu'il est bien difficile d'acquérir sans ce secours. »

Rousseau écrivit alors un traité de 200 pages sur l'usage et l'abus des spectacles; il montra tous les dangers de cette institution pour Genève au point de vue patriotique. Le Consistoire se joignit à Rousseau, et le mandement qu'il publia à ce sujet (17 novembre 1760) reflète, au point de vue religieux, les idées et les princi_pes défendus avec tant de chaleur par notre illustre concitoyen. 
L'opposition que Voltaire rencontrait ne fit que le fortifier dans ses résolutions: ne pouvant introduire officiellement la comédie dans les murs de Genève, il annonça à grand bruit l'ouverture du théâtre de Châtelaine. Les Genevois, amis des anciennes coutumes de la République, les citoyens, partisans des principes de Rousseau, s'employèrent à l'envi pour entraver ce projet. La Compagnie des Pasteurs ordonna une visite générale des paroisses, " aux fins d'obtenir des adhésions contre le théâtre de $\mathrm{M}$. de Voltaire. » Les promesses d'abstention furent si nombreuses qu'on put croire que les comédiens joueraient dans le désert. "Mais quelle déception, écrit un témoin oculaire, M. Mouchon. Le théâtre est achevé, le jour de l'ouverture fixé. Des assemblées ont eu lieu dans les cercles; les vrais patriotes, amis de la religion et du pays, s'engagent volontairement à n'y pas mettre les pieds; ils vouent les comédiens à l'abandon et à la misère: on se roidit, on se prépare à lutter contre la tentation; mais, hélas ! le jour arrive... et le soir de ce jour tout le monde va à Châtelaine... c'était comme une procession ! » Un peu plus tard, M. Mouchon écrit encore: « Tout l'intérêt que devait causer le tirage de la loterie a été absorbé cette semaine par la passion pour la comédie; il semblait qu'on allait chercher le gros lot à Châtelaine par la fureur avec laquelle on s'y portait. Ce grand concours a été excité par le sieur Lekain, célèbre acteur de Paris, qui, étant venu visiter Voltaire à Ferney, a été sollicité de représenter sur le théâtre de Châtelaine, et y a joué effectivement trois fois la semaine dernière dans trois pièces de Voltaire, Adélaïde, Du Guesclin, Mahomet et Sémiramis. Je ne saurais vous peindre toutes les folies qui se sont faites à l'envi pour voir représenter cet homme-là, et les foules de monde qui y couraient dès le matin, malgré le mauvais temps. On a payé jusqu'à un louis le louage d'une voiture; on n'en trouvait plus... L'on faisait venir les plus mauvaises carrioles de Chênes et de Carouge. Moi qui vous parle, j'ai participé à la folie générale et je n'ai pu résister à la curiosité de voir le célèbre acteur. Je me réservais pour samedi, qu'on devait jouer Sémiramis: je savais qu'il brillait le plus dans le rôle de Ninias. Je réparai à force de travail le temps que je devais donner le lendemain, car j'étais à Châtelaine à onze heures et demie du matin, et encore trouvai-je le parterre rempli. Mais je vis tout aussi bien depuis les secondes loges, et j'eus l'avantage d'avoir la compagnie de M. Mussard, ancien syndic, qui, lui aussi, avait fait une exception de ses principes patriotiques contre la comédie en faveur de l'acteur en question. -- Je vis des choses sublimes et qui sur- 
passèrent encore l'idée que la renommée m'avait donnée de ce parfait acteur. Comme toutes les passions venaient se peindre sur son visage ! Quelle magnifique récitation ! quels gestes cadencés ? quelle brillante pantomime! Mais c'est encore moins l'art que l'on admire en lui, ce sont ces écarts, cette fougue impétueuse, cet involontaire oubli de soimême qui enlève au spectateur le temps de l'examen et au critique le froid compas de l'analyse. Tel est le moment où il sort du tombeau de Ninus, croyant avoir frappé Assur, tandis qu'il vient de tuer Sémiramis. C'était le triomphe de la nature: aussi le frémissement était-il universel. Mais ce qui ne fut pas une des moindres parties du spectacle, ce fut Voltaire lui-même, assis contre la première coulisse, en vue de tous les spectateurs, applaudissant comme un possédé soit en frappant avec sa canne, soit par ses exclamations: «On ne peut pas mieux ! -Ah ! mon Dieu, que c'est bien ! » soit en prêchant l'attendrissement d'exemple et portant son mouchoir à ses yeux. Il fut si peu maître de son enthousiasme que, dans un moment où Ninias quitte la scène après avoir bravé Assur, sans crainte de déranger toute l'illusion il courut après Lekain, le prit par la main et l'embrassa vers le fond du théâtre. On ne pourrait imaginer un ambigu plus comique, car Voltaire ressemblait à un de ces vieillards de comédie, les bas roulés sur ses genoux et habillé suivant le costume du bon vieux temps, ne pouvant se soutenir sur ses jambes tremblantes qu'à l'aide de sa canne. Toutes les traces de la caducité sont empreintes sur son visage, ses joues sont caves et ridées, son nez prolongé, ses yeux presque éteints; mais, comme dit Fréron, cette tête glacée renferme un volcan toujours en éruption, quoique avec des flammes il jette aussi de la fumée et des cendres. »

Voltaire ne négligeait rien, comme on le voit, pour produire de l'effet sur les Genevois et les attirer à lui; il employait des acteurs de grand talent et faisait jouer à Châtelaine ses meilleures pièces; les habitués montraient leur gratitude pour ces procédés en applaudissant à outrance les oeuvres du poëte. Toutefois, un beau soir, les choses tournèrent autrement. Voltaire faisait, par exception, représenter une de ses plus insignifiantes productions, intitulée Charlot; c'est la vieille histoire d'un enfant de la campagne changé en nourrice contre le fils d'un seigneur. D'après les idées du temps sur la noblesse innée, le paysan anobli commet toutes les grossièretés imaginables, malgré la bonne éducation qu'il reçoit dès le berceau, tandis que l'enfant noble 
fait et dit naturellement les plus belles choses sous le sarrau du laboureur.

Cette donnée ne plut guère aux spectateurs républicains de Châtelaine, et comme, du reste, ce drame est fort médiocre, le parterre fit preuve de goût sinon de politesse, en sifflant sans miséricorde; il ne voulait pas laisser terminer la représentation. Tout d'un coup, au plus fort du tumulte, s'avance hors de sa loge le grand corps de Voltaire, qui, gesticulant de sa canne vers les spectateurs, leur crie de sa plus tonnante voix: "Magnifiques et très-honorés Seigneurs! je suis chez moi, et si vous ne vous tenez pas tranquilles, je vous fais administrer la plus robuste volée que votre République ait jamais reçue ! » Les applaudissements et les rires accueillirent cette boutade, qui fit écouter jusqu'au bout la pièce menacée.

Une plaisanterie d'écolier mit Voltaire dans un nouvel accès de fureur. Un jeune Anglais, le fils de lord Mahon, demeurait à Genève. Il imagina de faire habiller de neuf les chasse-gueux (valets de voirie) de la ville, et puis il leur remit l'argent nécessaire pour prendre des billets de loges au théâtre de Châtelaine. Lorsque les Genevois reconnurent ces étranges spectateurs, il s'éleva un tumulte difficile à décrire. Les chasse-gueux persistèrent longtemps, déclarant qu'on les avait payés pour voir le spectacle et qu'ils ne sortiraient point de la salle. Ils se rendirent néanmoins aux injonctions réitérées de la foule. Voltaire et le Président français se plaignirent amèrement au Conseil, qui désapprouva fort cette sotte manifestation; mais toute la répression dut se borner à écrire une lettre de blâme au jeune lord.

Le théâtre de Châtelaine resta ouvert jusqu'en 1766; cette année-là, des troubles survenus à Genève nécessitèrent une nouvelle intervention diplomatique de la France, de Berne et de Zurich. L'envoyé français, M. de Hauteville, fortement sollicité par Voltaire, demanda que les acteurs de Châtelaine vinssent jouer à Genève. Le Conseil, soutenu par un grand nombre de chefs de famille, refusa d'abord; mais il n'était pas en position de faire cette fois une résistance sérieuse; bientôt il dut céder à l'action de la diplomatie française, et le théâtre s'établit à Genève (avril 1766). On put voir alors combien l'influence de Rousseau était grande sur ses concitoyens: notre grand philosophe désapprouvait hautement l'introduction de la comédie au sein d'une république dont 
la vraie sauvegarde était, à son avis, « la dignité personnelle et la sévérité des moeurs. » Les amis de Jean-Jacques écoutèrent ses conseils et les mêmes hommes qui avaient été à Châtelaine prirent sur eux de ne pas mettre les pieds au théâtre de la place Neuve. Tout au contraire, les commensaux de Ferney et un certain nombre d'artisans profitèrent largement des récréations dramatiques. Voltaire en prit occasion pour couvrir Rousseau d'injures et proclamer un triomphe fort contestable. « Le théâtre est dans Genève, s'écrie-t-il. En vain Jean-Jacques a-t-il joué dans cette affaire le rôle d'une cervelle mal timbrée, les plénipotentiaires lui ont donné le fouet d'une manière publique. Quant aux prédicants, ils n'osent lever la tête: lorsqu'on donne le Tartuffe, le peuple saisit avec transport les allusions qui les concernent. »

Cette joie de Voltaire dura peu. Si ses partisans étaient assez nombreux pour garnir les loges et le parterre de la nouvelle salle de spectacle, la grande majorité du peuple désapprouvait encore cette institution, et le seigneur de Ferney put s'en convaincre par une désagréable expérience. Le 5 février 1768, vers six heures du soir, une lueur épouvantable rougissait le ciel du côté de la place Neuve: chacun d'accourir, portant, selon l'usage, sa seille ou son seillot pleins d'eau. Près de L'Hôtel-de-Ville, un certain nombre de personnes stimulaient le zèle des arrivants. Mais lorsque, du haut de la Treille, les hommes et les femmes découvraient le foyer de l'incendie, ils versaient brusquement leurs seaux le long de la rampe en disant: " Ah ! c'est le théâtre qui brûle ! Eh bien ! mes beaux messieurs, que ceux qui l'ont voulu l'éteignent ! » Ces paroles excitèrent l'indignation de Voltaire, qui s'écria: «Ah! cette Genève ! quand on croit la tenir, tout vous échappe ! Perruques et tignasses, c'est tout un!»

Voulant parer aux inconvénients qui, selon son opinion résultaient pour la ville de la destruction de son théâtre, il fit rouvrir celui de Châtelaine et, en outre, favorisa de tout son pouvoir les représentations à domicile chez les Genevois. Son principal coadjuteur fut un sieur Papillon, très-souvent mis à l'amende pour délit de comédie. Voltaire payait pour lui, et, voulant pousser à bout le Consistoire, il imagina la plaisanterie d'écolier que voici: Un matin on trouva affiché sur les portes des temples un placard portant ces mots: "Par permission de la Vénérable Compagnie des pasteurs, le sieur Papillon et sa compagnie à lui joueront le Barbier de Séville. » Le sieur Papillon fut 
incarcéré pendant quelques jours; puis, traduit devant le Consistoire, il voulut lire pour sa défense une apologie du théâtre composée par Voltaire; on lui en refusa la permission, et il répondit avec une insolence sans égale. Le Conseil le punit de nouveau, mais son autorité fut impuissante à empêcher les représentations, qui recommençaient presque chaque semaine. Cet état de choses dura jusqu'en 1782. A cette époque, une troisième médiation française ayant eu lieu pour calmer de nouveaux troubles politiques dans Genève, le théâtre fut reconstruit, et dès lors a subsisté sans interruption dans notre ville, sauf durant les temps de révolutions et de calamités publiques. 


\section{VII \\ CONTINUATION DE LA LUTTE AVEC VOLTAIRE}

L'impératrice de Russie et les institutrices genevoises. -- Colère de Voltaire contre les magistrats. -- Robert Covelle et le Consistoire. -- Rôle de Voltaire. -- Respect du peuple pour ses pasteurs. -- L'émeute de Saint-Gervais.

Si l'opposition d'une partie des Genevois à l'endroit de la propagande dramatique de Voltaire échauffa maintes fois sa bile contre « la cité pédante et la parvulissime République, » il ne manqua pas d'autres griefs à reprocher aux « intraitables magistrats calvinistes, » et l'impératrice Catherine de Russie fut cause d'un violent démêlé entre Genève et Ferney. Le poëte avait conçu pour cette souveraine un enthousiasme qui allait jusqu'au délire; il lui adressait les formules de louange que la religion consacre à la Divinité; il l'ornait de toutes les vertus, lui prêtait les vues les plus larges et les plus libérales pour la civilisation de son empire, et lui souhaitait toutes prospérités dans sa guerre contre les Turcs (Corresp., 1765). A Genève on jugeait les choses un peu différemment: le gouvernement se montrait peu partisan de l'agrandissement d'une puissance déjà colossale, et Voltaire fut très-scandalisé de ce que, les armées de Catherine ayant été battues, deux ou trois conseillers avaient allumé des feux de joie dans leurs campagnes. Il s'empressa de le mander au prince Galitzin. Il eut bientôt un nouveau et plus grave sujet de plainte. L'impératrice envoya à 
Genève un M. de Bulow, recommandé à Voltaire et chargé d'emmener à Saint-Pétersbourg un certain nombre d'institutrices et de domestiques destinées au service de la cour impériale. Nous lisons à ce sujet dans les registres du Conseil (20 août 1765): «M. Sales, syndic de la garde, ayant avis que le sieur de Bulow, colonel au service de Sa Majesté l'impératrice Catherine, vient d'arriver en cette ville avec charge d'engager des demoiselles pour les emmener en Russie, il a été attentif, depuis l'arrivée de cet officier, à éclairer sa conduite. Cet officier a essayé de débaucher quelques personnes; sur quoi l'avis a été de la part du Conseil que, de tels engagements étant opposés à nos lois, qui ne permettent pas ces sortes de voyages, on prierait le sieur de Bulow de se désister volontairement de ses efforts, afin de n'être pas obligé de lui faire de la peine. » $M$. de Bulow parla très-fièrement, déclara qu'il ne partirait pas avant d'avoir rempli sa mission, à moins qu'on ne le fît saisir par les soldats. Sa résistance fut inutile; Berne et Genève se mirent d'accord pour empêcher cette émigration, et l'envoyé de Catherine dut s'éloigner sans emmener personne. On s'était retranché derrière la loi, qui pourtant n'empêchait pas les demoiselles genevoises d'accepter des places d'institutrices en Angleterre: mais il y avait un autre motif, et Voltaire le sut. Tout ému de cette insolence, il interrogea là-dessus $\mathrm{M}$. Tronchin, qui ne se gêna nullement pour dire à l'adorateur de Catherine ces mots significatifs: "Monsieur de Voltaire, le Conseil se regarde comme le père de tous les citoyens; en conséquence il ne peut souffrir que ses enfants aillent s'établir dans une cour dont la souveraine est violemment soupçonnée d'avoir laissé assassiner son mari, et où les moeurs les plus relâchées règnent sans frein. » Voltaire ne fit pas grand bruit de cette réponse, et quand il raconta l'affaire à son ami d'Argental (Corresp., 1765), il se borna à lui dire: "Voici des choses d'une autre espèce. Je crois vous avoir mandé que l'impératrice de toutes les Russies, souveraine de 2,000 lieues de pays et de 300,000 automates armés qui ont battu les Prussiens, batteurs des Autrichiens, etc., que ladite impératrice daignait faire venir quelques femmes de Genève pour montrer à lire et à coudre à des jeunes filles de Pétersbourg; que le Conseil de Genève a été assez fou et assez tyrannique pour empêcher des citoyennes libres d'aller où leur plaît, enfin assez insolent pour faire sortir de la ville un seigneur envoyé par cette souveraine ! Monsieur le comte de Schouvalof, qui était chez moi, m'avait recommandé ces demoiselles. Je ne balance assurément pas entre Catherine II et les vingt-cinq perruques de Genève. 
Cette aventure m'a été fort sensible. Il y a dans ce Conseil trois ou quatre coquins, c'est-à-dire trois ou quatre dévots fanatiques qui ne sont bons qu'à jeter dans le lac. »

Un incident qui préoccupa longtemps la République fournit à Voltaire le moyen de répandre ses plus amères plaisanteries sur ces dévots fanatiques et sur le clergé protestant de Genève. C'est en 1764; un citoyen nommé Robert Covelle, homme d'un caractère violent et menant une conduite fort relâchée, fut appelé devant le Consistoire pour être censuré d'une faute grave; après qu'il eut avoué ses torts, le président du Consistoire lui dit de s'agenouiller, suivant l'usage, pour entendre la réprimande qui devait lui être adressée et demander pardon à Dieu. Covelle déclara qu'il lui fallait une semaine de réflexion pour décider s'il pouvait se soumettre à cette formalité. Au bout de quinze jours il revint, refusa absolument de s'humilier et présenta un mémoire dans lequel il prouvait que nulle part, dans les ordonnances ecclésiastiques, la génuflexion n'était exigée. Le mémoire était remarquablement écrit, et comme il était bien notoire que Covelle ne possédait nullement les facultés intellectuelles nécessaires pour la composition d'un semblable travail, on le pressa de questions sur sa véritable origine; il finit par convenir qu'il avait été conduit à Ferney, et que Voltaire l'avait fort engagé à braver le Consistoire; deux ou trois citoyens genevois présents à cette visite l'avaient eux-mêmes encouragé à la résistance, et avaient remis à Voltaire les matériaux nécessaires pour la rédaction du mémoire qui venait d'être présenté au Consistoire. « Maintenant, ajoutait Covelle, je suis parfaitement décidé; non-seulement je ne me soumettrai pas à ces messieurs, mais encore je vais faire imprimer ce travail contre la génuflexion. »

Le Consistoire vit bientôt que cette affaire prenait les proportions d'une question générale. En effet, le mémoire de Covelle-Voltaire reçut la plus grande publicité; on y répondit en montrant qu'un usage qui avait deux cents ans d'existence, et auquel tant d'hommes distingués s'étaient soumis, valait bien un paragraphe d'ordonnance; bref, les citoyens se divisèrent en deux camps. Les adversaires de la génuflexion déclarèrent que lors même que cette humiliante formalité aurait été inscrite dans les ordonnances, les temps étaient changés, et qu'un Genevois ne devait point être soumis à cette pénible coutume. "Le repentir, ajoutaient-ils, est une affaire entre la conscience humaine et le 
juge souverain: l'homme qui pense avoir violé la loi divine doit s'humilier, agenouiller devant son Dieu; mais, d'après les paroles mêmes de Jésus-Christ, cet acte s'accomplit dans le plus profond secret, sans témoins, nul ne pouvant intervenir entre la créature qui se repent et le Créateur qui pardonne. »

La raison était certainement du côté des citoyens, mais le Consistoire ne voulut pas céder: les brochures se multiplièrent; leur réunion forme trois gros volumes qui sont de la plus indigeste lecture. Voltaire, en particulier, défendit vivement Covelle à l'aide de cette raillerie acérée qu'il possédait si bien; puis, saisissant le moment où il jugea que, grâce à sa tactique, le ridicule commençait à s'attacher aux prétentions du Consistoire, il crut porter le dernier coup en lâchant sur les fanatiques son poëme intitulé: Guerre de Genève, libelle aussi scandaleux dans son genre que la Jeanne d'Arc dans le sien. Voltaire y critique les moeurs des Genevois avec une malice, chose singulière, un peu lourde; il assaille les pasteurs de plaisanteries, dont quelques-unes sont fort spirituelles; mais bientôt il abandonne la satire permise pour s'abaisser aux plus odieuses calomnies; les pages les plus infâmes s'adressent à Rousseau. Le dégoût le mieux motivé vous saisit à la lecture de ce pamphlet. Les Genevois de l'époque à laquelle nous nous reportons en éprouvèrent, du reste, cette impression.

Quoi qu'il en soit, peu après l'apparition de cette pièce odieuse, la querelle s'apaisa: le Conseil abolit la génuflexion et Robert Covelle vint demander à être admis à la Sainte-Cène; le Consistoire lui répondit qu'il acceptait volontiers tout repentir véritable, mais que, pour prouver sa sincérité, il devait désavouer publiquement les douze lettres écrites sous son nom par Voltaire, et surtout renoncer à la subvention annuelle de 300 francs que le seigneur de Ferney lui faisait pour avoir le privilége d'imprimer sous son couvert des choses impies et scandaleuses. Covelle nia la réalité de la subvention, on lui prouva la vérité de l'accusation; il persista dans son dire, et le Consistoire décida de ne plus s'occuper de cet individu: c'était certainement ce qu'il pouvait faire de plus sage.

Il semblerait, d'après ces circonstances, que Voltaire pût se féliciter d'une victoire remportée sur le clergé de Genève, mais il ne paraît pas qu'il l'ait estimée bien haut, car, à cette époque, il publia, en tête de sa 
tragédie des Scythes, une préface que l'on n'a pas réimprimée dans ses Oeuvres complètes, et où il exhale sa mauvaise humeur contre les Genevois ${ }^{6}(1)$.

« Il y avait, dit-il, en Perse, un bon vieillard qui cultivait son jardin; ce jardin était dans une vallée immense, entourée des montagnes du Caucase, couvertes de neiges éternelles. Ce vieillard n'écrivait ni sur la population, ni sur l'agriculture, comme on le faisait par passe-temps à Babylone, ville qui tire son nom de Babil. Il a fait représenter des tragédies par sa famille et quelques bergers du mont Caucase. Ce fait lui attire de violents ennemis dans Babylone, c'est-à-dire une douzaine de gredins qui aboient sans cesse après lui et lui imputent les plus impertinents livres qui aient jamais déshonoré la presse ${ }^{7}$ (1); il les laisse griffonner et calomnier, et pour être loin de cette racaille, il se retire auprès du mont Caucase avec sa famille et cultive son jardin. »

Cette citation, qui se reporte à la date de 1767, ne paraît guère provenir de la plume d'un homme qui jugerait avoir réussi dans les plans que nous connaissons, et le fait suivant, qui eut lieu dans la même année, prouve que si les railleries de Voltaire avaient flétri le caractère du clergé genevois auprès de quelques incrédules ricaneurs, la masse du peuple ne partageait nullement cette impression.

C'était au mois de décembre 1766, au plus fort des discussions politiques du moment; la disette commençait à se faire sentir. Les citoyens de Saint-Gervais, murmurant fort contre un accapareur de leur quartier, s'ameutèrent un soir devant la maison de cet homme, et voulurent s'emparer de ses provisions de blé. Le pasteur du quartier, homme fort âgé, averti du tumulte, revêt à la hâte son manteau et son rabat, et, précédé de sa servante portant une lanterne, il s'avance vers le rassemblement; on lui fait place, il arrive sur le seuil de la porte, qui était déjà brisée; puis, se tournant vers la foule, il se mit à genoux et dit ces simples mots: « Mes frères, prions Dieu ! » Ces hommes irrités

$6 \quad$ Collection de M. le docteur Coindet. Brochure contenant la tragédie des Scythes chargée des corrections de la main de Voltaire, faites après la première représentation.

$7 \quad$ Les douze lettres de M. Covelle, aujourd'hui imprimées dans les éditions complètes de Voltaire. 
demeurent un instant indécis, puis toutes les têtes se découvrent et le pasteur demande à Dieu de faire rentrer entrer la justice et le calme dans les coeurs agités; puis il récite les dix Commandements et le sommaire de la Loi, et conjure ses auditeurs de faire le sacrifice de leurs ressentiments... Pas une parole ne s'élève pour le contredire, la foule se dissipe en silence, et le lendemain l'accapareur, soit peur ou émotion généreuse, livrait ses provisions à un taux raisonnable.

Voltaire comprit cette leçon indirecte, et vit que le ridicule jeté sur la personne des pasteurs n'atteignait pas son but, et cette défaite lui fut aussi sensible que celle qu'il avait éprouvée neuf ans auparavant, lorsqu'il voulut dénaturer la doctrine des pasteurs genevois auprès de l'Europe chrétienne. C'est par cet incident que nous commencerons l'exposé de la lutte des idées religieuses entre le philosophe de Ferney et le clergé de Genève. 


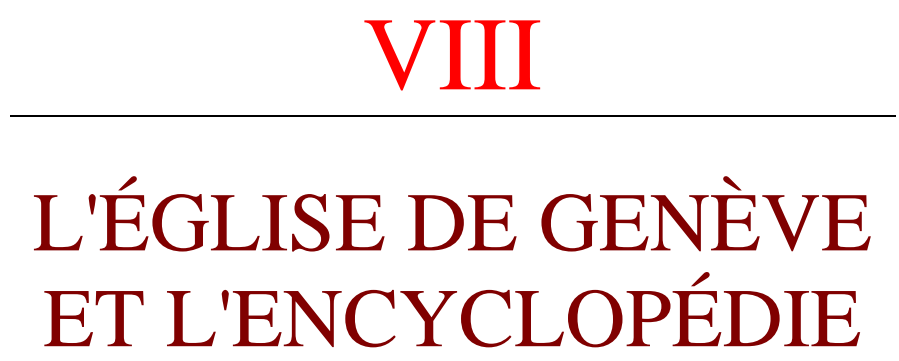

D'Alembert aux Délices. -- Description de Genève dans l'Encyclopédie. -Doctrine des pasteurs exposée d'une manière erronée. -_- Manifeste dogmatique de la Compagnie des Pasteurs. -- D'Alembert obligé par le ministre Vernes d'avouer que nul pasteur ne lui a fait des confidences antichrétiennes. -- Caractère éminemment chrétien du Mémoire justificatif de la Compagnie et son éloge par Rousseau -- Approbation de toute l'Europe protestante. -Chagrin de Voltaire.

Voltaire savait fort bien que les opinions et les croyances sont les biens les plus précieux pour les hommes sincères et convaincus, mais il ne pouvait concevoir que l'on admît sérieusement des vérités que lui-même considérait comme de lourdes erreurs, aussi la prédication journalière des dogmes chrétiens dans Genève lui agaçait les nerfs d'une façon toute particulière. Il conçut, dans son irritation, le plan de compromettre les ministres genevois aux yeux des chrétiens orthodoxes eux-mêmes et disposa sa nouvelle machine de guerre avec une grande habileté. Sachant que les pasteurs genevois proclament que leur foi chrétienne est uniquement fondée sur l'autorité divine des saintes Écritures, et que, satisfaits de cette base de leurs croyances, ils exposent leurs doctrines avec les seules expressions tirées de la Bible, Voltaire, dans cette position si claire et si logique, parvint à trouver un côté à exploiter. Le clergé genevois, ne donnant point un caractère infaillible et divin aux expressions de Trinité, de péché originel, etc., 
consacrées par l'Église et conservées dans les professions de foi des réformateurs, le philosophe incrédule saisit cette circonstance pour déclarer que ce clergé enlève à la religion tout caractère surnaturel et divin: il lui était d'autant plus facile de faire des ecclésiastiques genevois des Sociniens que l'Église romaine envisage comme tels ceux qui n'admettent pas le texte même de ses dogmes.

On était en 1767. D'Alembert, Diderot et leur entourage publiaient le fameux ouvrage de l'Encyclopédie: son succès dépassait toute prévision humaine; il atteignait toutes les parties du monde civilisé où avait pénétré la langue française, et pour né nous occuper que de Genève, il avait causé dans cette ville une véritable émeute intellectuelle. Les gens peu instruits acceptaient sans contrôle les affirmations les plus hasardées de ce livre; les maîtres et les ouvriers employaient un temps considérable à l'étudier; l'engouement était poussé jusqu'à la passion, et véritablement l'entreprise, par sa grandeur et son originalité, méritait la faveur populaire, bien que certains articles fussent indignes de vrais philosophes et de savants consciencieux. Au plus fort de cette vogue, d'Alembert vint passer un mois chez Voltaire; il fit quelques visites à Genève et témoigna le désir de connaître dans ses détails l'histoire de la République; on lui remit un mémoire à ce sujet. Il compléta ses notions sur la cité de Calvin dans la conversation de Voltaire, et, au mois d'octobre 1757, le célèbre article intitulé GENEVE parut dans L'Encyclopédie. D'Alembert débute par un exposé passablement exact de son histoire; il offre ensuite une description trèsfavorable et très-bienveillante des moeurs et des coutumes genevoises, et vient enfin à parler du clergé protestant. Voici le tableau qu'il en trace: « La constitution ecclésiastique de Genève est purement presbytérienne: point d'évêques, encore moins de chanoines; on ne croit pas l'épiscopat de droit divin, et l'on pense que des pasteurs peu riches et moins importants que des évêques conviennent mieux à une petite république. Le revenu des pasteurs ne va pas au delà de 1,200 francs; ils n'ont point de casuel. Quant aux moeurs il serait à désirer que la plupart de nos ecclésiastiques romains suivissent leur exemple; le clergé de Genève a des moeurs exemplaires; les ministres vivent dans une grande union; on ne les voit point, comme dans d'autres pays, se persécuter mutuellement ni s'accuser auprès des magistrats; il y a peu de contrées où les théologiens soient plus ennemis de la superstition et de l'intolérance, et comme la superstition et l'intolérance ne servent qu'à 
multiplier les incrédules, on se plaint à Genève moins qu'ailleurs des progrès de l'incrédulité. Les ecclésiastiques font encore mieux à Genève que d'être tolérants; ils se renferment uniquement dans leurs fonctions, ils donnent les premiers l'exemple de la soumission aux lois. -- Le service divin est très-simple; point d'images, point de cierges, point d'ornements dans les églises; il faudrait seulement une musique meilleure; mais la vérité nous oblige à dire « que l'Être suprême est adoré dans Genève avec une décence et un recueillement que l'on ne remarque point dans nos églises. » Ah! si l'Encyclopédie n'eût contenu que de semblables paroles, certes le clergé de Genève aurait pu se croire en paix avec Voltaire ! Mais attendons la fin: in cauda venenum, dit l'ancien adage. -- Passant au dogme, d'Alembert ajoute: « Plusieurs ministres ne croient point à la divinité de Jésus-Christ; ils prétendent qu'il ne faut jamais prendre à la lettre ce qui, dans les saints Livres, pourrait blesser l'humanité et la raison: leur religion est un socinianisme parfait, rejetant tout ce qu'on appelle mystère révélé. Ils s'imaginent que le principe d'une religion véritable est de ne rien proposer à croire qui heurte l'intelligence. »

Le 23 décembre 1757, M. le professeur de la Rive parle avec une profonde douleur, à la Compagnie des Pasteurs, de cet article, qui avait paru dans le tome VII de l'Encyclopédie; la Compagnie désigne aussitôt une commission composée de MM. Sarasin, de la Rive Vernet, Trembley, Maurice, Le Cointe, Tronchin, Eynard, " pour composer avec toute la maturité possible une déclaration de principes en réponse à l'ouvrage français. »

Pendant que la commission travaille, une violente discussion s'engage dans le public sur les assertions de l'Encyclopédie. Rousseau, le premier, prend la défense des pasteurs, et il découvre aisément la main qui avait dirigé la plume de d'Alembert. Dans une lettre imprimée, qui eut un immense retentissement, comme tout ce qui sortait de la plume de notre illustre compatriote, il dit à d'Alembert: " Plusieurs pasteurs de Genève n'ont, selon vous, qu'un socinianisme parfait: voilà ce que vous déclarez à la face de l'Europe. J'ose vous demander comment vous l'avez appris ? C'est sur le témoignage d'autrui ou l'aveu des pasteurs. L'aveu des pasteurs ? Vous seriez bien embarrassé d'en citer un seul qui vous ait confié de pareilles choses! Le témoignage d'autrui? N'avez-vous pas de fortes raisons de douter de son impartialité ? 
D'Alembert persistant à déclarer que ses informations sur la doctrine lui étaient fournies par plusieurs pasteurs de Genève, M. Jacob Vernes lui écrivit et lui demanda de nommer ces ecclésiastiques et d'articuler leurs paroles. Refus de d'Alembert, qui déclara « ne vouloir trahir ni le secret, ni les noms dans une affaire dite en confidence. » -Monsieur, lui répliqua M. le ministre Vernes, « feu M. le pasteur Lullin, M. de la Rive et moi, sommes les seuls ecclésiastiques que vous ayez vus à Genève; aussi notre surprise est profonde en lisant ce que vous avez dit de notre théologie. Rien dans nos paroles n'a pu vous autoriser à cette publication, car nous avons fait devant vous une profession franche et complète de notre foi à la divinité des Saintes Ecritures. » A quoi d'Alembert répondit: « Monsieur, je ne me rappelle pas les discours qu'on a tenus devant moi; je serais au désespoir de vous compromettre: je n'ai point prévu que ce que j'écrivais dût faire tant de peine aux pasteurs de Genève. Mais comme, selon moi et selon Bossuet, dès qu'on n'admet pas l'autorité et la tradition de l'Église romaine, on est socinien, c'est ce que j'ai voulu dire, et je ne saurais empêcher que ce que j'ai écrit soit écrit. Du reste, j'ai prié M. Voltaire d'arranger toute cette affaire avec M. Tronchin; mais en vérité, on fait bien du bruit pour peu de chose. »

Maintenant voici comment le plénipotentiaire de d'Alembert accommoda la difficulté; il écrivit à $M$. Vernes: « Je n'ai point encore vu le nouveau tome de l'Encyclopédie. M. d'Alembert me dit que vous vous plaignez de lui; je sais seulement qu'il a voulu donner à votre ville des témoignages de son estime. Il dit que le clergé de France l'accuse de vous avoir trop loués, tandis que vous vous plaignez de n'avoir pas été loués comme il faut. Que vous êtes heureux dans votre petit coin de monde de n'avoir que de pareilles plaintes à faire, tandis qu'on s'égorge ailleurs ! -- Or ça, voyons: êtes-vous bien fâchés dans le fond du coeur qu'on dise dans l'Encyclopédie que vous pensez comme Origène et les deux mille prêtres qui protestèrent contre Athanase ? Vous voilà bien malades que quelques gros Hollandais vous traitent d'hétérodoxes ! Serez-vous bien lésés quand on vous reprochera d'être des infâmes. des monstres qui ne croient qu'en un seul Dieu plein de miséricorde ? -- Allez! vous n'êtes pas si fâchés! Soyez comme Dorine qui aimait Lycas. Lycas s'en vanta. Dorine qui en fut bien aise, dit: 
Lycas est peu discret

D'avoir trahi mon secret.

D'Alembert est Lycas, et vous autres vous êtes Dorine. »

La discussion en était restée là, lorsque parut le manifeste de la Compagnie, en février 1758.. Voici les principaux passages de ce remarquable document: "La Compagnie a été surprise et affligée de voir que dans l'Encyclopédie, on donne une très-fausse idée de notre doctrine: on avance, contre toute vérité, que plusieurs pasteurs ne croient plus à la divinité de Jésus-Christ; que notre religion n'est qu'un socinianisme parfait. On s'efforce d'exténuer notre christianisme en disant que, parmi nous, la religion est presque réduite à l'adoration d'un seul Dieu, du moins chez presque tout ce qui n'est pas peuple, et que le respect pour Jésus-Christ et pour l'Ecriture sont peut-être la seule chose qui distingue du pur déisme ce christianisme de Genève. - De pareilles imputations sont d'autant plus dangereuses qu'elles se trouvent dans un livre fort répandu, et qui d'ailleurs parle favorablement de notre ville et de son Église. Or, contre ces assertions, nous protestons que notre grand principe, notre foi constante est de tenir la doctrine des saints prophètes et des apôtres, contenue dans les livres de l'Ancien et du Nouveau Testament pour une doctrine divinement inspirée, seule règle infaillible de notre foi et de nos moeurs. Pour nous, la vie éternelle est de connaître le seul vrai Dieu et Celui qu'il a envoyé, Jésus Christ, son Fils, en qui a habité corporellement toute la plénitude de la divinité et qui nous a été donné pour Sauveur, pour Médiateur et pour Juge, afin que tous honorent le Fils comme ils honorent le Père. Par cette raison, le terme de respect pour les Ecritures nous paraissant trop faible ou trop équivoque pour « exprimer la nature de nos sentiments à son égard, nous disons que c'est avec une foi complète, une vénération religieuse, une soumission entière d'esprit et de coeur, qu'il faut écouter ce divin Maître et le Saint-Esprit parlant par les Ecritures. C'est ainsi qu'au lieu de nous appuyer sur la sagesse humaine, si faible et si bornée, nous sommes fondés et enracinés sur la Parole de Dieu, seule capable de nous rendre véritablement sages à salut par la foi en Jésus-Christ. » 
Cette déclaration, traduite dans toutes les langues européennes, fut envoyée à toutes les Églises. Tous les journaux du temps l'attendaient avec impatience et l'insérèrent à l'envi; elle fut lue et commentée dans tous les lieux où l'Encyclopédie elle-même avait pénétré. Son effet fut profond, universel; des adresses arrivèrent de toutes parts à la Compagnie, énonçant toutes, sous les formes les plus diverses, ce voeu commun que la citadelle qui avait tenu ferme contre les papes et les souverains catholiques fût de nouveau le boulevard de la foi chrétienne, en défendant cette foi contre les incrédules la divinité des saintes Ecritures. Rousseau ne voulut pas rester en arrière, et dans une nouvelle lettre à d'Alembert, il exprime sa joie de voir son premier jugement ainsi confirmé.

La malice de Voltaire lui causa donc encore cette fois un amer désappointement. Il avait cru déconsidérer le clergé de Genève, en comptant sur son silence, dans un temps où les croyances religieuses osaient à peine se formuler d'une manière timide. Il se trouva tout au contraire appeler l'attention de l'Europe sur l'Église de Genève, pour la lui montrer tenant haut et ferme le drapeau de l'Évangile. Ce fut certes un beau jour pour les pasteurs de Genève que celui où leur voix proclama dans la presse, devant les cours, les académies et les Églises, ces grandes vérités religieuses qui étaient à la fois tout le christianisme et le protestantisme tout entier, jour d'autant plus beau que grandes étaient alors les douleurs causées par les attaques incessantes de la philosophie matérialiste. Voltaire lui-même sentit combien toute son habileté avait porté à faux, car jamais il ne fit dans la suite la moindre allusion à cette affaire; or, on sait s'il s'épargnait le souvenir de ces triomphes, grands et petits.

Du reste, une cause des plus intéressantes s'offrit bientôt à son esprit inquiet: ce fut celle de la tolérance et de la liberté de pensée, pour lesquelles il entreprit une lutte de plusieurs années qui, nous en sommes convaincus, lui procura plus de pures jouissances que tant d'autres victoires où sa vanité seule se trouvait intéressée. 
VOLTAIRE ET LES GENEVOIS

\section{IX \\ VOLTAIRE ET LA LIBERTÉ DE CONSCIENCE}

Intolérance française en 1760. -- Voltaire se décide à la combattre. -- Affaire des Calas. -- Procès de Sirven. -- La Barre et d'Etallonde. -- Le galérien protestant Chaumont. -- Les oreilles du grand inquisiteur. -- Le seigneur allemand et les Calas. -- Le curé de Moëns rossant ses ouailles. -- Les serfs du mont Jura. -- Influence de Genève sur les efforts de Voltaire en faveur de la tolérance. -- Jugement de Charles Bonnet touchant les travaux de Voltaire en faveur de la tolérance. -- Motifs qui mirent Voltaire au service de cette cause.

La liberté de conscience, ou le droit pour chaque homme de choisir ses opinions religieuses et de les professer sans entraves, est un des principes dont l'admission a rencontré et rencontre encore les plus sérieuses difficultés dans la vie morale des nations. Cette indépendance, proscrite par les catholiques, fut considérablement restreinte, durant près de deux siècles, par les protestants eux-mêmes. Longtemps les Églises réformées, infidèles à l'un des principes sur la base desquels elles s'étaient constituées, traitèrent elles-mêmes d'hérétiques les hommes qui n'admettaient pas tous les points des confessions de foi de Luther ou de Calvin, et cette grave erreur ne fut abandonnée que vers le commencement du XVIIe siècle. Ce fut encore Genève qui eut l'honneur de précéder le monde réformé dans cette noble voie, et son église donna la première l'exemple d'une liberté complète sous le rapport religieux. Cette seconde émancipation de la conscience était un fait accompli dans notre ville depuis soixante-dix ans, lorsque Voltaire 
conçut le projet de faire goûter les idées de tolérance au peuple français.

La tâche était rude et périlleuse. En 1760, les hommes qui rejetaient l'autorité du pape étaient encore emprisonnés et confondus sur les galères du roi avec les voleurs et les assassins; leurs femmes étaient ensevelies dans des cachots infects, et leurs enfants, élevés par des moines, apprenaient, de par le roi, à maudire sur la croix de Jésus le souvenir et la religion de leur père et de leur mère. Les montagnes de France recélaient encore dans leurs déserts des populations désireuses de servir Dieu en esprit et en vérité, et les troupes royales faisaient feu sur ces rebelles comme sur les plus dangereux brigands de grands chemins; puis les hauts dignitaires de l'Église romaine louaient et bénissaient Dieu lorsqu'ils recevaient ces lugubres et sanglants rapports!

Si les réformés souffraient durement des abus du fanatisme, ils n'étaient cependant pas seuls à en gémir: sur divers points de la France les chanoines et les prieurs traitaient leurs ressortissants comme vassaux et serfs taillables et corvéables à merci; les emprisonnements et les confiscations s'opéraient sans enquête judiciaire, à la demande des seigneurs ecclésiastiques, et la voix des catholiques opprimés était aussi soigneusement étouffée que les plaintes des protestants euxmêmes.

En vain quelques personnes, aussi hardies que généreuses, s'efforçaient de parvenir jusqu'aux oreilles du roi: nulle réclamation n'abordait le trône qu'après avoir passé par le confessionnal. Des mémoires retraçant ces iniquités étaient imprimes, mais ils demeuraient sans résultats, leurs auteurs n'ayant pas le talent qui fixe l'attention des foules, ou l'influence sociale qui force l'opinion publique à se prononcer. Dans les hautes sphères de l'intelligence on frappait de rudes coups sur la superstition et sur l'autorité romaine, mais le but était la démolition des croyances religieuses: la liberté de conscience, le droit de conserver sa foi et de la publier restaient inconnus sur la terre de France, et, il faut le dire, la plus dédaigneuse indifférence accueillait les faits qui transpiraient dans le public et les bruits lointains des persécutions religieuses; le genre même de leur crime rendait les victimes 
odieuses au grand nombre, et ridicules aux yeux de ceux-là seuls que leurs opinions avancées eussent pu appeler à les défendre.

Tout d'un coup, en face de ce dédain matérialiste des philosophes, de ces juges qui punissent le délit de culte par l'exil, les galères et la potence, de ces parlements qui laissent passer la justice de Rome, de ces ministres d'État qui s'inclinent devant elle et de ce royal libertin qui échange des billets de galère contre des billets de confession, se lève un homme à la fois historien, philosophe, poëte et satirique, qui possède la réputation la plus étendue, le crédit littéraire le plus incontesté, qui correspond avec tous les souverains de l'Europe, que les papes tolèrent lors même qu'il foule aux pieds leur dogme et leur puissance, un homme dont tous les journaux, tous les salons, toutes les académies, tous les théâtres, tous les peuples se disputent les écrits, et à cet homme il monte au coeur de descendre dans la lice et de prendre en main la cause de la liberté religieuse. Cette résolution prise, il met au service de son oeuvre toute son immense influence, une persistance qui n'est égalée que par son infatigable activité, et il ne s'arrête que lorsqu'il a fait réprimer les excès du fanatisme par les mêmes lois et par les mêmes tribunaux qui naguère les sanctionnaient.

Voici l'événement qui amena Voltaire à se faire le champion de la cause de la tolérance.

Un jour, c'était au mois d'avril 1762, un réfugié français, M. de Végobre ${ }^{8}$, faisait une visite à Voltaire:

«Qu'y a-t-il de nouveau ? -- Du nouveau ? Il arrive la plus horrible histoire que les fastes judiciaires puissent enregistrer ! -- Quoi donc ? Racontez vite ! -- Il existe à Toulouse une famille de réformés, digne de considération et possédant une position honorable. Ils se nomment Calas. Un des fils s'est fait catholique, et le père, quoique sincèrement affligé de son changement de religion, lui a continué sa pension alimentaire. Le frère aîné mène une vie désordonnée: il hante les salles d'armes et les billards, et se tient dans un état d'ivresse à peu près

$8 \quad$ M. de Végobre fils, de qui nous tenons ces détails, a été durant toute sa vie le protecteur zélé de ses coreligionnaires français, et l'un des membres les plus respectables et les plus actifs de l'Église de Genève. 
continuel, et comme il est criblé de dettes, son père refuse d'apaiser ses créanciers et de lui donner les moyens de continuer ses désordres. Dès lors une exaltation furieuse s'est emparée de ce jeune homme: il a lu des ouvrages qui font l'apologie du suicide, et un jour on a trouvé ce malheureux pendu à la traverse d'une porte. Aussitôt le bruit s'est répandu que son père l'avait pendu lui-même parce qu'il avait manifesté le désir de se faire catholique: son père ! pauvre vieillard de soixante-neuf ans! faible, infirme, fort incapable de soulever seulement le corps géant de son fils, dont la taille dépassait six pieds ! Pour corroborer cette accusation, la confrérie des pénitents blancs a fait célébrer des messes pour le repos du défunt; on a exposé une peinture qui le représente tenant d'une main la palme du martyre et de l'autre la plume qui devait signer son abjuration: on a fait courir le bruit que les réformés assassinent fréquemment en secret ceux de leurs enfants qui veulent passer au catholicisme. Bref, on a si bien fanatisé la population de Toulouse qu'elle a demandé à grands cris la mort du vieux Calas; c'est un magistrat nommé David qui a conduit le procès, et malgré toutes les invraisemblances, les absurdités accumulées dans cette affaire, le malheureux a été déclaré coupable, condamné au supplice de la roue et exécuté le 9 mars dernier ! Il est mort comme un martyr, pro testant de son innocence et pardonnant à ses juges, qui sans doute, disait-il, avaient été égarés par de faux témoins... Sa femme et ses filles étaient également accusées de ce meurtre: on a pourtant reculé devant l'idée de les mettre à mort; on leur a rendu la liberté, et elles sont arrivées à Genève depuis trois jours, -- Elles sont à Genève! Que je les voie au plus tôt!» s'écrie Voltaire qui pleurait à chaudes larmes et dont le corps frémissait à ce récit. $M$. de Végobre court chercher les dames Calas. Voltaire écoute le récit détaillé de leurs infortunes, et, convaincu de l'innocence de cette famille, il veut obtenir pour son chef une éclatante réhabilitation.

La tâche qu'il venait de prendre était lourde et dangereuse: il fallait combattre et réduire au silence une magistrature puissante, un clergé fanatisé, des préjugés les mieux enracinés peut-être entre tous. Mais les obstacles ne firent qu'exciter l'ardeur du philosophe. Il intéressa à cette cause le duc de Choiseul, ministre du roi; il écrivit à tous les grands personnages sur lesquels il pouvait avoir quelque influence; la duchesse d'Anville, arrière-petite-fille de Larochefoucault, étant venue à Genève consulter Tronchin, celui-ci, d'accord avec Voltaire, la ga- 
gna entièrement à la cause des Calas. Enfin la révision du procès commença: Voltaire se fit remettre les longs et diffus mémoires des avocats qu'il transforma en pages brèves, concluantes, étincelantes d'esprit et d'éloquence. Il remplit les journaux des détails de cette affaire, multiplia les brochures, tint en haleine l'opinion publique, écrivit à tous les souverains. Enfin, au printemps de 1766, après quatre années d'efforts et de travaux dont Ferney fut le centre et Voltaire le directeur, l'arrêt qui condamnait Calas fut cassé et son innocence reconnue; l'accusateur David, accablé sous le poids de la réprobation universelle, perdit la raison; le roi, cédant à l'entraînement général, accorda 36,000 livres à la veuve du martyr, et les Français reçurent de Voltaire une des plus hautes leçons de tolérance qui aient jamais frappé le coeur d'un peuple.

Une nouvelle occasion se présenta bientôt pour continuer le grand procès de la liberté humaine contre le fanatisme. Pendant que Voltaire était dans le premier feu de ses travaux au sujet des Calas, un de ces horribles drames, qui s'étaient joués par milliers durant les dragonnades sans que personne songeât à s'en formaliser, eut lieu dans une petite ville du Languedoc, et les Genevois n'eurent rien de plus pressé que de raconter le fait à Voltaire. Cela se passait en 1762: une famille du nom de Sirven s'était vu arracher une jeune fille qui, disait-on, avait manifesté quelque penchant pour le catholicisme, et qu'une lettre de cachet avait livrée à des religieuses. Les soeurs, rencontrant une vive résistance chez leur catéchumène, la traitèrent avec tant de rigueur qu'elle s'enfuit du couvent, et dans sa fuite nocturne ayant heurté la margelle d'un puits, elle y tomba et se noya. Au bout de quelques jours on retrouva son corps: l'opinion publique, adroitement égarée comme à Toulouse, s'acharna sur la famille Sirven et accusa le père et la mère du meurtre de leur fille! Ces infortunés, prévoyant leur arrestation, s'enfuirent au coeur de l'hiver: la femme mourut de fatigue et de froid dans les neiges du Jura. Sirven, arrivé à Genève, fut conduit à Voltaire, qui frémit à la vue des souffrances physiques et des tortures morales endurées par ce malheureux père. Il embrassa sa cause avec autant d'ardeur que celle des Calas, et bientôt il put voir que l'opinion publique avait déjà fait des progrès véritables. Dès qu'à Paris on apprit que Voltaire patronnait la cause d'un nouveau martyr protestant, des avocats du premier ordre s'offrirent pour le seconder. Avant que le procès s'engageât, il fallut que Sirven se constituât prisonnier à Tou- 
louse. Voltaire, sûr de la majorité du Parlement, lui conseilla cette démarche dont le péril n'était plus qu'apparent, grâce à ses efforts; $\mathrm{cl}$, en effet, ses amis l'emportèrent sur ses adversaires, et après neuf années de travaux, Sirven fut déclaré innocent: c'était une nouvelle leçon de liberté religieuse donnée autant à l'Europe qu'à la France, grâce aux brochures, aux incessantes correspondances de Voltaire.

Il peut paraître singulier, au premier abord, que nous parlions de liberté religieuse et de liberté de conscience à propos de choses que de notre temps on appellerait simplement impartialité judiciaire. Mais, à la honte de la civilisation française du XVIIIe siècle, cette impartialité judiciaire n'existait pas pour les réformés: c'était un véritable nonsens que de croire qu'il y eût réellement une justice faite pour autre chose que pour poursuivre et condamner des gens qui étaient hors la loi dans toute la force du terme. Ce fut donc véritablement une double conquête de la tolérance, une double victoire de la liberté de penser, remportée à grand'peine sous l'égide de Voltaire, que d'avoir pu obtenir justice pour des protestants et réhabilitation tardive pour des hérétiques.

Les deux affaires des Galas et des Sirven ne furent pas, du reste, les seules occasions dans lesquelles Voltaire lutta contre le fanatisme religieux. Peu après, un procès qui, sans lui, eût passé sans doute inaperçu comme tant d'autres analogues, jugés par l'inquisition, vint encore effrayer le monde civilisé, et ce fut Voltaire qui se chargea de mettre au ban de l'opinion publique les juges qui avaient fait trancher la tête du chevalier La Barre, dénoncé par un bourgeois d'Abbeville comme ayant profané, pendant la nuit, un crucifix de bois placé sur un pont. -- En outre, un des coaccusés de La Barre, le jeune d'Etallonde, fut recueilli à Ferney. Voltaire soigna son éducation, et le fit nommer lieutenant du génie par le roi de Prusse, qui se montra heureux de participer, à cet acte de réparation.

Il ne faut pas croire cependant que, malgré l'ardeur qu'il y mettait, Voltaire fût si fortement absorbé par ces hautes questions judiciaires, et ces vastes procédures que, durant leur cours, son esprit satirique dormît le moins du monde. Son instinct malicieux perçait encore à tout propos et donnait une couleur excentrique aux faits les plus intéressants. Ainsi les amis de Genève lui avaient recommandé un de 
leurs compatriotes nommé Chaumont, qui depuis vingt ans était aux galères pour cause de protestantisme. Par l'entremise de M. de Choiseul, Voltaire obtint la délivrance de ce malheureux, et voici comment M. Peyronet, pasteur de Dardagny, raconte à Paul Rabaut la visite de remercîment faite par Chaumont à son libérateur: « Il y a trois jours je conduisis mon petit prisonnier à Ferney. Nous parlâmes longtemps de la justice et de la nécessité de la tolérance; enfin, je dis à M. de Voltaire que je lui avais amené un petit homme qui venait se jeter à ses pieds pour le remercier de ce que par son intercession, il avait été délivré des galères. -- C'est Chaumont, que j'ai laissé dans votre antichambre, et je vous prie de me permettre de le faire entrer. -- Au nom de Chaumont, M. de Voltaire me témoigne un transport de joie et, sonne tout de suite pour qu'on l'introduise. Jamais scène ne me parut plus bouffonne, et plus réjouissante. -- Quoi, lui dit-il, mon pauvre petit bout d'homme, on vous avait mis aux galères ? Que voulait-on faire de vous ? Quelle conscience de mettre à la chaîne un petit être qui n'avait commis d'autre crime que de prier Dieu en mauvais français ! -- _ Puis, changeant de ton, Voltaire se tourna vers moi et s'exprima de la manière la plus violente contre la persécution. Il fit venir dans sa chambre plusieurs personnes qu'il avait chez lui pour qu'on participât à la joie qu'il ressentait envoyant le petit Chaumont: celuici, quoique proprement vêtu selon son état, était tout stupéfait de se voir si bien fêté. Quelques piastres que Voltaire lui glissa dans la poche, achevèrent de le rendre le plus heureux des hommes. »

Le pape Clément XIV, dont l'esprit élevé et le coeur profondément chrétien détestaient le fanatisme, avait approuvé ces grandes oeuvres de Voltaire, et celui-ci, connaissant les opinions du pontife, pensa qu'il accepterait volontiers une bonne plaisanterie. II profita, dans ce but, de la présence d'un seigneur irlandais qui visitait Ferney en se rendant à Rome. -- " N'avez-vous point de commissions pour le saint-père, Monsieur de Voltaire ? Je m'en chargerais volontiers. » -- « Oui, Milord, remettez-lui ceci... » Et, profitant de ce que l'étranger ne savait pas un mot de français, il lui confia un carton sur lequel il avait écrit: "Sa Sainteté est priée d'envoyer au philosophe de Ferney les oreilles du grand inquisiteur dans un papier de musique. » L'Anglais s'acquitta scrupuleusement de sa commission dans la première audience qu'il obtint du pape. Clément XIV sourit et écrivit au revers de la feuille: «Sa Sainteté est bien fâchée de ne pouvoir exécuter votre commis- 
sion, mais sous le pontificat actuel, le grand inquisiteur n'a ni yeux ni oreilles. »

Comme nous l'avons dit plus haut, l'affaire des Calas fut, pendant plusieurs années, la plus constante préoccupation de Voltaire; il ne souffrait aucune contradiction sur ce sujet, et un visiteur en fut un jour la victime. C'était un gros seigneur allemand qui, sorti des solitudes d'une lointaine résidence, connaissait fort peu les événements du jour; il est introduit dans le salon de Ferney, et, immédiatement après les premières révérences: "Monsieur, lui dit Voltaire, que pensez-vous du pauvre Calas qui a été roué ? -- Il a été roué ?... Ah ! il faut que ce soit un grand coquin !... » -- Voltaire se précipite sur la sonnette. -« Le carrosse de Monsieur est-il dans la cour ? -- Oui, Monsieur. -Qu'on attelle à l'instant ses chevaux et qu'il parte vite! » Le pauvre Allemand s'en alla sans pouvoir s'expliquer cette boutade. Lorsqu'il la raconta à Genève, on lui fit comprendre le sujet de l'indignation de Voltaire, et il déclara qu'il avait pris Calas pour quelque brigand des environs que le seigneur de Ferney avait fait rouer à bonne fin.

Si Voltaire prit chaudement la défense du faible opprimé contre le puissant oppresseur, ce ne fut pas seulement en faveur des protestants. Il sut aussi protéger sérieusement les habitants du pays de Gex et du mont Jura, ses voisins, contre la tyrannie des prêtres et des abbés. Dans ces circonstances, sa verve railleuse se donna largement carrière, et des faits peu importants prenaient sous sa plume une effrayante publicité. -- Ainsi deux jeunes hommes de Moëns, village situé près de Ferney, soupaient un soir bruyamment dans une maison du hameau: cela déplut au curé; mais, au lieu de faire une remontrance paternelle à ces étourdis, il crut trouver des arguments plus solides en soudoyant des paysans, qui guettèrent, par son ordre, le départ des inculpés et les accablèrent de coups de bâton; l'un d'eux demeura longtemps sans connaissance. Le père va sur-le-champ confier ce fait à Voltaire, qui dicte rapidement quelques phrases à son secrétaire; puis, remettant la feuille de papier au paysan: «A merveille, mon ami ! tenez, voici une plainte toute rédigée contre votre curé; signez-moi cela, et nous le ferons aller loin! -- Moi, Monseigneur ! signer cette plainte contre mon curé !... mais demain je serais assommé à mon tour. -- Tant mieux, mon ami, tant mieux ! Si cela arrive ? son affaire n'en sera que plus mauvaise ! -- Permettez, Monseigneur, il y a déjà assez d'os cassés 
sans y joindre encore les miens. _Voltaire dut se passer de la signature du prudent plaignant, mais il n'en réussit pas moins à faire punir le curé de Moëns, et il égaya sa correspondance des détails de cette anecdote.

La lutte ne resta pas dans le domaine des faits isolés, et bientôt elle prit un caractère plus élevé: les habitants du mont Jura furent l'occasion d'un des plus éloquents et des plus irréprochables écrits de Voltaire. En 1770, les habitants de quelques communes du Jura étaient serfs ou esclaves, comme on voudra, des moines de l'abbaye de SaintClaude; ces malheureux, opprimés de diverses manières, s'adressèrent au philosophe de Ferney, qui prit aussitôt la plume en leur faveur. Il va sans dire qu'à l'aide de ce puissant auxiliaire ils gagnèrent haut la main contre les moines leur procès, dans les détails duquel nous ne pouvons entrer ici.

Nous venons de présenter, bien que d'une manière rendue nécessairement fort incomplète par le cadre restreint que nous avons adopté, les grands travaux entrepris et exécutés par Voltaire en faveur de la tolérance. Peut-être nous reprochera-t-on d'avoir trop exalté ces efforts, sans assez pénétrer les principes mondains qui peuvent l'avoir dirigé, comme le désir d'occuper l'Europe du bruit de sa générosité et de l'étonner par le spectacle de son influence, comme le besoin de se mêler de tout et de primer partout, comme enfin sa passion insatiable de louanges.

Charles Bonnet, qui se montra l'un des plus rudes adversaires de Voltaire, Charles Bonnet, qui ne lui pardonna jamais ses railleries contre le christianisme, met les efforts de Voltaire sur le terrain qui nous occupe, complètement à part de la généralité de ses actes, et n'étend pas à ceux-là la sévérité d'appréciation qui lui est ordinaire; les lignes suivantes en font foi: elles ont été écrites au grand Haller, et portent la date du 9 avril 1765 (Lettres de Bonnet , No 97)... Voltaire a fait un livre sur la tolérance qu'on dit bon; il ne le publiera qu'après que l'affaire des malheureux Calas aura été décidée par le conseil du roi. Le zèle de Voltaire pour ces infortunés peut couvrir une multitude d'écarts; ce zèle ne se ralentit point, et s'ils obtiennent satisfaction, ce sera principalement à ce protecteur qu'ils le devront. Il reçoit bien des applaudissements pour cette affaire, et il les mérite pleinement. » 
À ces paroles du philosophe chrétien de Genève, qu'il nous soit permis d'ajouter que, si nous étions dans un monde où les belles actions fussent en grande majorité dépouillées de tout motif d'intérêt humain, de tout désir de gloire, de toute tendance secrète, dissimulée avec soin au dehors, il serait naturel de sonder rigoureusement l'oeuvre de Voltaire et de chercher à en juger la cause première. Mais comme tel n'est pas le cas, et qu'il n'y a que trop lieu d'appliquer aux actions pures de toute influence intéressée le fameux rara avis in terris, nous dirons avec saint Paul: « Chacun apporte à l'édifice ses matériaux d'or, d'argent, de bois ou de chaume. » A Dieu seul appartient de faire le grand triage des intentions et des motifs.

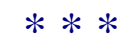




\section{$\mathrm{X}$ \\ VOLTAIRE ET M. MOULTOU}

Influence des Genevois sur Voltaire au sujet de ses travaux en faveur de la tolérance. -- Relations de M. Moultou avec Rousseau. -- Correspondance avec Voltaire au sujet des Calas -- Correspondance au sujet des Sirven. -Lettre de M. Moultou au père du condamné La Barre. -- Relations entre Moultou et son parent Ripert de Montclar, rapporteur touchant l'expulsion des jésuites de France. -- Révélations touchant la mort de M. de Montclar et ses prétendus remords de la condamnation des jésuites. -- Lettres de Voltaire à Moultou sur les protestants du Désert. -- Travaux des Genevois pour obtenir la liberté des protestants français. -- Jacob Vernet et Malesherbes.

Il y a quelques années, lorsqu'on publia les ouvrages de Dumont, plusieurs Français se refusèrent à admettre que le publiciste genevois eût corrigé souvent les discours prononcés à la tribune par Mirabeau, son intime ami. Je pense qu'une incrédulité analogue accueillera la thèse que je vais développer, à savoir que les Genevois, amis de Voltaire, eurent une très-notable influence sur ses efforts en faveur de la tolérance religieuse: cette prétention peut paraître, en effet, ambitieuse ou du moins fort nouvelle.

Il était difficile néanmoins de croire que Genève fût demeurée complétement étrangère à cette grande oeuvre entreprise à ses portes, et qui est le couronnement des sacrifices sans nombre que depuis quatre-vingts ans notre ville accomplissait silencieusement pour soutenir et consoler les protestants persécutés. Isoler Genève du travail de Vol- 
taire en faveur de la liberté de conscience serait même peu logique: un homme, si grand que soit son génie, peut-il échapper à toute influence exercée par le milieu dans lequel il passe ses jours ? Voltaire, vivant dans la société matérialiste de Paris ou de Berlin, eût sans doute continué ses pamphlets moqueurs contre le fanatisme de Rome; mais aurait-il joint l'action à la parole ?... Aurait-il pris la défense des Calas, des Sirven, des galériens protestants ? Au milieu des fêtes scandaleuses de ces cours, la nouvelle des supplices infligés aux réformés français serait-elle seulement parvenue à ses oreilles ? Aurait-il rencontre ces Genevois, fils de réfugiés ou réfugiés eux-mêmes, qui surent faire vibrer les cordes les plus sympathiques de son âme ? Voltaire, si impressionnable, ne fut-il pas ému d'entendre répéter ces détails des misères éprouvées par les fugitifs de la révocation ? Les papiers de famille contenant ces horreurs que les enfants des martyrs lui communiquaient, n'enflammèrent-ils pas son courage et sa persévérance ? Et quoi de plus naturel que le projet de délivrer l'Europe du fléau des persécutions religieuses fût conçu sur le seuil même de la grande hôtellerie où se réfugiaient, depuis un siècle, les victimes de toutes les persécutions ${ }^{9}$ ?

Mais nous ayons plus sur ce sujet que de simples inductions: nous avons des faits. La Correspondance générale contient déjà les lettres à M. Vernes, pasteur genevois, lettres dans lesquelles Voltaire lui fait confidence de ses travaux et de ses efforts en faveur des Calas. Nous avons aujourd'hui sous les yeux une collection toute nouvelle de documents précieux à cet égard: ce sont les lettres de Voltaire au ministre Moultou, lettres entièrement inédites et que nous sommes heureux d'offrir à nos lecteurs, car cette correspondance est aussi honorable pour le philosophe français qui l'écrit que pour l'ecclésiastique genevois qui la reçoit.

Deux mots d'abord au sujet de Moultou. Il était fils de réfugié; dans sa jeunesse il voyagea longtemps, et ses facultés distinguées lui valurent un favorable accueil de la part des hommes marquants de

9 Cette idée est admise par un historien français, M. Mary Lafon (Histoire de la France méridionale), qui, partisan de la culpabilité de Calas, exhale sa mauvaise humeur « contre ces Genevois sans lesquels Voltaire n'aurait jamais songé à prendre la défense du roué de Toulouse. » 
l'époque avec lesquels il eut occasion de se rencontrer. Voltaire, avec qui il entra en relations, charmé de son esprit, lui voua une amitié qui ne s'est jamais démentie, malgré les principes chrétiens que Moultou professait et plaçait au-dessus de toute chose. Les hommes familiers avec les oeuvres de Rousseau contesteront probablement cette assertion; en effet, une lettre de Rousseau (14 février 1769. Corresp., t. III Edit. Deterville) contient ces mots: " J'ai vu, mon ami, que le torrent de la mode vous gagne et que vous commencez à vaciller dans des sentiments où je vous croyais inébranlable, etc. » Un ministre genevois qui vacille dans la croyance à la vie à venir ! Il faut avouer que ce passage semble bien fait au premier coup d'oeil pour jeter quelque doute sur le caractère religieux de l'homme auquel il est adressé: or, on ne peut avoir la clef de cette lettre de Rousseau qu'en consultant, comme je l'ai fait, les héritiers de Moultou. Voici ce qui l'explique. Un jour on discutait devant Moultou sur les convictions religieuses de son malheureux ami: "Rousseau, disait-on, Rousseau n'a que des doutes dans le coeur; il est heureux de ces doutes: il jouit lorsqu'il peut par ses sophismes arracher la foi des âmes dans lesquelles elle règne encore. » -- «Et moi j'affirme, répondait Moultou, que vous êtes dans l'erreur. Rousseau, s'il ne peut admettre complétement la base miraculeuse des Évangiles, croit à la nécessité, à la vérité des dogmes chrétiens, aux effets de la mission de Jésus-Christ touchant la vie à venir, à la compensation des douleurs de ce monde dans l'existence céleste et la rétribution des justes et des injustes, et je me fais fort de le lui faire écrire. » -- " Nous serions fort curieux de lire cette profession de foi, » s'écrièrent les assistants. Là-dessus Moultou demande un secret qui, il faut le dire, a été parfaitement gardé, et entame avec Rousseau une correspondance dans laquelle il feint d'être ébranlé dans ses convictions chrétiennes. Bientôt Moultou put montrer aux sceptiques de tout à l'heure cette admirable page de Rousseau, cette démonstration de l'existence de Dieu et de la vie à venir, la plus belle et la plus simple peut-être que fournissent les monuments de la langue française: «Voulez-vous rejeter l'intelligence universelle ?... les causes finales vous crèvent les yeux. Voulez-vous étouffer l'instinct moral ? la voix interne s'élève dans votre coeur, y foudroie les petits arguments à la mode et vous crie qu'il n'est pas vrai que l'honnête homme et le scélérat, le vice et la vertu, ne soient rien; car vous êtes trop bon raisonneur pour ne pas voir à l'instant, qu'en rejetant la Cause Première on ôte toute moralité de la vie humaine. Eh ! quoi, mon Dieu ! le juste infor- 
tuné en proie à tous les maux de cette vie, sans même en excepter l'opprobre et le déshonneur, n'aurait nul dédommagement à attendre après elle, et mourrait en bête après avoir vécu en Dieu ? Non, non, Moultou, Jésus, que ce siècle a méconnu, parce qu'il est indigne de le connaître, Jésus, qui mourut pour avoir voulu faire un peuple illustre et vertueux de ses vils compatriotes, Jésus ne mourut point tout entier sur la croix, et moi, qui ne suis qu'un chétif homme, plein de faiblesse, c'en est assez pour qu'en sentant approcher la dissolution de mon corps, je sente en même temps la certitude de vivre. »

Les relations de Moultou avec Voltaire furent des plus sérieuses. Voltaire savait que Moultou ne pouvait supporter la raillerie touchant le christianisme; aussi retenait-il volontiers sa verve ironique en lui écrivant. Du reste, leur correspondance ne paraît être devenue active et suivie qu'à l'occasion de l'affaire des Calas. Après la visite à Ferney de M. de Végobre, dont nous avons parlé précédemment, Voltaire fit mander M. Moultou et le pria de lui donner quelques directions touchant les meilleurs moyens à employer: Moultou se chargea de lui remettre l'attirail historique et les pièces de jurisprudence nécessaires à la composition des mémoires en faveur de la tolérance. Voltaire paraissait un peu effrayé du poids et de la responsabilité de cette entreprise; Moultou, avec M. et Mme de la Rive, qu'il affectionnait beaucoup, l'encouragèrent de toutes leurs forces: « C'est une oeuvre à vous, M. de Voltaire, lui dirent-ils; joignez le fait à la parole, la gloire du bienfaiteur de l'humanité à la gloire de l'écrivain... Votre nom sera plus grand par la destruction du fanatisme que par la production des plus beaux chefs-d'oeuvre de poésie. » Voltaire serra les mains de ses amis, et l'événement lui prouva que, pour cet autre levier d'Archimède qu'il avait en main, son immense influence littéraire, il pouvait trouver un point d'appui dans l'opinion publique.

Voici la première lettre de Voltaire à Moultou ${ }^{10}$, écrite par le philosophe après la rédaction d'un mémoire en faveur des Calas, en mai 1762.

10 Cette correspondance est malheureusement incomplète: un grand nombre des lettres de Voltaire à Moultou ont été perdues durant les bouleversements que la révolution de 1793 occasionna dans plusieurs familles genevoises. 
Il consulte son ami dans les termes suivants: "Voilà à peu près, Monsieur, comment je voudrais finir le petit ouvrage en question; ensuite j'en enverrais des exemplaires aux ministres d'État sur la protection et la prudence de qui je puis compter, à Mme la marquise de Pompadour et à quelques amis discrets qui pensent comme vous et moi; j'accompagnerais l'envoi d'une lettre circulaire par laquelle je les supplierais de ne laisser lire l'ouvrage qu'à des personnes sages, et d'empêcher que leur exemplaire ne tombât entre les mains d'un libraire. J'en enverrais un au roi de Prusse et à quelques princes d'Allemagne, et je les supplierais de se joindre à ceux qui ont déjà secouru la famille Calas, plongée dans l'indigence par l'arrêt injuste et barbare du Parlement de Toulouse. Le reste demeurerait enfermé sous la clef en attendant le moment "favorable de le rendre public. -- Voyez, Monsieur, si le plan est de votre goût, et ce qu'on doit ajouter ou retrancher à la feuille que j'ai l'honneur de vous soumettre. »

Après cette lettre, où Voltaire déploie toute la prudence et la diplomatie du dévouement en faveur de ses protégés, nous trouvons plusieurs pages écrites vers le moment où l'affaire des Calas était portée devant le conseil du roi, qui devait décider si le procès serait ou non revisé; elles sont empreintes en plusieurs endroits de l'agitation que l'attente causait à Voltaire.

(5 janvier 1763.) "L'aventure des Calas peut servir à relâcher beaucoup les chaînes de vos frères qui prient Dieu en mauvais vers. Je suis convaincu d'ailleurs que, si l'on a quelque protection à la cour, on verra clairement que des ignorants qui portent une étole ne gagnent rien à faire pendre des savants à manteau noir, ce qui est le comble de l'absurdité comme de l'horreur.

« Je vous supplie de vouloir bien envoyer chez MM. Séchehaie et Le Fort le commentaire de Bayle sur le Contrains-les d'entrer et la lettre de l'évêque d'Agen par laquelle cet animal veut vous contraindre d'entrer.

«On m'a mandé de Toulouse qu'un jeune homme qui allait prier tous les jours à l'église de Saint-Etienne, sur le tombeau du saint martyr Marc-Antoine Calas (celui qui s'était pendu), est devenu fou pour 
n'avoir pas obtenu de lui le miracle qu'il lui demandait, et ce miracle... c'était de l'argent.

« On ne peut rien ajouter, Monsieur, ni à ma compassion pour les fanatiques, ni à ma sincère estime pour vous. »

(9 janvier 1763.) «Voici un mémoire qu'on envoie; il avait été fait à Toulouse il y a très-longtemps; je suis fâché que les avocats de Paris ne l'aient pas connu: il y a des choses bien essentielles dont ils auraient fait usage. Votre indignation et votre pitié redoubleront, s'il se peut, à la lecture de ce mémoire. On est tenté de se faire débaptiser quand on lit la Saint-Barthélemy, les massacres d'Irlande et l'histoire des Calas; on aurait du moins grande raison de se décatholiciser. -- Je vous supplie, Monsieur, de vouloir bien envoyer le mémoire à M. de Brus, quand vous l'aurez lu.

« Vous savez que l'affaire ne sera rapportée que le huit février. Je ne dormirai point la nuit du 7 au 8. Mon Dieu ! que d'abominations ! Je prends la liberté de vous embrasser de tout mon coeur. »

Pendant qu'on délibère à Paris, Voltaire prépare toutes les armes nécessaires pour faire pencher la victoire de son côté, et cet écrivain, si léger à l'ordinaire dans ses productions, cet auteur dont la plume facile entasse les pages à heure fixe, multiplie cette fois les soins et les travaux, et laisse de côté tout amour-propre de poëte, afin de donner la plus grande valeur possible à ses plaidoyers pour la liberté religieuse. C'est sous cette impression qu'il écrit encore à Moultou:

(26 février 1763.) « Je suis en peine d'Olympie et de la tolérance; je trouve qu'il y a beaucoup à faire au premier ouvrage et que le second est bien délicat; je vous soumets l'esquisse d'un nouveau chapitre; il ne tient qu'à vous qu'il soit meilleur.

« N'auriez-vous point de livres sur ce sujet ? Mais quelques lignes de votre main vaudraient mieux que tous les livres. Je suis sûr que le contrôleur général, $M$. le duc de Praslin, $M$. le duc de Choiseul ont de très-bonnes intentions; il faut assurément en profiter; ne pourriez-vous point quelque jour en venir causer avec moi ? Votre jeunesse est faite pour éclairer tous les âges. » 
Enfin le rapport sur les Calas est terminé; le préavis du conseil du roi est favorable à la révision, et il est décidé que cette révision sera faite par le Parlement de Toulouse. Voici le chant de triomphe que laisse échapper Voltaire:

(Samedi 12 février 1763.) "C'était un bien vilain jour pour moi, Monsieur, que celui où j'étais à Ferney quand vous me faisiez l'honneur de venir aux Délices; mais c'est un bien beau jour, malgré la bise ou la neige, que celui où nous apprenons l'arrêt du conseil et la manière dont le roi a daigné se déclarer contre les décrets fanatiques qui voulaient qu'on abandonnât les Calas. Nous devons beaucoup à $\mathrm{M}$. le duc de Choiseul et à $\mathrm{M}$. le duc de Praslin. Le règne de l'humanité s'annonce: ce qui augmente ma joie et mes espérances, c'est l'attendrissement universel dans la galerie de Versailles; voilà bien une occasion où la voix du peuple est la voix de Dieu ! Je parie que vous avez pleuré de joie en apprenant cet heureux succès; je vous demande pardon de vous avoir fait lire mes esquisses informes, mais je crois vous devoir des prémices comme un tribut que mon coeur et mon esprit payent au vôtre. »

Nous n'avons retrouvé qu'une lettre qui appartînt à l'époque où la révision du procès s'opérait à Toulouse; c'est la seule qui ait probablement échappé au pillage révolutionnaire de Genève, et son contenu fait vivement regretter la perte des autres, car, sans nul doute, elle n'a pas dû être isolée; la voici:

(2 mars 1764.) "Mon très-cher et très-aimable prêtre, vous avez très-grande raison de vouloir qu'on fasse sentir que la mauvaise métaphysique, jointe à la superstition, ne sert qu'a faire des athées. Les demi-philosophes disent: Saint Thomas est un sot, Bossuet est de mauvaise foi, donc il n'y a point de Dieu..-- Il faut dire au contraire: donc il y a un Dieu qui nous apprendra un jour ce que Thomas d'Aquin ne savait point et ce que Bossuet ne disait pas. Je me suis fort étendu sur cette idée dans un chapitre précédent. -- L'affaire des Calas prend le meilleur train qu'il soit possible; je me flatte toujours qu'on tirera un très-grand parti de cette horrible aventure. Je finis en vous embrassant avec le plus tendre respect. » 
L'affaire des Sirven occasionna entre Voltaire et Moultou une correspondance aussi active que celle des Calas. -- Lorsque, en 1762, Sirven atteignit Genève, le coeur brisé par la fin tragique de sa fille et la mort récente de sa femme, il se rendit chez M. Moultou, son compatriote. Celui-ci le présenta à Voltaire, et l'entrevue ne fut pas moins touchante que celle qui avait eu lieu précédemment entre le philosophe et Mme Calas. Moultou estime que la résolution prise alors par Voltaire de faire rendre justice à ce malheureux père fut peut-être plus méritoire que la défense des Calas, puisqu'il savait cette fois, par expérience, toutes les fatigues attachées à une oeuvre de ce genre. S'il avait travaillé uniquement pour la gloire d'un succès, ses premiers travaux étaient suffisants, il pouvait craindre même d'en compromettre l'éclat par un échec subi dans la seconde lutte qui s'offrait à lui. Heureusement Voltaire n'était pas mû par ces seuls sentiments; il ne recula pas devant des considérations égoïstes, et sans tenir compte des obstacles, il poursuivit avec un véritable acharnement la justification de Sirven. La longueur du procès ne ralentit point son dévouement, ainsi qu'on en peut juger par les fragments de lettres qui vont suivre.

(23 décembre 1767, Ferney.) «Mon cher philosophe (Moultou), l'affaire des Sirven devient d'une importance extrême; le rapporteur me demande un écrit imprimé depuis quelques mois à Toulouse, dans lequel on justifie l'assassinat juridique des Calas; les maîtres des requêtes, qui ont déclaré unanimement la famille innocente, $\mathrm{y}$ sont trèsmaltraités; leur tribunal y est déclaré incompétent et leur jugement injuste. J'ai malheureusement perdu cet écrit précieux, qui doit être une pièce produite au procès; je ne me souviens plus du titre, il me semble que c'était une lettre adressée à un correspondant imaginaire, comme celle de Vernet. Je vous demande en grâce d'écrire sur-lechamp à vos amis du Languedoc qu'il faut qu'ils déterrent cette lettre et qu'ils l'envoient en droiture à $\mathrm{M}$. de Chardon, maître des requêtes, sous l'enveloppe de $\mathrm{M}$. le duc de Choiseul. Cela est de la dernière importance, il n'y a point de peine qu'on ne doive prendre pour recouvrer cet ouvrage c'est un préliminaire nécessaire pour casser le dernier arrêt de Toulouse qui révolte tout le monde.

« Je me porte fort mal, mais je mourrais content avec l'espérance de voir la tolérance établie; l'intolérance déshonore trop la nature humaine; nous avons été trop longtemps au-dessous des Juifs et des Hot- 
tentots. Je vous embrasse bien tendrement, mon cher philosophe. Vous devriez bien venir quelque jour coucher chez nous, nous causerions. "

Du reste, les incidents désagréables ne manquaient pas autour de Voltaire, qui vit plus d'une fois ses efforts compromis, aussi bien par ses partisans que par ses adversaire. Quelques jours après la lettre que nous venons de citer, le 29 décembre il écrivait: «Eh bien ! le diable qui se mêle de toutes les affaires de ce monde, et qui détruit toutes les bonnes oeuvres, ne vient-il pas d'arrêter tout net $\mathrm{M}$. de Chardon lorsqu'il allait rapporter l'affaire des Sirven ? Le Parlement ne lui fait-il pas une espèce de procès criminel pour avoir rapporté devant le roi l'affaire de Cayenne ? Le roi est, à la vérité, indigné contre le Parlement, mais le procès des Sirven n'en est pas moins retardé. Je vais animer M. de Chardon, il est un de nos philosophes, et l'on verra à la fin que la philosophie est bonne à quelque chose. -- La facétie de la Sorbonne ${ }^{11}$ contre Bélisaire paraît enfin; elle ressemble aux pièces nouvelles de cet hiver: elle est sifflée, mais le nonce la dénonce à Rome comme scandaleuse, et cette dénonciation dudit nonce est encore sifflée; la condamnation de Rome le sera aussi, et de rire. -- Je ne ris pas sur les Sirven; je suis surtout très-sérieux quand je vous renouvelle mon tendre et inviolable attachement. »

Voltaire, qui agissait avec un tact égal à son zèle et qui dictait à ses amis genevois toute la prudence possible dans leurs démarches, était sur le brasier à la seule idée d'une publication qui pût irriter les parlements dans ce moment délicat. Or, un protestant célèbre, Court de Gebelin, fit justement alors imprimer à Lausanne ses Lettres toulousaines, où il écrase le fanatisme méridional sous la plus généreuse indignation. L'oeuvre était juste et vraie, mais inopportune au plus haut degré; c'était faire feu avant l'ordre, et Voltaire fut outré de cette imprudence: "Vous partagez, mon cher Moultou, mes craintes et ma douleur; les Lettres toulousaines s'étendent beaucoup sur l'affaire de Sirven et de sa fille: voilà ce qui nous perdra. -- L'affaire de Sirven n'a point été jugée. -- Le Parlement de Toulouse joindra ces deux affaires ensemble et justifiera l'une par l'autre: il soutiendra que les protestants sont en possession d'assassiner leurs fils et leurs filles quand ils veu-

11 Le Bélisaire de Marmontel avait été mis à l'interdit par la Sorbonne. 
lent changer de religion; Ils feront voir, en trois mois de temps, deux pères de famille accusés par la voix publique de ce crime épouvantable; ils diront qu'ils ont cru absolument nécessaire de faire un exemple. J'avais recommandé à nos trois avocats de ne jamais parler de l'affaire des Sirven: ils ont tenu parole. -- Vous écrivez sans doute à Lausanne et à Vevey. Si vous pouvez obtenir que l'auteur supprime le débit du livre jusqu'à la fin du procès, nous sommes sauvés, sinon tout est perdu. L'auteur ne risque rien en différant; il détruit tout notre ouvrage en se pressant. Qu'il attende la fin de notre procès, il aura de quoi faire un second volume intéressant: je lui fournirai plusieurs pièces et plusieurs anecdotes. J'espère beaucoup du pouvoir que votre aimable éloquence doit avoir sur tous les esprits. »

Voltaire avait raison dans cette confiance, car Court de Gebelin attendit.

Lorsqu'enfin ses efforts sont couronnés de succès, comme dans l'affaire Calas, c'est encore M. Moultou qui reçoit le premier l'épanchement de la joie du philosophe (3 février 1768): " Mon cher Moultou ! Enfin, après cinq ans de peines et de soins incroyables, la requête des Sirven fut admise au conseil samedi 23 janvier, après un débat assez long, et le procès doit avoir été rapporté vendredi dernier, 29, devant le roi. Il n'est plus douteux que cette famille ne soit rétablie dans son honneur et dans ses biens, et que l'arrêt infâme qui la condamnait à mort ne soit cassé comme celui des Calas. -- Vous le voyez, mon cher philosophe, il ne faut désespérer de rien; mandez cette nouvelle à vos amis du Languedoc. Mais quand le pauvre vieillard aura-t-il la consolation de vous revoir? »

Des mois s'écoulèrent en effet dans les lenteurs judiciaires, et ce fut seulement le 17 novembre de l'année suivante que Voltaire put mander à son actif collaborateur, alors dans le Midi: "Si vous ne savez rien des Sirven, je vous envoie la Gazette de Berne: vous y verrez que, le 17 septembre 1769, Sirven a été élargi avec mainlevée de son bien; il en appelle au Parlement pour avoir des dédommagements. »

Enfin les affaires pécuniaires de cette malheureuse famille sont réglées, et, le 6 décembre 1771, Voltaire écrit à Moultou: «Mon cher philosophe, vous m'avez cruellement abandonné; vous ne venez plus 
coucher dans mon ermitage; il faut pourtant que je vous dise que le nouveau Parlement de votre Languedoc vient de rendre une justice pleine et complète à Sirven: il lui accorde des dépens considérables et la restitution de ses revenus, malgré l'ancien usage. Nous allons prendre les premiers juges à partie, au nom des filles de Sirven. C'est M. le premier président qui a la bonté de me mander ces nouvelles. Souvenez-vous qu'il n'a fallu que deux heures pour condamner cette vertueuse famille à mort, et qu'il nous a fallu neuf ans pour lui faire rendre justice.

« Mes respects à la sainte Vierge, devant qui les assassins du roi de Pologne ont communié et fait serment d'assassiner leur roi légitime. »

Au sujet de la condamnation de La Barre, la correspondance de Voltaire avec Moultou prit un caractère encore plus intime et plus confidentiel que précédemment. Un des griefs allégués contre cet infortuné portait qu'il s'était agenouillé devant le Dictionnaire philosophique de Voltaire, et les juges menaçaient sérieusement le défenseur de La Barre de l'impliquer dans l'affaire comme complice du prévenu. Voltaire dut se condamner au repos pendant quelques semaines, mais il ne pouvait se résoudre à un silence absolu, et ce fut Moultou qu'il chargea de transmettre aux parents des condamnés le témoignage de sa vive sympathie. " Le vieux malade, lui écrit-il, espère mourir bientôt pour ne plus voir de ces horreurs: il ne voit que trop que le même esprit qui les fit naître les maintient et les maintiendra.

« On nous trompait quand on nous promettait de la douceur envers cet infortuné jeune homme: un tigre mangera toujours des agneaux, mais ne le deviendra pas. La lettre que ce pauvre père de famille m'écrit me déchire le coeur, je me trouve moi-même dans une position bien pénible pour avoir pris hautement son parti; ceux qui sont payés et honorés pour faire du mal au nom de Dieu sont les maîtres absolus dans leur tripot infernal et sacré. J'ai reçu des lettres anonymes dans lesquelles on me menace beaucoup si je continue à prendre parti dans cette affaire...

« Je vous prie, mon cher philosophe, de vouloir bien écrire au père de famille l'état où je žne trouve, sans me nommer; Mme la duchesse 
d'Anville serait la seule personne qui pourrait me rendre service dans cette affaire auprès d'un athée qui cherche à plaire à des fanatiques.

« Je vous embrasse bien tendrement et ne puis vous en dire davantage, ni ne puis écrire au père de famille -- Je vous supplie instamment de lui mander que de très-tristes raisons me forcent à ne pas écrire un seul mot par la poste sur la tolérance et sur la justice qu'on doit aux hommes. Vous, mon cher Moultou, vous pouvez mander ce que vous voudrez, vous êtes libre; vous êtes né libre, et je suis né esclave. »

Un scandale d'un autre genre, qui remua fortement les esprits dans le midi de la France, tient aussi une large place dans les relations épistolaires de Voltaire avec Moultou.

M. Ripert de Montclar venait de mourir; on sait que les éloquents et courageux réquisitoires prononcés par ce magistrat contre les jésuites furent une des principales causes de leur bannissement de France; en 1764, le roi, entraîné par la puissance des raisonnements de son procureur général, signa leur expulsion. Neuf ans plus tard, le 12 février 1773, M. de Montclar mourut; le bruit courut partout qu'il avait, à ses derniers moments, rétracté sa conduite et fait amende honorable envers la Société de Jésus. Aujourd'hui ce fait est consigné dans les livres et les biographies qui ont trait à l'histoire des jésuites. "Son confesseur, affirme-t-on, par ordre de l'évêque d'Apt, exigea de lui qu'il rétractât ce qu'il avait avancé de défavorable au clergé en général, et il se résigna à cet acte de repentir et de soumission. »

Or, M. Moultou, proche parent des Montclar, reçut, peu de temps après la mort du procureur général, une relation détaillée de ses derniers moments, relation que la famille du défunt le priait instamment de communiquer à Voltaire. Voici cet étrange document, qui est livré ici pour la première fois à la publicité:

« M. de Montclar, ancien procureur général au Parlement de Provence, étant malade à Saint-Saturnin, diocèse d'Apt, fut administré, le 12 février 1773, par le vicaire de sa paroisse, nommé Jouval, en présence de Madame sa femme, de son frère, de M. de Salonet, capitaine de cavalerie, de quelques parents, de tous ses domestiques, de quoi fut dressé procès-verbal -- L'évêque d'Apt, nommé Boçon, gouverné par 
quelques ex-jésuites, mande le 14 février le vicaire, lui fait un crime d'avoir conféré les sacrements à $\mathrm{M}$. de Montclar; il le menace, l'intimide et exige de lui une fausse déclaration, dans laquelle il est dit en termes exprès que $\mathrm{M}$. de Montclar, en mourant, a protesté d'être soumis à la bulle Unigenitus, qu'il rétractait ce qu'il a fait et dit contre ladite bulle, qu'il demande pardon d'avoir persécuté les saints jésuites, qu'il leur rend hommage et se repent d'avoir prêté son ministère à la destruction d'une société si utile.

«Ce sont les propres termes de l'écrit signé par le vicaire Jouval.

"Ce malheureux prêtre remontre humblement à l'évêque que rien de tout cela n'est vrai, que lui, Jouval, a déjà attesté tout le contraire dans la famille, de vive voix et par écrit; qu'enfin il ne peut se résoudre à mentir avec tant d'impudence. L'évêque l'assure que c'est pour la plus grande gloire de Dieu; un ex-jésuite lui fait comprendre que, si M. de Montclar n'a pas proféré exactement ces paroles, il doit les avoir dans le coeur. Enfin le malheureux signe cette pièce calomnieuse. -- De retour à Saint-Saturnin, il est troublé de remords; il demande pardon à Mme de Montclar et à toute sa famille de la faiblesse qu'il a eue; il désavoue, les larmes aux yeux, les mensonges que l'évoque d'Apt avait arrachés à sa timidité. Ce désaveu, signé de quatre témoins, est du 16 février 1773. -- Dès lors, Jouval, pressé entre les reproches de la famille du défunt et les menaces de son évêque, supplie M. de Montclar, le frère, de vouloir bien supprimer les pièces qui pourraient prouver cette manoeuvre. $M$. de Salonet lui répond le 23 février, de Marseille, où il était pour lors: « Je ne puis me prêter à la proposition que vous me faites; quand on nous représentera cette déclaration que l'évêque d'Apt vous a fait signer chez lui contre la vérité, que pourrons-nous répondre ? On ne trafique pas ainsi de la vérité; nous ne le pourrions pas pour nous-mêmes, encore moins pour la réputation d'un père de famille respectable. »

Lorsque M. Moultou eut pris connaissance de cette déclaration de ses parents de Montclar, il communiqua, selon leur désir, ces faits à Voltaire; celui-ci lui écrit, en date du 25 avril 1773: « En vous remerciant du fond de mon coeur, le vôtre doit être bien ulcéré. Je ne doute pas que vous ne fassiez voir le jour à des pièces aussi importantes, et que vous ne manifestiez ces excès de l'imposture d'un évêque et de la 
faiblesse de ce pauvre vicaire. Ce sera servir à la fois les rois de France, d'Espagne, de Portugal et de Naples, justifier la mémoire de M. de Montclar et rendre service à tous les honnêtes gens de l'Europe. La publication d'une telle calomnie est d'autant plus nécessaire qu'une pareille friponnerie est en usage dans presque toutes les paroisses catholiques; on gêne, on persécute les vivants, et on calomnie les mourants. Il ne faut pas manquer une telle occasion de démasquer les loups qui se cachent sous la peau des agneaux qu'ils ont mangés. »

M. Moultou hésitait; il lui répugnait de frapper un ennemi terrassé, les jésuites étant alors chassés de toutes parts. L'esprit de liberté religieuse faisait d'ailleurs de jour en jour de plus grands progrès, et il lui paraissait inutile, en même temps que peu généreux, d'accabler des adversaires désormais impuissants. Il témoigna ses scrupules à Voltaire, qui lui répondit: "Mon cher philosophe, faites comme il vous plaira avec votre maudit évêque. Vos papiers sont à vous: chacun est le maître de son bien, mais il est triste que la fraude pieuse de ce sycophante ne soit pas assez connue. »

M. Moultou suivit son premier mouvement, et la déclaration des Montclar ne fut pas imprimée. Aujourd'hui les jésuites sont plus puissants que jamais; exilés ou présents, ils troublent et dominent également les pays chrétiens, nous ne voyons donc pas qu'il y ait lieu à avoir les mêmes scrupules que Moultou, et qu'il soit convenable, au point de vue de la vérité historique, de retenir par devers soi quelque pièce attenant au grand procès que leur intentent devant l'opinion publique les amis de la liberté.

Les faits particuliers dont nous nous sommes occupés jusqu'ici ne sont pas les seuls qui aient alimenté la correspondance de Voltaire avec Moultou. La question générale de la liberté due aux protestants français et de leur rétablissement dans le droit civil commun les préoccupait également tous les deux: Voltaire était soigneusement instruit de toutes les démarches qu'on essayait à la cour de Louis XV, mais souvent les affaires lui paraissaient fort mal conduites; ainsi le 11 mars 1764, il écrivait à Moultou: " Il est bien étrange, cher et aimable philosophe, qu'on propose le rappel des protestants en France, car assurément on ne les en a pas chassés; au contraire, on les retient malgré eux, et on confisque leurs biens quand ils viennent déjeuner à 
Genève ou à Lausanne. Ce qu'on devrait proposer, ce me semble, ce seraient des conditions raisonnables, moyennant lesquelles ils ne seraient plus tentés d'abandonner leur patrie. Mais on m'assure que, dans le livre de $\mathrm{M}$. de la Morandière, on avance qu'il ne doit pas être permis à deux familles de se réunir pour prier Dieu: c'est conseiller la persécution sous le nom de la tolérance ! mais il se pourrait qu'on m'ait trompé; je n'ai point vu ce livre; tout ce que je sais, c'est que les Parlements brûlent à présent tous les livres qui leur déplaisent. Vous savez que l'auteur de l'apologie de la Saint-Barthélemy est à Rome en personne, tandis qu'à Paris il est au carcan en peinture. -- Dieu le récompensera, il sera peut-être cardinal. »

Et (même date): «Comptez, mon cher Monsieur, que nous sommes tous des imbéciles: ce n'est point avec des livres qu'on obtient les grâces de la cour, et l'Apologétique de Tertullien ne fut pas lue seulement d'un marmiton de la cour de l'empereur. Les bons livres peuvent faire des philosophes, encore n'est-ce que chez les jeunes gens; les autres ont pris leur pli. C'est ce qui fait que monsieur de Crosne est entièrement pour nous, indépendamment même des formes juridiques. Mais il faut des formes à MM. d'Aguesseau et Gilbert, qui ne sont point du tout philosophes; il faut auprès des ministres d'État de très grandes précautions, et point de livres: un bon ouvrage peut porter ses fruits dans quinze ou vingt ans, mais aujourd'hui il s'agit d'obtenir la protection de Mme de Pompadour; le grand point est d'intéresser son amourpropre à faire autant de bien à l'État que Mme de Maintenon a fait de mal. Je répondrai bien de sa bonne volonté, et de celle de MM. de Choiseul et de Praslin; mais, avec tout cela, cette tolérance ne serait pas encore accordée, tant il est difficile de changer ce qui est une foi établi. C'est assurément une très-belle entreprise, et je mourrais tranquille si j'avais mis une pierre à cet édifice. -- Nous raisonnerons de tout cela avec M. Moultou, l'homme que j'estime le plus, et en qui j'ai la plus grande confiance. »

En 1764, M. Moultou travaillait à une histoire des premiers siècles de l'Église; il en communiqua des fragments à Voltaire. A cette occasion, la verve railleuse du philosophe de Ferney reprit le dessus, et il enfourcha, pourrait-on dire, son dada, qui était, ainsi que nous l'avons vu, de confondre le christianisme avec le fanatisme romain. « Il fallait, écrit-il à son ami le 17 mars 1764, il fallait que les premiers chrétiens 
donnassent d'eux une bien mauvaise idée, pour qu'on les accusât d'être anthropophages; pour moi, je vous avoue que j'aimerais mieux qu'ils eussent mangé autrefois un ou deux petits garçons, que de faire brûler tant d'innocents et de se rendre coupables des massacres des Albigeois, de Mérindol, de Cabrières, de la Saint-Barthélemy, et de tant d'autres horreurs. Cette abomination nous est particulière; il faut que notre religion soit bien vraie, puisqu'on n'a jamais craint de lui nuire en la prêchant ainsi. Adieu, Monsieur, je regarde comme la consolation de ma vie l'amitié d'un homme tel que vous. »

Un peu plus tard, en 1766, nous retrouvons encore, dans la correspondance de Voltaire avec Moultou, l'expression de cette horreur que lui inspirait le fanatisme: "J'ai avec vous la conformité d'un trèsgrand mal aux yeux; mais les vôtres sont jeunes, et je perdrai bientôt les miens, ils lisent en pleurant cet amas d'horreurs rapporté dans le livre que vous m'envoyez: en vérité, cela rend honteux d'être catholique; je voudrais que de tels livres fussent entre les mains de tout le monde. Mais l'opéra-comique l'emporte, et presque tout le monde ignore que les galères sont pleines de malheureux condamnés pour avoir chanté de mauvais psaumes. Ne pourrait-on point faire quelque livre qui pût se faire lire avec quelque plaisir par les gens mêmes qui n'aiment point à lire, et qui portât les coeurs à la compassion ? -- Plus j'y pense, plus il me paraît difficile d'avertir que les fruits d'un arbre sont mortels sans faire sentir aux esprits exercés que l'arbre est d'une bien mauvaise nature. -- Me permettrez-vous de garder quelques jours le compte de vos frères (protestants égorgés ou bannis) ? Il me paraît, par leur nombre, que vous n'auriez pas dû vous laisser pendre; mais, entre nous, je crois ce nombre terriblement exagéré; je vais écrire dans une province dont je pourrai recevoir des instructions, et ce qu'on m'apprendra de ce canton me servira de règle pour les autres. -- Je voudrais bien que votre confrère de Céligny (M. Vernes) vous envoyât le petit chapitre en question; je ne sais s'il n'est point trop plaisant pour être mis dans un ouvrage sérieux; mais il me paraît essentiel de le faire lire par tout le monde, si on peut. Ce n'est pas assez de prouver que l'intolérance est horrible, il faut prouver aux Français qu'elle est ridicule. -- Je vous embrasse de tout mon coeur, comme un véritable ami des hommes; vous êtes au-dessus des cérémonies. » 
L'année suivante, Voltaire charmé de l'expulsion des jésuites hors de toutes les terres de la domination espagnole, voudrait que ce grand travail fût couronné par la rentrée en France des protestants, laquelle semblait avoir quelques chances de succès (24 avril 1767). "Voilà deux grandes nouvelles, mon cher Monsieur; voilà une espèce de persécuteurs bannie de la moitié de l'Europe, et une espèce de persécutés qui peut enfin espérer de jouir des droits du genre humain que le Père Lachaise et Michel Letellier leur ont ravis. Il faudrait piquer d'honneur M. de Maupeou: je réponds bien de MM. de Choiseul et de Praslin; mais, dans une affaire de législation, le chancelier a toujours une voix prépondérante. Mme la duchesse d'Anville est à la Roche-Guyon, mais écrivez-lui; flattez la grande passion qu'elle a de faire du bien, qui vous est commune avec elle; elle est capable d'aller exprès à Versailles. Le succès d'une pareille entreprise rendrait le roi chéri de toute l'Europe. Est-il possible que les Turcs permettent aux chiens de chrétiens de porter leur Dieu dans les rues, de chanter ô filii, ô filiae à tuetête, tandis que les Welches ne permettent pas à d'autres Welches de se marier ? La conduite welche est si folle et si odieuse qu'elle ne peut pas durer. -- Je vous embrasse tendrement. »

Si les démarches des deux amis, le philosophe incrédule et le philosophe chrétien, ne purent amener encore le triomphe complet de la liberté religieuse en France, du moins bien des injustices isolées furent réparées grâce à leur zèle. Ainsi, le 13 décembre 1769, Voltaire écrivait à Moultou: "Je vous fais compliment de vos deux galériens mis en liberté; si c'est par Mme d'Anville que vous êtes parvenu à cette bonne oeuvre, cela prouve qu'elle a du crédit auprès de $M$. de SaintFlorentin; si c'est par vous-même, vous ferez casser la révocation de l'édit de Nantes ${ }^{12}$. »

Enfin, six ans plus tard, la cause de la tolérance avait fait de sérieux progrès, puisque ( 9 août 1775 ) Voltaire pouvait écrire: «L'archevêque de Toulouse a parlé il y a quelque temps des mariages pro-

12 La famille Moultou conservait une volumineuse correspondance entre son chef et la duchesse d'Anville. Ces lettres qui paraissent avoir été du plus haut intérêt touchant la question de la liberté religieuse, ont été détruites par les pillards révolutionnaires et nous sommes privés d'un travail qui aurait fait le plus grand honneur à la mémoire de $\mathrm{M}$. Moultou. 
testants, et il a montré dans ses propos autant de tolérance que de politique. M. Turgot est en train de rendre les plus grands services à la nation et à la raison; sa sagesse et sa bienfaisance s'étendent jusque sur nous, pauvres habitants ignorés du mont Jura. Attendez-vous, vous autres Genevois, aux choses les plus agréables, c'est tout ce que je puis vous dire. Ceux qui vous mandent que le clergé français n'a jamais eu plus d'activité et de crédit se trompent de moitié, ils n'ont raison que sur l'activité. -- Je vous embrasse avec tendresse et joie, quoique fort malade. »

Dès ce moment, en effet, on put prévoir en France que l'heure allait sonner où la liberté de conscience devait rentrer sur ce sol qu'elle avait quitté depuis si longtemps: son principe était décidément inoculé à la nation, il ne restait plus qu'à en développer les progrès et la pratique, en se résignant aux lenteurs inséparables d'une semblable révolution. Toutefois, ces retards empêchèrent les ardents promoteurs de la tolérance de contempler le résultat de leurs efforts: avant-garde dans la lutte, ils succombèrent avant de voir leur drapeau fixé dans la place conquise; mais en emportant l'assurance qu'ils seraient victorieux. Heureusement les ministres d'État ne songeaient point à revenir en arrière; Rulhières et Malesherbes mirent à cette cause le plus sérieux intérêt. Dans le but de s'entourer de toutes les lumières possibles, ils s'adressèrent à Genève, et le professeur Jacob Vernet fut chargé de répondre à cette question venue de Versailles: "Que doit-on, que peut-on faire actuellement en faveur du protestantisme français ? " Le mémoire que Vernet rédigea à cette occasion fut très-goûté par les hommes placés alors à la tête des affaires en France, et en 1788 Louis XVI, écoutant les inspirations de son coeur généreux, termina l'ère des persécutions antichrétiennes sur le sol français en signant l'acte qui rendait la liberté religieuse et la sécurité personnelle aux réformés de son royaume.

Soixante-dix années ont passé depuis que Voltaire et ses amis genevois obtinrent la victoire légale sur le fanatisme romain; mais l'adversaire de toutes les libertés est loin d'être vaincu; et lorsque de nos jours les incessantes manifestations de sa mauvaise volonté pénètrent d'inquiétude les amis de la vérité philosophique et religieuse, ne devons-nous pas conserver une vive reconnaissance envers des hommes 
qui ont délivré l'Europe française de la tyrannie sanglante des Lachaise et des Le Tellier?

$* * *$ 
VOLTAIRE ET LES GENEVOIS

\section{XI \\ LA PRESSE VOLTAIRIENNE À GENÈVE}

Confusion faite par Voltaire entre le christianisme et le fanatisme. -Craintes des Genevois religieux au sujet du séjour de Voltaire. - Publication de la Jeanne d'Arc. -- Elle est brûlée à Genève par la main du bourreau. -Législation genevoise sur la liberté de la presse. -- Le carrosse de Voltaire visité à l'octroi. -- Candide et le Dictionnaire philosophique brûlés. -- Propagande organisée par Voltaire pour inonder Genève de ses pamphlets. -- Résistance des pasteurs et jugement porté par Rousseau sur cette affaire.

Nous avons éprouvé une satisfaction véritable en rendant justice aux nobles efforts de Voltaire en faveur de la tolérance, mais maintenant la scène change, et nous sommes obligés de transporter nos lecteurs sur un terrain où le philosophe de Ferney est loin de paraître à son avantage. Si Voltaire est grand lorsque, suivant les inspirations de son coeur, il travaille à la cause de l'humanité, il s'abaisse singulièrement lorsqu'il veut, par les efforts de son esprit, détruire les principes chrétiens.

Nous avons déjà constaté à quelle tactique il empruntait ses armes agressives contre le christianisme, et quel merveilleux parti il savait tirer de la confusion qu'il affectait de faire entre la loi de l'Évangile et les erreurs ou les crimes que les passions humaines ont, depuis des siècles, cherché à vêtir du manteau de cette religion. Voici du reste quelle était, pour Voltaire, la définition de la loi de Jésus, "la plus forte et la mieux conçue. »(Corresp. génér., 1768, p. 399): « Je la 
trouve absurde, extravagante, injurieuse à Dieu, pernicieuse aux hommes, facilitant, même autorisant les rapines, les séductions, l'ambition, l'intérêt de ses ministres, la révélation du secret des familles. Je la vois comme une source intarissable de meurtres, de crimes, d'atrocités commises sous son nom; elle est le bouclier de la tyrannie contre les peuples qu'elle opprime, et la verge des bons princes quand ils ne sont point superstitieux: je suis donc dans l'obligation de mépriser ceux qui la prêchent, et de vouer à l'exécration publique ceux qui la soutiennent de leurs violences et de leurs superstitions. »

Évidemment, pour Voltaire, l'Évangile et la politique de Borgia c'était tout un.

À peine arrivé à Genève, Voltaire avait conçu des intentions réformatrices à l'endroit de " cette ville hargneuse " où l'on prêchait publiquement, chaque dimanche, les dogmes de cet Évangile détesté. Toutefois, trop habile pour dévoiler dès l'abord ses projets, il se posa en brave et digne homme, incapable de prononcer une parole contre la religion ou la morale; il en fit même la déclaration, formelle au professeur Jacob Vernet, qui entretenait avec lui des relations littéraires. On était au mois de juin 1755; ce pasteur lui avait écrit la lettre suivante: "Monsieur, la seule chose qui trouble la satisfaction générale de voir arriver parmi nous un homme aussi célèbre que vous êtes, c'est l'idée que des ouvrages de jeunesse ont donnée au public sur vos sentiments par rapport à la religion: je ne vous dissimulerai point que les gens sages qui nous gouvernent, et la bonne bourgeoisie, ont manifesté, dans leurs discours, de graves inquiétudes à ce sujet: j'espère que vous les dissiperez complètement. Si chez nous les théologiens, les jurisconsultes et les philosophes sont d'accord sur la religion, c'est que les pasteurs ont la sagesse de s'en tenir au pur Évangile, et les gouvernants savent que l'Évangile est nécessaire. Ainsi, Monsieur, nous espérons que vous entrerez dans nos vues, et que vous vous unirez à nous, quand l'occasion s'en présentera, pour détourner notre jeunesse de l'irréligion, qui conduit au libertinage. Soyez sûr qu'alors vous serez honoré, chéri de tous, et craint de personne. »

Voltaire lui répondit: «Mon cher Monsieur, ce que vous me dites est fort raisonnable. Je déteste l'intolérance et le fanatisme; je respecte vos lois religieuses, j'aime et je respecte votre République; je suis trop 
vieux, trop malade et un peu trop sévère avec les jeunes gens. Vous me ferez le plaisir de communiquer ces sentiments à vos amis. »

Cette lettre rassura les amis de la religion à Genève; mais cette tranquillité dura peu. Déjà en 1756, le registre du Conseil porte: « Messieurs ont reçu la visite de Spect. Lullin, modérateur de la Vénérable Compagnie, au sujet d'un écrit fort licencieux qui court la ville: c'est 14 vers extraits d'un poëme sur la vie de Jeanne d'Arc. Ce poëme est un des écrits les plus détestables contre la religion et les moeurs: on l'attribue au sieur de Voltaire. » Le Conseil ordonne là-dessus « une visite des anciens et des dizainiers, qui ramasseront toutes les copies de ces vers qu'on pourra trouver dans la ville. » M. Vernes, qui était alors en correspondance avec Voltaire, lui écrivit à ce sujet: «On m'a communiqué un exemplaire de cette détestable poésie; je crains beaucoup qu'elle ne soit de vous; tous ceux qui vous connaissent sont navrés que vous ayez rabaissé votre génie jusqu'à mettre au jour une aussi scandaleuse production. » -- " Moi ! lui répondit l'auteur, il faut que je sois tombé bien bas dans votre estime, puisque vous me croyez capable d'une pareille saleté ! » Et vingt lettres écrites à ses amis nous reproduisent les mêmes dénégations; mais Voltaire voulut en outre se jouer des magistrats genevois: il s'adressa à eux, feignant une grande colère contre un libraire de Lausanne, nommé Grasset, qui, ignorant que ce poëme fût de Voltaire, vint lui en offrir une copie manuscrite; il faut avoir lu l'original de cette lettre envoyée aux syndics de Genève (1756), pour croire qu'un homme puisse être capable de se couvrir luimême d'aussi violentes injures: "Vos bontés et celles du magnifique Conseil m'ayant déterminé à m'établir ici sous votre protection, je désire assurer mon repos en ayant recours à votre prudence et à la justice du Conseil. Je vous informe qu'un nommé Grasset est parti de Paris, chargé d'un manuscrit abominable qu'il veut faire imprimer sous mon nom. J'ai pris les mesures nécessaires pour empêcher cette indignité. Grasset, se voyant empêché, est venu me proposer ce manuscrit pour 50 louis, et me dit que, si je ne l'achetais pas, il le vendrait à d'autres. Je fus saisi d'horreur à la vue de cette feuille, qui insulte avec autant d'insolence que de platitude à tout ce qu'il y a de plus sacré. Grasset, prenant mon silence pour une approbation, m'offrit de me faire une copie de ce manuscrit. Je lui dis que ni moi, ni personne de ma maison ne transcririons jamais des choses si infâmes et que, si un de mes laquais en copiait une ligne, je le chasserais sur-le-champ. Ma juste in- 
dignation me détermina à faire remettre entre les mains d'un magistrat cette feuille punissable, qui ne peut avoir été composée que par un scélérat insensé, imbécile. J'ignore ce qui s'est passé depuis; j'ignore de qui Grasset tient ce manuscrit odieux, mais ce que je sais, c'est que ni vous, ni aucun des membres de cette République ne permettront des ouvrages si horribles, qui outragent également les moeurs, la religion, et le repos des hommes. Mais il n'y a aucun lieu sur la terre où j'attende une justice plus éclairée qu'à Genève. » Et cela est signé: Voltaire, gentilhomme ordinaire du roi !!

Ce poëme de la Jeanne d'Arc, il l'avait composé à la cour de Berlin dix ans auparavant; il conservait le manuscrit avec un tel soin qu'en voyage il le portait constamment sur lui dans une poche secrète. A Ferney, il le communiquait à ses intimes; il s'en faisait lire des fragments le soir lorsqu'il était fatigué de travail: et il se montra charmé d'entendre, en 1778, le peuple de Paris qui l'entourait, unir dans son engouement le plus beau et le plus vil de ses poëmes, et crier: "Vive la Henriade ! vive la Jeanne d'Arc ! » On peut juger d'après cela quels furent ses sentiments, lorsqu'il apprit que le 4 août 1756, devant l'hôtel de ville de Genève, à la réquisition du procureur général Tronchin, un des Genevois qu'il estimait le plus, et aux applaudissements d'une foule nombreuse, on avait brûlé par là main du bourreau les exemplaires manuscrits de ce poëme qu'on avait trouvés dans la ville. Toutefois ne nous y trompons point: cette exécution légale, souvenir affaibli de l'inquisition, servait à merveille le plan de Voltaire; il savait bien que les livres brûlés étaient lus avec une avidité sans exemple par tous les amateurs du fruit défendu.

Puisque nous y sommes amenés, disons ici en deux mots en quoi consistait à Genève la législation en matière de presse. La loi était sur ce sujet aussi simple que brève: " Il est défendu d'imprimer dans des lieux occultes: on ne se servira que d'imprimeries déclarées, à peine de 50 écus d'amende; défendu de rien imprimer sans la permission des seigneurs scolarques (c'étaient trois conseillers chargés de surveiller l'instruction publique). » Ce régime, qui sous un gouvernement autocratique eût pu facilement aboutir à détruire toute liberté de pensée, n'empêchait nullement à Genève, grâce au bon sens des gouvernants, l'opinion publique de se faire jour sur toutes les questions: le pour et le contre s'imprimaient largement en toute affaire; les seigneurs scolar- 
ques n'arrêtaient la publication que des écrits décidément scandaleux sous le rapport moral.

Les mauvais livres étaient, à l'époque dont nous parlons, ordinairement importés du dehors: trois libraires, Chirol, Grasset et Gando furent punis à cette occasion, mais les brochures impies n'en continuèrent pas moins à circuler dans la ville; aussi le gouvernement ordonna que les visiteurs de l'octroi surveilleraient rigoureusement les ballots, surtout ceux qui viendraient du côté de Ferney. Les préposés cumulèrent dès lors avec leurs fonctions ordinaires une chasse active aux feuilles d'imprimerie. Une scène burlesque eut lieu par suite de cette mesure. On savait que maintes fois le carrosse de M. de Voltaire, que par considération on ne visitait jamais, avait déposé des caisses suspectes à la porte du libraire Chirol. Ordre fut donné d'y prendre garde. Un jour ledit carrosse vient à passer au grand trot: le chef du poste l'arrête, le domestique insiste pour continuer la route et il s'engage une querelle dans laquelle les plus gros mots sont lancés contre M. de Voltaire. Malheureusement la voiture était vide, en sorte que Voltaire put se plaindre amèrement du procédé, et le Conseil dut prendre acte d'une missive peu agréable du résident de France (Portef. historiq. Archives de Genève, no 4962): " Messieurs les syndics, j'apprends par beaucoup de témoins que sous prétexte de visiter le carrosse de M. de Voltaire, le sergent et le visiteur ont vomi mille injures contre sa personne: je vous demande que ces gens soient punis exemplairement; il parait inutile de vous dire que c'est moins le moment que jamais de mécontenter le ministre de France. »

Après la Jeanne d'Arc, le premier ouvrage qui fut prohibé fut Candide, publié en 1759, sans nom d'auteur. Malgré tout le respect que l'on doit porter à la réputation de lord Brougham et malgré les éloges que dans son livre sur Voltaire et Rousseau il a donnés au roman soidisant moral de Candide, nous ne pouvons, pour notre part, l'envisager que comme un livre vraiment infernal: c'est l'histoire de gens qui, candidement et sans penser à mal, commettent tous les crimes connus sur cette terre. Ingratitude, débauches, vols, meurtres de divers genres sont accomplis comme les choses les plus naturelles: naturellement aussi les peines et les châtiments les plus intimement liés à ces actes tombent sur les héros du livre qui chargent alors l'Être suprême de la responsabilité de leurs misères et trouvent qu'il eût bien dû arranger 
les choses de manière à ce qu'on pût tuer son prochain sans être poursuivi par la justice et déshonorer la maison de son bienfaiteur sans en être chassé. Il est peu de livres mieux calculés pour anéantir les scrupules d'une conscience encore mal affermie dans le sentier du devoir. - Tel fut aussi le jugement de la Compagnie des Pasteurs: le 2 mars 1759, la présence de ce livre dans Genève étant dénoncée au Conseil parle Modérateur, sur sa réquisition, l'on arrêta que tous les exemplaires seraient immédiatement détruits. -- Voltaire, pour composer ce livre, s'était enfermé trois jours, ne voulant ouvrir sa porte qu'à ses repas et à son café: au bout de ce temps, $\mathrm{M}^{\mathrm{me}}$ Denis, effrayée d'une pareille séance, voulut forcer la consigne; Voltaire lui jeta le manuscrit à la figure en lui disant: "Tenez, curieuse ! voilà qui est bon pour vous ! » Ses amis lui demandèrent s'il était réellement l'auteur de ce pamphlet. A M. Vernes il répondit: « J'ai lu enfin Candide, et comme pour la Jeanne d'Arc je vous déclare qu'il faut avoir perdu le sens pour m'attribuer une pareille..... » ( Ici une épithète qui n'a de place que dans le dictionnaire du langage des halles.) A un autre il dit: "Plus j'ai ri en lisant Candide, plus je suis fâché qu'on me l'attribue. Dieu me garde d'avoir la moindre part à cet ouvrage !» On devine que, malgré les soins du Conseil, Voltaire et son libraire en introduisirent bon nombre d'exemplaires dans Genève.

Il en fut de même peu après pour une tragédie intitulée Saül, dans laquelle Voltaire se fait un jeu de tronquer le sens des récits scripturaires, transforme le prophète Samuel en grand inquisiteur, et se servant de traductions infidèles, cite des faits qui ne furent jamais consignés dans la Bible.

La publication de Voltaire qui fut accueillie avec le plus de sévérité de la part du gouvernement genevois fut le Dictionnaire philosophique portatif. C'est, en effet, dans ces deux petits volumes que Voltaire a condensé les plus tristes assertions concernant l'Évangile. Ils furent imprimés à Londres et à Amsterdam, et de nombreux exemplaires en arrivèrent à Genève au mois de septembre 1764. Dès l'abord, M. Tronchin, sur le rapport du Consistoire, fait saisir ces ballots, et le Conseil déclare ce livre impie, scandaleux, téméraire, destructif de la religion. Un peu plus tard, il apprend que le libraire Chirol en a vendu 12 exemplaires: mandé à l'hôtel de ville, cet homme déclare qu'ils lui ont été remis par la femme de son collègue Grasset. Grasset, mandé à 
son tour, répond qu' "il ne sait ce qui sort, ni ce qui entre dans son imprimerie. » Le Conseil l'oblige à demander pardon à Dieu, le condamne à 50 florins d'amende, et il lui déclare qu'«il sera cassé d'imprimeur s'il ne veille mieux à ses affaires. » Puis la délibération s'engage sur Voltaire lui-même, et l'on cherche les moyens de manifester le plus rudement possible le mécontentement que l'on éprouve à son égard. Sur ces entrefaites, M. Tronchin, faisant une visite à Ferney, reprocha à Voltaire la publication de cet ouvrage, et lui dit qu'il pourrait bien passer par la main du bourreau. «Vraiment, Monsieur le magistrat, répondit-il, on croirait que vous regrettez d'avoir brûlé l'Emile de Jean-Jacques, et que vous voulez vous faire bien venir auprès des citoyens représentants, ses amis ${ }^{13}$. -- Vous détournez la question, répliqua Tronchin; retirez ce livre, exigez de vos complices la remise de tous les ballots, ou je me verrai dans l'obligation de faire contre vous le plus désagréable réquisitoire, et je vous avertis que, dans ce moment, les ministres du roi de France sont peu disposés en votre faveur. »

Voltaire haussa les épaules, mais le lendemain il écrivit au Conseil une lettre qui fait le pendant de celle qu'il lui avait déjà envoyée à propos de la Jeanne d'Arc: « Je suis obligé, dit-il, d'avertir le magnifique Conseil que parmi les libelles pernicieux dont cette ville est inondée, et qui sont tous imprimés à Amsterdam chez Michel Rey, il arrivera lundi prochain chez le libraire Chirol, de Genève, un ballot contenant des Dictionnaires philosophiques, Évangiles de la raison, et autres sottises que je méprise autant que les Lettres de la Montagne du sieur Rousseau ! Je crois faire mon devoir en donnant cet avis, et je m'en remets entièrement à la sagesse du Conseil, qui saura bien réprimer toutes les infractions à la paix publique et au bon ordre. » Mais Voltaire, Chirol et Gando se promettaient d'employer une ruse familière aux contrebandiers littéraires, comme aux autres. Pendant qu'en saisissait les ballots de Chirol, une forte cargaison passait la frontière sur un autre point, à l'adresse de Gando, qui put fournir largement Genève de la denrée prohibée. $M$. Tronchin, indigné de se voir ainsi joué par Voltaire, lança contre lui un réquisitoire des plus énergiques, et

13 Ce fait, antérieur effectivement à l'époque où se passaient les choses que nous racontons dans cette page, trouvera sa place dans le chapitre suivent, consacré plus spécialement à Rousseau. 
son ouvrage fut brûlé par la main du bourreau, le 26 septembre 1764 . L'auteur, malgré toute sa susceptibilité, ne jugea pas à propos de se brouiller, pour cet affront, avec le procureur général, qui connaissait trop bien sa vie privée pour qu'il voulût s'en faire un ennemi.

Cette vigilance et cette sévérité paraissant par trop désagréables à Voltaire, il essaya de s'en débarrasser au moyen d'une ruse des plus malicieuses. Il fit imprimer ses plus tristes productions sous des titres religieux, ou tout au moins de nature à faire illusion au premier abord. Afin de tromper mieux les autorités genevoises, il avait soin de faire débuter la plupart de ces pamphlets par trois ou quatre pages du meilleur aloi, et qui servaient d'introduction aux plus indignes blasphèmes contre la doctrine et la personne du Sauveur. Ainsi, sous les titres de: Almanach philosophique, Pensées sérieuses sur Dieu, Sermons du Rév. Jacques Rossetes, Homélie du pasteur Bourn, Évangile du jour, Lettres d'un proposant à M. le pasteur De Roches, Adresse des pasteurs de Genève à leurs collègues, Conseils aux pères de famille, Lettre sur la Terre-Sainte établissant la réalité des miracles de JésusChrist, Voltaire vida dans Genève tout l'arsenal de son incrédulité.

À la vérité, le Consistoire faisait bonne garde, les pasteurs multipliaient les visites, conjuraient les chefs de famille de ne point acheter ces mauvais livres, et souvent ils réussissaient, témoin le fait suivant. Un horloger avait une nombreuse collection des pamphlets de Voltaire, et la tenait soigneusement cachée. Un jour, après le dîner: « Il avait bon goût, le fricot ? lui demande sa mère. -- Mais oui, très-bon, et surtout chaud à point. -- Ah! pour chaud, je le crois bien! si tu veux savoir de quel bois je l'ai chauffé, va voir ta cachette à Voltaire ! » La bonne femme avait trouvé le nid, et il n'y restait pas une plume des oiseaux de contrebande. -- Mais Voltaire, afin de déjouer cette surveillance ecclésiastique, inventa des moyens où parfois le burlesque le dispute à l'impudence; l'attention une fois éveillée sur le procédé des faux titres, la vente chez les libraires était devenue impossible: Voltaire, qui voulait continuer son oeuvre, fût-ce au prix de grands sacrifices d'argent, fit distribuer gratis toutes ses productions, en recourant à toutes les petites manoeuvres qu'il put imaginer. Des Genevois, entièrement à sa dévotion, et qui du reste appartenaient aux plus hautes comme aux plus basses classes de la société, ne se firent aucun scrupule de seconder ses vues, et leurs services furent complé- 
tés par ceux d'une troupe de colporteurs chèrement payés. En fin de compte, les prétendus sermons se trouvaient partout: en entrant dans les boutiques, les affiliés, sous prétexte d'une petite emplette, glissaient quelques brochures impies sous des papiers ou des ballots; de jeunes femmes se trouvaient-elles au comptoir, ils avaient soin de choisir les écrits les plus propres à corrompre leur imagination. Les colporteurs parcouraient les montres et fixaient ces libelles au cordon des sonnettes, ou les glissaient sous le seuil des portes; on en trouvait des piles dans les cabinets des horlogers, et les petits messagers avouaient qu'un Monsieur leur avait donné six sous pour déposer le paquet sur l'établi du patron. Chaque soir, sur les bancs des promenades, se trouvaient des feuilles oubliées à dessein. Bien plus on réussissait à s'introduire dans les classes du collége, et les enfants rencontraient ces petits livres parmi leurs cahiers; ceux qui connaissent l'attrait des choses mystérieuses pour cet âge, peuvent comprendre que ces ouvrages n'étaient livrés aux maîtres et aux parents qu'après avoir été lus et dévorés. La propagande voltairienne allait plus loin encore: dans les locaux où se donnaient les leçons de catéchumènes, souvent les catéchismes furent remplacés par des brochures, reliées dans le même format et contenant ces dialogues perfides où l'incrédule triomphe à plaisir de son interlocuteur chrétien; on reliait les dictionnaires philosophiques portatifs avec le titre et l'apparence des psaumes, et on les laissait sur les bancs du temple de la Madeleine, au service des jeunes gens.

Plusieurs familles genevoises, comme nous l'avons déjà dit, fréquentaient Voltaire, et celles qui n'applaudissaient pas formellement à ses paroles satiriques et à sa croisade contre le christianisme, ne paraissaient pas tout au moins se formaliser beaucoup des petites agressions dont elles ne pouvaient manquer d'être les témoins dans l'intérieur du seigneur de Ferney. Ainsi, un jour, une dame lui rendait visite, accompagnée de sa petite fille. Voltaire trouve l'enfant fort à son gré et se hâte de chercher à lui rendre service à sa manière: "Quelle charmante petite créature! Elle est, je pense, aussi studieuse que belle ? -- Oh ! oui, Monsieur; cependant il y a une chose qu'elle ne peut apprendre. -- Quoi donc ? -- C'est son catéchisme. -- Et pourquoi donc cela ? -- Elle n'y comprend rien! -- Ah ! que vous avez de l'esprit, ma petite ! Vous ne comprenez pas... « Ah ! de la bouche des enfants sort la vérité: vous ne comprenez pas votre catéchisme !... Te- 
nez, mon enfant, voici un magnifique pêcher, cueillez tant que vous voudrez ! » -- Grâce au silence de la mère, la leçon de Voltaire faillit porter son fruit, et plus tard l'enfant, devenue une personne pieuse, a raconté les longs efforts qui lui avaient été nécessaires pour effacer l'impression produite sur elle par cette scène.

Un voyageur qui visitait Genève à cette époque se trouva dans un embarras qui peint assez bien la bigarrure qu'offrait la société genevoise d'alors au point de vue des sentiments religieux. «Un jour, ditil, je dînais dans une maison où un feu roulant de plaisanteries rapportées de Ferney égayaient l'assemblée. Le lendemain, je me trouvais chez des personnes du même nom; je voulus redire quelques bons mots antichrétiens dont on m'avait régalé la veille, mais une phrase polie de la dame du logis m'avertit que ses hôtes respectaient l'Évangile. Toutefois, il me parait que près du tiers des familles riches sont infatuées de Voltaire, et son succès n'est pas moins grand chez les artisans. "

Ainsi se réalisaient les éloquentes appréhensions de Rousseau, adressées en 1760 au professeur J. Vernet: « Lorsque le soi-disant philosophe de Ferney vint à Genève, je prévoyais ce qui arrive. La satire irréligieuse, le noir mensonge, les libelles sont devenus les armes de M. de Voltaire; il paye ainsi l'hospitalité dont, par une funeste indulgence, Genève use avec lui. Ce fanfaron d'impiétés, ce beau génie et cette âme basse, cet homme si grand par les talents et si vil par leur usage, laissera de longs et cruels souvenirs parmi nous; la ruine des moeurs, la perte de la liberté qui en est la suite inévitable, seront chez nos neveux les monuments de sa gloire et de sa reconnaissance. S'il reste dans leurs coeurs quelque amour pour la patrie, ils détesteront sa mémoire; il sera plus maudit qu'admiré. Je sais toutefois qu'il reste beaucoup de vrais citoyens qui respectent les lois, les moeurs et la liberté: mais ceux-là diminuent, les autres augmentent. -- La pente donnée, rien ne peut arrêter le progrès du mal. La génération présente l'a commencé, celle qui vient l'achèvera; chaque citoyen qui meurt est remplacé par un agréable. Le ridicule, ce poison du bon sens et de l'honnêteté, la satire, ennemie de la paix publique, la mollesse, le faste arrogant forment parmi nous un peuple de petits plaisants, de bouf- 
fons, de baladins, de philosophes de ruelles et de beaux esprits de comptoirs, gens reniant la gloire de leurs pères et ses causes, et qui n'auraient jamais voulu sortir de leur lit à l'Escalade, non par lâcheté, mais par crainte de s'enrhumer. » 


\section{Résistance des Genevois aux idées voltairiennes}

Efforts de Rousseau contre les satires irréligieuses de Voltaire. -- Fâcheuse influence des affaires politiques dans les questions religieuses. -L'Emile et les Lettres de la Montagne. -- Conduite des pasteurs envers Rousseau.

$\underline{\text { Retour à la table des matières }}$

Si Genève, au lieu de renfermer des hommes généralement développés par les études littéraires de son collège, eût contenu une classe lettrée peu nombreuse et une population ignorante et soumise à une Église qui ordonne de croire sans examen, l'action de Voltaire fût devenue irrésistible, la religion et la morale eussent disparu, et cette ville eût subi le sort des républiques ses aînées, grandes et petites, qui sont tombées en dis solution sous le poids trop lourd d'une liberté pourrie par le vice et par le despotisme. Mais les grands patriotes du XVIe siècle connaissaient mieux que personne les causes de la durée ou de la décadence des États, et tout, dans la constitution genevoise, avait été calculé pour développer l'intelligence et la moralité des citoyens, ces deux conditions indispensables à la vie des républiques. Les réformateurs, ainsi que nous l'avons déjà vu, n'admettant pas que la moralité pût exister sans la religion chrétienne, avaient introduit celle-ci dans toutes les parties de la carrière du citoyen; la religion, d'abord enseignée, puis librement examinée, se mêlait intimement à 
toutes les phases de la vie genevoise. L'enfant la rencontrait d'abord comme portion essentielle de ses études au collége; dans le sein de sa famille, il la retrouvait, sous la forme de prières et de lectures; il entendait son père et sa mère invoquer le nom de Dieu dans toutes les occasions où le secours du Ciel peut être imploré. La santé ou la maladie, la réussite ou le malheur, le gain ou la perte étaient placés sous la garde du Seigneur. Tous les événements dont l'enchaînement formait l'histoire de Genève avaient la religion pour pivot: c'était en elle que tous les beaux dévouements avaient puisé leur source, en même temps que dans l'amour de la liberté; les infortunes mêmes de la république étaient des sacrifices acceptés pour la conservation de la foi autant que pour celle de l'indépendance nationale, et rien, plus que les sacrifices, n'attache à la cause qui les exige. Chaque famille genevoise avait, de plus, ses archives religieuses, ses souvenirs d'exils, de persécutions, de ruines, et même d'échafauds. La religion, par une conséquence logique de ces circonstances, était devenue, pour les Genevois, une affaire nationale, une affaire de famille, une affaire d'intelligence et de conscience.

Aussi ne faut-il pas s'étonner si au milieu du XVIII ${ }^{\mathrm{e}}$ siècle, lorsque l'irréligion et l'incrédulité envahissaient en France les collèges, les académies, la presse, Genève présenta un étrange contraste avec sa puissante voisine. On vit la philosophie et la science, qui en France formaient des incrédules, demeurer dans la cité de Calvin les alliées du christianisme; bien plus, ces philosophes, ces savants qui battaient en brèche la religion, virent à Genève leurs disciples, leurs émules, leurs maîtres peut-être, devenir les défenseurs de l'Évangile.

Les philosophes genevois furent donc religieux, et par là même engagés plus ou moins dans la lutte avec Voltaire. Nous citerons en premier lieu Rousseau... Rousseau défenseur de la religion ! cette assertion étonne, car la pensée se reporte immédiatement à ses malheureuses Lettres de la Montagne, et l'on se demande comment l'homme qui nie le caractère surnaturel de la révélation peut être considéré comme un champion des croyances religieuses. Malgré ce fait nous persistons à dire que Rousseau défendit la religion, et qu'il sut inspirer à ses amis du respect pour les choses saintes et pour les idées religieuses. Pour admettre cette affirmation, il faut se reporter au temps dont il s'agit; sans doute, aujourd'hui, dans des sociétés où les principes chré- 
tiens se sont de nouveau largement développés, où l'on s'incline devant les convictions sincères, où les oeuvres qui portent un cachet vraiment évangélique sont respectées de tous les hommes au coeur droit; aujourd'hui, on se pourrait peut-être pas émettre la même appréciation.

Mais, il y a cent ans, les circonstances étaient tout autres; alors des auteurs impartiaux pouvaient écrire: "La Suisse elle-même, où le bonheur, le bon sens et la foi avaient trouvé un dernier asile, la Suisse commence à produire de petits docteurs incrédules Dans Genève, des gens qui entendent à peine leur métier et des femmes beaux esprits argumentent un Voltaire à la main contre Jésus-Christ et font les agréables sur l'histoire de l'Évangile. » -- Il y a cent ans, l'ironie et la satire se déversaient sur les Livres saints, le respect pour les choses religieuses se flétrissait chez beaucoup dès l'enfance, l'incrédulité gagnait de haut en bas, de long en large, dans la société française, habituée à considérer l'intelligence, la réflexion, la science comme incompatibles avec les convictions chrétiennes; le ridicule, en un mot, était attaché à l'Évangile et couvrait en même temps ceux qui se consentaient pas à le renier en ricanant. Comment, dans un pareil milieu, ne pas considérer comme un défenseur de la religion un écrivain qui, n'écoutant que sa seule conscience, vient adorer publiquement ce que ses admirateurs s'attendent à le voir brûler avec mépris ? comment ne pas estimer à l'égal d'une sincère profession de foi chrétienne cette belle page dans laquelle Rousseau s'écrie: « Pour moi, la majesté des Ecritures m'étonne, leur sainteté parle à mon coeur. Voyez les livres des philosophes avec toute leur pompe, qu'ils sont petits auprès de celui-là ! Se peut-il qu'un livre, à la fois si sublime et si simple, soit l'ouvrage des hommes ? Se peut-il que celui dont il raconte l'histoire ne soit qu'un homme lui-même ? Est-ce là le ton d'un enthousiaste ou d'un ambitieux sectaire? Quelle douceur, quelle pureté dans ses moeurs ! Quelle grâce touchante dans ses instructions! Quelle élévation dans ses maximes! Quelle profonde sagesse dans ses discours. Où est l'homme, où est le sage qui sait agir, souffrir et mourir sans faiblesse et sans ostentation ? -- Où Jésus avait-il pris chez les siens cette morale élevée et pure dont lui seul a donné les leçons et l'exemple ? Du sein du plus furieux fanatisme la plus haute sagesse se fit entendre et la simplicité des plus héroïques vertus honora le plus vil de tous les peuples. La mort de Socrate, philosophant tranquillement 
avec ses amis, est la plus douce qu'on puisse désirer. Celle de Jésus expirant dans les tourments, injurié, raillé, maudit de tout un peuple, est la plus horrible que l'on puisse craindre. Socrate, prenant la coupe empoisonnée, bénit celui qui la lui présente et qui pleure. Jésus, au milieu d'un supplice affreux, prie pour ses bourreaux acharnés. Oui, si la vie et la mort de Socrate sont d'un sage, la vie et la mort de Jésus sont d'un Dieu. -- Dirons-nous que l'histoire de l'Évangile est inventée à plaisir ? Mon ami, ce n'est pas ainsi qu'on invente, et les faits de Socrate, dont personne ne doute, sont moins attestés que ceux de JésusChrist. Au fond, c'est reculer la difficulté, sans la détruire; il serait plus inconcevable que plusieurs hommes d'accord eussent fabriqué ce livre, qu'il ne l'est qu'un seul en ait fourni le sujet. Jamais des auteurs juifs n'eussent trouvé ni ce ton, ni cette morale, et l'Évangile a des caractères de vérité si grands, si frappants, si inimitables, que l'inventeur en serait plus étonnant que le héros!»

Et Voltaire comprit bien, lui aussi, la page que nous venons de citer, comme une profession de foi véritablement chrétienne, car lorsqu'il l'eut sous les yeux, il entra dans une violente colère: « Rousseau, s'écria-t-il, Rousseau est le Judas de la confrérie ! Le Vicaire savoyard est digne de toutes les peines imaginables! Quel temps, grand Dieu ! a-t-il pris pour rendre notre philosophie odieuse ? Le temps même où elle allait triompher. » (Corresp. génér., 1762.)

À Genève, l'effet des paroles de Rousseau fut puissant sur le coeur des citoyens; il ranima chez un grand nombre le sentiment religieux détruit par les sarcasmes et les sophismes de Voltaire. Des hommes qui ne voulaient point entendre la défense du christianisme de la bouche des pasteurs, parce qu'ils ne faisaient que leur métier, étant payés pour cela, rafraîchissaient leur âme à la lecture de l'Emile. Néanmoins, comme l'Emile niait les miracles de Jésus-Christ, les pasteurs ne pouvaient l'accepter tel quel, et $\mathrm{M}$. Vernes, entre autres, accompagna le morceau sur les Évangiles d'observations qui sont un type admirable de controverse éloquente et digne en même temps. Il réimprime le fragment que nous avons transcrit, puis il ajoute: «Oui, cher compatriote, votre peinture des Évangiles est admirable. Mais si Jésus n'a pas fait les miracles, toute cette beauté n'est-elle pas flétrie ? -Que devient la piété de Jésus, s'il usurpe un titre qu'il ne tient point du Dieu qu'il sert et qu'il invoque ? -- Que devient le support de Jésus 
pour les pécheurs, si ce n'est pas avec une autorité divine qu'il leur dit: Vos péchés vous sont pardonnés. -- Que devient l'humilité de Jésus? se dire sorti du sein du Père ! L'orgueil le plus effréné porta-t-il plus loin ses téméraires prétentions? -- Que devient l'affection de Jésus pour ses disciples? il les fait tout quitter pour le suivre, et il les trompe par des promesses qu'il sait bien ne pouvoir tenir. - -- Si Jésus n'est pas le distributeur des grâces immortelles, sa plus belle parole: Que votre coeur ne se trouble point, il y a plusieurs demeures dans le ciel et je vais vous y préparer des places; est donc le plus odieux des mensonges ? -- Pour moi, je l'appelle le Fils unique qui était dans le sein du Père, parce que j'ai connu qu'il est un Docteur venu de Dieu, car nul ne peut faire les oeuvres qu'il fait si Dieu n'est pas avec lui. »

La discussion, réduite à ces proportions, eût tourné tout entière à l'avantage de l'Évangile, et l'on aurait vu la religion naturelle de Rousseau ramener peu à peu les incrédules au christianisme révélé, si une politique aussi violente que maladroite n'était venue se jeter à la traverse. Nous voulons parler de la condamnation de l'Emile et de sa destruction par la main du bourreau.

Les auteurs de la condamnation de l'Emile firent par cet acte preuve de peu de clairvoyance et de prudence: nous n'avons pas à nous occuper de ses suites au point de vue politique, mais en tout cas il nuisit considérablement à la religion dans Genève.

Dès son apparition, cet ouvrage avait été accueilli par un mandement désapprobateur de l'archevêque de Paris; le 11 juin 1762, le parlement l'avait condamné à être brûlé par la main du bourreau. Le 18 juin, le Conseil genevois reçut de $\mathrm{M}$. de Sellon, représentant de la république à Paris, le texte de ce jugement. Aussitôt, sans consulter l'opinion publique ni le Consistoire, le procureur général Tronchin, que nous avons vu si énergique contre les libelles de Ferney, cède à l'influence française bien évidente dans toute cette affaire; le Conseil se laisse aller au désir de faire quelque chose d'agréable à la cour de Versailles; il ne sait pas résister aux petites rancunes qu'il garde à ceux des Genevois qui aiment Rousseau, et le lendemain du jour où il a reçu l'arrêté de Paris, le 19 juin 1762, sans prendre la peine de formuler une opinion, empruntant dans ses considérants le jugement et les paro- 
les même de l'archevêque de Paris, il décide que l'Emile sera lacéré et brûlé par l'exécuteur de la justice. Voici comment un témoin oculaire raconte cet acte, qui eut lieu le jour même: «Le 19 juin, une délégation du Conseil se transporta sur les degrés placés devant la façade de l'hôtel de ville, où l'on prononçait les jugements. L'exécuteur attisait un brasier. La proclamation concernant l'Emile avait amassé une foule considérable; la sentence fut lue à haute voix: le bourreau déchira lentement les pages du livre et les jeta sur le feu. Au lieu des applaudissements qui éclataient naguère lorsqu'on brûlait les saletés du vieux diable de Ferney, on voyait une rage muette, une stupéfaction profonde sur le visage des citoyens, et il était facile de prévoir à quel débordement de haines politiques Genève allait être livrée. »

Ce qui blessait surtout le cœur des citoyens, c'était l'influence positive de la France : on avait vu le résident auprès des magistrats ; il avait obtenu communication du jugement avant son exécution, et il le transmit à Paris comme un témoignage de la bonne volonté de Genève. Si l'on trouvait juste la condamnation des ouvrages de Voltaire où débordaient l'immoralité, l'impiété, l'ironie et l'injure, on ne pouvait aisément consentir à placer au même rang les oeuvres de Rousseau, qui, en attaquant quelques idées chrétiennes, le faisaient avec tout le sérieux et le respect exigés par un semblable sujet : on trouvait étrange surtout que certains magistrats, amis déclarés de Voltaire et s'opposant toujours à la condamnation de ses livres, eussent réservé pour leur concitoyen une rigueur exceptionnelle et signé la flétrissure imprimée à l'Emile. M. Pictet, membre des Deux-Cents, publia une remontrance énergique à ce sujet, mais il fut obligé de se rétracter.

On se tromperait, néanmoins, si l'on croyait qu'une émeute intellectuelle ou politique suivit la condamnation de l'Emile, les bons Genevois étaient las des discussions sociales et durant une année l'affaire fit peu de bruit, mais la lettre par laquelle au mois de mai 1763 Rousseau renonçait à la bourgeoisie, souleva les esprits. La ville entière prit parti pour ou contre Rousseau: les citoyens représentèrent que la condamnation des mauvais livres ne devait avoir lieu que sur le rapport du Consistoire, et que ce corps n'avait pas été consulté. Le Conseil répondit que le Consistoire, consulté après coup, avait déclaré qu'on n'avait point violé ses droits. Le Conseil ajoutait que l'Emile 
était d'autant plus dangereux, qu'il était écrit dans le style le plus séducteur, qu'il avait pour auteur un citoyen de Genève, et que, dans l'intention de celui-ci, il devait servir à l'instruction de la jeunesse. Ces raisons ne parurent pas concluantes à tout le monde. Neuf fois dans l'espace de trois ans les citoyens réclamèrent le retrait de la condamnation du livre de Rousseau : neuf fois ils reçurent une réponse négative Puis la question s'agrandit: les opposants prétendirent qu'ils avaient le droit de porter au Conseil des représentations sur divers objets, les Conseils répliquèrent qu'ils répondraient quand ils le trouveraient bon ; et Genève se trouva de nouveau divisée en deux partis acharnés l'un contre l'autre.

Rousseau était alors à Motiers-Travers. Exaspéré des injures que plusieurs Genevois lui adressaient, il perdit toute mesure, et, dans ses fatales Lettres de la Montagne, la colère lui fit envelopper dans ses attaques, la religion elle-même qu'il avait si fort louée auparavant. On comprend fort bien l'état d'irritation auquel ont correspondu, dans l'esprit de Rousseau, ces pages aussi futiles que violentes ; mais lorsqu'on cherche aujourd'hui à peser la valeur des arguments du philosophe jeté hors des gonds, on a peine à se figurer, par exemple, que tout ce qu'on y peut trouver de plus concluant contre les miracles, se réduit à ces ridicules déclamations : "Les miracles, où sont-ils ? Jadis les prophètes faisaient descendre à leur voix le feu du ciel, aujourd'hui les enfants en font autant avec un petit morceau de verre. Josué fit arrêter le soleil ; un faiseur d'almanachs va le faire éclipser. Les foires fourmillent de miracles : j'ai vu un paysan hollandais rallumer sa pipe avec son couteau ; en Syrie, il eût été prophète. J'ai vu quelque chose de plus fort, des académiciens et des savants qui couraient aux conclusions de l'abbé Pâris et revenaient convaincus. On n'est point parvenu aux limites de l'art de guérir ; qui sait ? on arrivera peut-être à remettre un mort sur ses jambes ; on a trouvé le secret de ressusciter des noyés, on parviendra à rendre la vie des corps qu'on en avait privés. »

Les pasteurs, quoique séparés d'opinions sur les objets politiques, s'entendirent pour s'imposer un silence absolu dans cette déplorable affaire, et ne dirent pas un mot, en bien ou en mal, de la condamnation de l'Émile. Cette ligne de conduite ne leur fut pas aisée à tenir. Les citoyens voulaient les forcer à s'expliquer : leur attention était devenue si soupçonneuse que, durant ces troubles, on allait au sermon, non 
pour s'édifier, mais pour savoir s'il serait prononcé un mot contre Rousseau. La plus lointaine allusion aux miracles était prise pour une attaque politique. Chaque représentant, ayant adopté la cause de Rousseau comme une affaire personnelle, ne pouvait souffrir qu'on ajoutât les dogmes révélés à la religion naturelle du philosophe ; chaque négatif, tenant à voir l'Emile lacéré en chaire comme il l'avait été sur la place de l'Hôtel-de-Ville, blâmait amèrement les prédicateurs modérés qui refusaient de faire descendre la chaire chrétienne au rôle de tribune politique. A la Sainte-Cène, nouveau scandale: dans un temple on voyait se presser le parti gouvernemental, tandis que dans un autre communiaient les seuls représentants. La lutte était d'autant plus vive que les deux partis n'étaient pas très-inégalement partagés sous le rapport numérique, quatre cents citoyens environ étant favorables à Rousseau, tandis que six cents appartenaient au parti contraire.

Plusieurs pasteurs genevois, MM. Vernet, Perdriau, Roustan, Claparède, Moultou, étaient restés en correspondance avec Rousseau, espérant le ramener, adoucir son coeur ulcéré, et se flattant d'éviter une rupture qui, selon leurs prévisions, ne pouvait qu'être funeste à la cause du christianisme à Genève. Leurs espérances furent trompées. La fureur des partis politiques l'emporta sur toutes les considérations, et lorsque survint la publication des Lettres de la Montagne, ils se virent contraints de rompre leurs relations avec Rousseau, mais ce fut par des lettres pleines de dignité, de douceur et de regrets, où ils déclaraient que leurs sentiments de chrétiens étaient trop grièvement froissés pour leur permettre de conserver avec lui leurs anciens rapports fraternels. Rousseau se trouvait malheureusement dans un de ces moments de crise où il n'avait pas une vue très-distincte du juste et de l'injuste : «M. Perdriau, écrivit-il, si juste et si bon, est possédé de la rage cléricale; $\mathrm{M}$. Vernet s'éloigne de moi, il va sacrifier au bel air voltairien ; M. Roustan donnait des espérances, il s'est traîné dans la fange ; M. Vernes avait fait concevoir la meilleure opinion de lui, c'est le plus hypocrite et le plus fanatique de mes détracteurs. » Ces injures de Rousseau avaient du reste à ses yeux une apparence de fondement. Le vieux diable de Ferney, imitant le style des ministres genevois, s'était hâté d'écrire un pamphlet adressé par les pasteurs à Rousseau ; l'infortuné rêveur tint cette indigne brochure pour authentique. M. Vernes se justifia pleinement, et produisit même une déclaration du secrétaire de Voltaire ; Rousseau, néanmoins, ne voulut pas lui dire 
autre chose que ces mots : "Monsieur, vous êtes le plus digne ou le plus vil des hommes. »

Lorsqu'on lit aujourd'hui, loin des passions du temps, les brochures écrites par les pasteurs pour réfuter soit l'Emile, soit les Lettres sur la Montagne, on est frappé de leur ton calme et mesuré ; à plus forte raison cette modération dut-elle se faire apprécier au moment du plus fort de la lutte. Cette conduite ramena plusieurs personnes aux sentiments chrétiens ; MM. Vernes, Mercier, Vernet, Claparède et Roustan furent considérés comme des médiateurs naturels entre le peuple et les magistrats, et grâce à la prudence en même temps qu'à l'activité de leur zèle, ils purent enfin amener les deux partis à se faire le sacrifice mutuel de leurs rancunes.

Cette réconciliation eut lieu en 1768, après six ans de disputes acharnées, elle produisit des résultats très-heureux pour l'Église de Genève qui avait rudement souffert des luttes politiques. Aussi la joie fut grande, lorsque les citoyens purent enfin prendre part de nouveau à la Sainte-Cène, réunis dans un même esprit, comme dans les mêmes temples. 


\section{XIII \\ LES PHILOSOPHES GENEVOIS ET VOLTAIRE}

Caractère chrétien des philosophes genevois au XVIIIe siècle -- Abauzit, Calandrini, De Saussure, Tronchin, Odier, Tingry ; De Luc, Bonnet. -- Relations de Charles Bonnet et de Voltaire.

En France, les philosophes sensualistes étaient tous incrédules. A Genève, les disciples de cette école se montrèrent, au contraire, franchement chrétiens. Les médecins, les naturalistes, les géologues, peu soucieux d'imiter les allures de leurs confrères de Paris et de Berlin, prenaient hautement la défense de la religion, et manifestaient en toute occasion leurs croyances. Les exemples sont nombreux, et prouvent que, si Voltaire avait de l'influence sur des hommes légers ou superficiels, son action n'atteignait guère les penseurs d'élite. Cette circonstance, qui ne lui échappait pas, lui causait beaucoup de chagrin, aussi ne leur ménageait-il pas ses railleries. Un seul des philosophes genevois trouva grâce devant son ironie : ce fut Abauzit.

Abauzit, fils d'un réfugié français et naturalisé Genevois, était doué d'un véritable génie investigateur, et son caractère moral l'entourait d'un respect universel. On en peut juger par ce seul fait, qu'il mérita les louanges sans réserve de Voltaire et de Rousseau. 
Un jour, un grand seigneur visitait Ferney : «J'ai fait, dit-il, un bien long voyage pour voir un homme supérieur. -- Vous êtes donc allé à Genève voir Abauzit ? " répondit Voltaire. Et Rousseau lui adresse le seul éloge sans restriction qu'il ait jamais accordé à une personne vivante: "Non, ce siècle de la philosophie ne passera point sans avoir produit un vrai philosophe. J'en connais un, un seul, j'en conviens ; mais c'est beaucoup, et, pour comble de bonheur, c'est dans mon pays qu'il existe. Savant et vertueux Abauzit, que votre sublime simplicité pardonne à mon cœur un zèle qui n'a point votre nom pour objet ; non, ce n'est pas vous que je veux faire connaître à ce siècle indigne de vous admirer ; c'est Genève que je veux illustrer de votre séjour. Ce sont mes concitoyens que je veux honorer de l'honneur qu'ils vous rendent. Heureux le pays où le mérite qui se cache est d'autant plus honoré ! Heureux le peuple où la jeunesse altière vient abaisser son ton dogmatique devant la docte ignorance du sage ! Vénérable et vertueux vieillard, vous n'aurez point été prôné par de beaux esprits : leurs bruyantes académies n'auront point retenti de vos éloges ; au lieu de déposer, comme eux, votre sagesse dans des livres, vous l'aurez mise dans votre vie pour l'exemple de la patrie que vous aimez et qui vous respecte. Vous avez vécu comme Socrate, mais il mourut de la main de ses concitoyens, et vous êtes chéri des vôtres. »

Abauzit était profondément chrétien ; il avait pour principe qu'une conviction religieuse n'est vraie qu'autant qu'elle réagit réellement sur la conduite morale, sur la dignité de caractère de celui qui la professe, et il se fit une sincère application de cette règle, à l'aide de laquelle, comme le philosophe athénien auquel le compare Rousseau, il parvint à corriger ses défauts naturels. C'est ainsi, entre autres, qu'à force d'énergie employée sur lui-même, il arriva à dompter assez une grave disposition à la colère, pour qu'on puisse citer de lui le trait suivant. Abauzit s'occupait avec le plus grand succès de l'étude de plusieurs points de l'histoire naturelle ; les variations du baromètre étaient alors l'objet d'une attention générale. Abauzit, qui ne publiait aucun fait sans l'avoir analysé à fond, travaillait depuis vingt-sept ans à recueillir des observations atmosphériques. Dans ce but, il avait disposé dans son cabinet un baromètre fixé contre une large paroi, et le papier qui la recouvrait s'était jour par jour couvert de notes indiquant tous les phénomènes constatés à l'aide de l'instrument. Une servante nouvellement installée vient ranger ce cabinet en l'absence du maître ; celui- 
ci, en rentrant, pousse une exclamation : «Qu'avez-vous fait de ce papier qui était autour du baromètre ? -- Holà ! Monsieur, il était si sale que je l'ai brûlé, et j'ai mis à la place celui-ci, qui est tout battant neuf. » Abauzit se croisa les bras, et, après quelques secondes de lutte intérieure, lui dit du ton le plus calme : « Vous avez détruit vingt-sept ans de travaux... à l'avenir ne touchez à rien dans ce cabinet. »

Abauzit fut du reste essentiellement un homme d'étude ; il ne prit pas une part active et personnelle à la grande lutte de la philosophie et du christianisme, et se borna à publier quelques remarquables brochures sur diverses questions d'un ordre général, sans faire de polémique directe avec ses adversaires.

Ses confrères les naturalistes et les médecins se montraient plus tranchés et plus positifs dans leurs appréciations religieuses. Tous, sans exception connue du moins, furent chrétiens, non pas de ces croyants qui dissimulent leur foi lorsqu'ils écrivent pour des incrédules, mais de ceux qui savent l'honorer aux yeux de tous, et prendre au besoin la plume pour la défendre directement. Si cette observation s'appliquait à des savants dont la réputation toute locale n'eût pas franchi les six lieues carrées d'espace qu'occupait la petite république genevoise, elle n'aurait que peu d'importance. Mais les naturalistes genevois, par leurs travaux, leurs découvertes, et grâce à la marche rapide qu'ils surent imprimer à certaines parties de la science, possédaient une haute position dans les académies et les journaux du XVIIIe siècle. Dans la géologie, De Luc et De Saussure ; Charles Bonnet et Abraham Trembley, dans l'histoire naturelle ; Odier, Tingry, Vieusseux, Tronchin, dans la médecine, étaient connus et appréciés de toute l'Europe savante. Or, ces hommes distingués professèrent hautement le christianisme, qui se retrouve comme une partie intégrante de leur pensée, soit au chevet des malades, soit dans les leçons publiques, soit dans les publications qui rendent compte des découvertes de la science au monde incrédule et sceptique de l'époque.

On eût donc pu, pour la rapporter aux savants genevois, retourner avec vérité le sens de la phrase que, dans l'Encyclopédie, d'Alembert avait avec tant de légèreté appliquée aux pasteurs, et dire " A Genève, chez tous les savants, l'adhésion la plus complète aux dogmes évangéliques les distingue de leurs confrères de France et d'Allemagne. » 
Voltaire, on le comprend, était peu satisfait de ces dispositions ; il eût mis un plus grand prix à l'encens que lui dérobaient ces penseurs sérieux, qu'aux applaudissements d'esprits légers dont il n'était flatté qu'un instant ; suivant son procédé ordinaire, il ne manquait pas une occasion pour essayer de les ridiculiser. Ainsi il appelle Trembley le père l'escarbotier, et c'est de son style religieux qu'il se moque lorsqu'il dit (Évangile du jour, p. 204) : « Moi aussi, j'adore l'intelligence suprême dans un colimaçon et dans les millions de soleils allumés par la puissance éternelle. » Lorsque De Saussure et De Luc établissent que la mer a recouvert les Alpes et mentionnent les débris qu'elle y a laissés, il écrit : «Donc le monde n'a été peuplé que de poissons, donc lorsque les eaux se sont retirées et ont laissé le terrain à sec, les poissons se sont changés en hommes ! Cela est fort beau, mais j'ai peine à croire que je descende d'une morue. »

De tous les savants genevois, celui que Voltaire poursuivit avec le plus d'acharnement fut Ch. Bonnet. Bonnet, tout en adoptant la philosophie de Condillac, a été le chrétien peut-être le plus convaincu qu'ait offert l'Église de Genève. Son respect pour la Divinité fut tel que le nom de Dieu se trouve toujours écrit en grandes lettres jusque dans ses plus intimes correspondances, et son amour pour les croyances évangéliques lui fit publier une Défense du christianisme qui est l'apologie la plus complète qu'on puisse présenter de la religion de Jésus-Christ. Charles Bonnet faisait peu de cas de la science de Voltaire, et ses sarcasmes sur les nouvelles découvertes ne l'étonnaient pas de la part d'un "garçon naturaliste qui, disait-il, traitait le monde extérieur comme la Bible. » Le naturaliste de Genthod ayant publié un mémoire sur les Feuilles, où il établissait la volonté divine dans les lois de la création, Voltaire lui joua un tour d'écolier en faisant réimprimer une partie de ce travail avec de légères modifications: lorsque Bonnet parlait de Dieu, Voltaire mettait la nature et les forces aveugles du destin à la place de la volonté intelligente du Créateur. Mais Bonnet ne jugea pas à propos de relever cette mauvaise plaisanterie.

Lorsque, en 1769, il publia la Palingénésie, Voltaire, indigné de ce qu'un auteur qui vivait dans son voisinage eût osé écrire en faveur de la religion contre laquelle il épuisait ses railleries, s'empressa de chercher à ridiculiser à la fois le livre et l'écrivain, jugeant cela plus aisé 
que de le réfuter. Dans la préface d'une brochure intitulée Dieu et les hommes, il leur consacra les lignes suivantes : «Etrange imagination de Charles Bonnet. Je ne sais quel rêveur nommé Bonnet de Genthod, dans un recueil de facéties appelé par lui Palingénésie, paraît persuadé que nos corps ressusciteront sans estomac. »-- Puis vient la plus ignoble parodie de ces paroles de Jésus-Christ : "Après la résurrection, on ne se mariera point, mais on sera comme les anges dans le ciel... » -- « Nous aurons donc des fibres intellectuelles et d'excellentes têtes. Celle de Bonnet me paraît un peu fêlée, il faut la mettre avec celle de notre Ditton : je lui conseille, quand il ressuscitera, de demander un peu plus de bon sens et des fibres un peu plus intellectuelles que celles qu'il eut de son vivant. Mais que Ch. Bonnet ressuscite ou non, Milord Bolinbrocke, qui n'est pas encore ressuscité, nous prouvait pendant sa vie comment toutes ces chimères tournaient la tête à des idiots, subjugués par des enthousiastes. » -- Cette brochure était à l'impression lorsqu'une personne qui fréquentait Ferney supplia Voltaire de modifier ces paroles : il y consentit, tout en ajoutant qu'il ne pouvait souffrir les gens qui prenaient la défense de cette religion. » La personne en question ayant rapporté ces détails à Charles Bonnet, celui-ci la pria de dire à Voltaire qu'il préférait ses railleries à ses éloges, et que si Voltaire réimprimait sa brochure, il l'obligerait en rétablissant le texte primitif » Voltaire n'eut garde d'y manquer, et dans une autre occasion il dit, en parlant du philosophe genevois : " Figurez vous un certain Bonnet de Genthod. Connaissez-vous cette célébrité ? Non. Je n'ai pas de peine à le croire, il est assez ignoré pour cela. Croiriez-vous que ce Monsieur admet la résurrection des corps ? Ce sera un drôle de spectacle au dernier jour, dans les cimetières et sur les champs de bataille, lorsque les ressuscités se disputeront les bras et les jambes qui leur manqueront! » Bonnet dit à ce sujet : " Il paraîtrait que M. de Voltaire n'a aimé personne dans ce monde, il n'a su regretter ni son père ni sa mère, car si son âme était susceptible d'un attachement ou d'un regret, il n'aurait pas le triste courage de plaisanter sur les plus douces espérances des malheureux et des déshérités de ce monde, » Plus tard il prononça sur son antagoniste un jugement qui n'était pas propre à le faire rentrer en faveur auprès de lui : " Je n'ai guère lu, dit-il, des tragédies du seigneur de Tournay qu'Alzire et Zaïre; vous voyez que je m'en suis tenu à ses chefs-d'oeuvre. J'ai parcouru ses ouvrages en prose ; je l'ai vu terrasser cette idole (Rome) dont on baise les pieds, et porter ensuite sur la croix ses mains sacrilè- 
ges ; je l'ai vu chercher à la Chine des arguments contre Moïse et puiser dans les almanachs, des calculs contre Daniel ; je l'ai vu remplir les montagnes de pétrifications en dépouillant les pèlerins et les cuisines des grands seigneurs ; je l'ai vu commenter Locke qu'il n'a jamais lu et insulter à Leibnitz qu'il ne peut entendre ; je l'ai vu expliquer Newton par vanité et critiquer Montesquieu par jalousie; je l'ai vu déchirer Fréron et Pompignan, l'un parce qu'il a trop d'esprit, l'autre trop de religion; je l'ai vu représenter Maupertuis aplatissant de sa main savante le globe de la terre et l'inonder ensuite de ses sarcasmes.... etc. "

Il faut avouer qu'il y en avait assez pour mettre hors des gonds un homme essentiellement irritable, et cependant Voltaire conserva au fond, pour Bonnet, une considération qui le portait à s'informer soigneusement des faits et gestes de son adversaire. et il ne cachait qu'à demi sa satisfaction lorsqu'il apprenait que quelques paroles honorables sorties de sa bouche avaient été répétées à Genthod.

Les philosophes et les savants étant chrétiens à Genève, il pourrait sembler que le peuple de cette ville dût être victorieusement préservé de l'irréligion par l'exemple des élus de la science et de la pensée ; mais tous ceux qui s'occupent d'éducation savent que, pour les jeunes hommes élevés au milieu des plus nobles exemples et des meilleures doctrines, il suffit d'un seul mauvais conseil pour les entraîner au mal. Le même phénomène se présente chez les grandes familles qu'on appelle peuples. Dans la ville natale, comme dans la maison paternelle, on éprouve qu'en morale aussi bien qu'en médecine, le mal vient au galop et s'en retourne au pas. 


\section{XIV \\ Résistance des pasteurs genevois à la presse voltairienne.}

Plan de la Vénérable Compagnie des Pasteurs pour combattre les brochures de Ferney. -- Jacob Vernet et les imprimés de Voltaire. -- Jacob Vernet dans le carrosse de Voltaire. -- M. Perdriau aux Délices : le pasteur et la brebis. Le ministre Roustan -- Sermons patriotiques du professeur Claparède. Colportage religieux. -- La lettre chrétienne au dîner de Voltaire. -Le pasteur Picot loué chez Voltaire. -- Le professeur Claparède et le chapitre de saint Paul touchant la charité.

Lorsque les pasteurs genevois entreprirent la défense de leur Église contre les arguments et les plaisanteries de Voltaire, ils firent volontairement le sacrifice de toute paix en ce monde, sachant bien que la lutte durerait autant que leurs forces et leur vie. Elle s'ouvrit par un mandement dans lequel la Compagnie annonçait à ses membres qu'elle verrait avec plaisir que quelques pasteurs entreprissent de réfuter les attaques de Voltaire contre l'Évangile et la Réforme, en observant les règles les plus exactes de la modération et de la vérité, « car plus nos adversaires s'abaissent aux injures, plus nous devons nous élever dans notre langage, afin qu'on voie en nous l'esprit de notre Maître. » On arrêta que, dans les sermons proprement dits, on insisterait sur la certitude d'une autre vie, sur les devoirs moraux et sur leur existence (!) ; que, dans les catéchismes, on ramènerait sans cesse l'instruction sur la personne du Sauveur et les sentiments qui lui sont dus, afin de combattre les tendances railleuses qui flétrissent chez les 
jeunes gens la vénération et le culte dus à Jésus-Christ. Les ecclésiastiques habiles à manier la plume devaient, dans des ouvrages et des traités aussi brefs que possible, défendre la divinité des Ecritures et les miracles gui en sont la preuve pour les hommes.

Le plan était logique et sage. Toutefois, dès l'abord, on pouvait deviner que le rôle de la défense serait plus difficile que celui de l'attaque. Les objections se font en trois mots, et les réfutations sont nécessairement très-longues ; cependant cet obstacle fut souvent surmonté avec habileté, et même plus d'une fois les rôles changèrent, et l'agresseur se trouva à son tour attaqué dans son camp, et avec ses propres armes. Mais une autre cause d'insuccès tenait au caractère des pasteurs, et à la nature de leurs écrits : décidés à en appeler seulement à la froide raison, et à ne se départir jamais d'une modération vraiment chrétienne, ils attiraient comparativement beaucoup moins l'attention que les saillies de l'ironique esprit qu'ils avaient pour adversaire. « Allez, avait dit celui-ci, qui du premier coup avait compris la position, allez, vieilles perruques! ce n'est pas votre plate douceur qui vous tirera de mes griffes!»

Ce fut $\mathrm{H}$. Vernet qui le premier tomba sous sa griffe, c'est-à-dire sous ses épigrammes. Il avait publié deux petits traités, courts, serrés, bien raisonnés, contre les assertions de Voltaire, relatives aux miracles. Voltaire pour se venger, publia en 1760, un libelle intitulé : Dialogue chrétien, ou préservatif contre l'Encyclopédie, par M. V., professeur à Genève. Ce pamphlet débute par quelques pages sérieuses, puis tourne graduellement à l'incrédulité, et enfin $\mathrm{M}$. Vernet, qui est censé l'interlocuteur, avoue qu'il ne croit pas en Dieu, et déclare que tous ses collègues sont des hypocrites ou des individus immoraux faisant leur métier pour l'argent qu'il leur rapporte. -- Le Conseil d'État ordonna que tous les exemplaires qui pourraient être saisis seraient brûlés par la main du bourreau, et la générosité de Voltaire à faire distribuer ce libelle avait été si grande que, le jour de l'exécution (17 septembre), on put croire un instant, aux Rues-Basses, qu'il y avait un incendie à l'hôtel de ville. Une proclamation des syndics et du Consistoire rendit, en outre, pleine et entière justice à $\mathrm{M}$. Vernet : " $\mathrm{A}$ votre aise, Monsieur le professeur ! dit alors Voltaire, vous devez être bien satisfait. Le Conseil a déclaré que vous n'avez ni tué, ni mis la main dans la poche d'autrui. » 
Quelques années plus tard, c'était en 1766, et à la suite de divers travaux pleins de douceur et de jugement, par lesquels $M$. Vernet avait de nouveau réfuté Voltaire, celui-ci eut recours à une nouvelle machination. Il publia, soit dans la Guerre civile de Genève, soit dans une lettre imprimée sous le nom de R. Covelle, la note suivante : « Vernet, professeur en théologie, très-plat écrivain, fils de réfugié. -- Nous avons des lettres originales de lui, par lesquelles il prie M. de Voltaire de vouloir bien lui confier l'édition de l'Histoire universelle, et l'accepter pour correcteur d'imprimerie. Il fut refusé et se jeta dans la politique. »

Cette affaire causa beaucoup de scandale : un professeur de théologie de Genève avoir sollicité d'imprimer l' Essai sur l'Histoire universelle, qui fourmille d'erreurs et de calomnies contre la religion ! La Compagnie voulut éclaircir cette accusation; heureusement M. Vernet, homme de beaucoup d'ordre, avait soigneusement conservé les lettres de Voltaire et ses réponses. Ces pièces authentiques prouvèrent d'abord que Vernet avait été sollicité par Voltaire de soigner l'édition de l'Histoire universelle, comme il avait soigné celle de Montesquieu ; ensuite que Vernet, après y avoir découvert des erreurs et des attaques contre le christianisme, avait prié l'auteur d'accepter ses rectifications, et, sur son refus, avait abandonné l'ouvrage, en exprimant à Voltaire son blâme et son regret. Le Conseil publia un nouvel arrêté dans lequel il donnait une approbation formelle au professeur Vernet.

Quelques jours plus tard, celui-ci apprenant que Voltaire nie tout haut la réalité de ces faits et lit à ses amis des lettres supposées qui donnent à Vernet tous les torts, il se rend à Ferney où il est reçu avec une politesse affectée : il profite de la présence au salon d'un assez grand nombre de personnes, sort de son portefeuille deux lettres relatives à l'impression de l'Histoire universelle et en lit une. Voltaire l'interrompt : "Qu'est-ce que cela prouve ? -- Cela prouve que vous avez tort de dire que j'ai sollicité l'impression de votre ouvrage ! -- Allons, vous avez raison : nous avons tous de vieux péchés et de vieilles paroles à nous reprocher ; touchez là et qu'il ne soit plus parlé de cette affaire ; dînez avec nous. " -- M. Vernet refusa et voyant qu'il ne pourrait rien obtenir, se retira. Voltaire le pressa d'accepter son carrosse 
qui ramenait en ville deux hôtes de Ferney. Arrivé à la porte de Cornavin, M. Vernet veut descendre : le cocher qui a ses ordres n'écoute rien, fouette les chevaux, traverse Coutance au grand trot et vient s'arrêter au milieu de la place de Bel-Air. La foule s'amasse comme d'ordinaire, et la stupéfaction est grande quand du carrosse de Voltaire on voit descendre M. Vernet. Déjà plusieurs personnes se hâtaient de déclarer la chose scandaleuse, mais Vernet eut bientôt sa revanche : «Monsieur le professeur, vous n'avez pas de commission pour M. de Voltaire ? lui dit ironiquement un des amis du philosophe. -- Je vous demande pardon ; veuillez dire à votre hôte que je suis charmé de ce que sa petite malice m'ait fourni l'occasion de répéter devant mes concitoyens ce qu'il vient de m'avouer devant vous à Ferney, c'est que ses calomnies à mon égard sont de vieux péchés qu'il espère qu'on voudra bien oublier. » Le personnage ne dit mot et Vernet compléta la confusion des gens du carrosse par les explications qu'il donna à ceux qui entouraient la voiture.

M. le pasteur Perdriau eut aussi le privilège de s'attirer la rancune particulière de Voltaire pour avoir déclaré dans un sermon «que les idées d'un grand philosophe du voisinage étaient fort confuses touchant la Divinité, » et pour avoir réfuté à l'aide de la théorie de la liberté morale de l'homme, les armes que ce philosophe se forgeait contre l'existence d'un Dieu puissant, sage et bon, en attribuant à son oeuvre le caractère d'un « cloaque épouvantable de misères et de forfaits. » Un peu plus tard, M. Perdriau, qui était pasteur de l'église du Petit-Saconnex, faisant sa visite de paroisse (il devait, selon la loi, inscrire sur son registre tous les habitants de sa circonscription), se présente aux Délices, demande le secrétaire et lui explique le motif légal de sa venue. Le secrétaire communique la chose à Voltaire, qui était au salon, entouré d'une nombreuse compagnie : "Faites entrer, dit-il, ce pasteur de l'église de Saconnex, de cette église où j'ai un banc. » M. Perdriau entre : frappé de sa figure, dont l'expression était simple et douce, Voltaire lui dit : "Qui êtes-vous, Monsieur? -- Monsieur, ainsi que $\mathrm{M}$. Vagnières a dû vous le dire, je suis le pasteur de la paroisse. -- Vous, pasteur ! je vous aurais pris plutôt pour une brebis. » Eclat de rire général après lequel $M$. Perdriau répond : "Monsieur, le pasteur vous aurait peut-être répondu, mais la brebis restera muette. » Voltaire prend son parti de rester court cette fois, ce qui ne lui arrivait pourtant pas souvent; il lui tend la main, puis il lui dit : "Voyons, 
vous avez quelque chose à faire avec ce gros livre. -- Oui, Monsieur, je dois inscrire toutes les personnes qui habitent cette maison. -- Eh bien ! commencez par le maître. Ecrivez: J.-Marie Arouet de Voltaire, gentilhomme ordinaire du roi. -- C'est fait, Monsieur ! -- Ensuite, catholique apostolique et bon romain.. -- Pas tant, Monsieur, pas tant ! dit M. Perdriau, tenant sa plume en l'air. -- Pas tant ! Ecrivez, vous dis-je. -- Impossible, Monsieur, la page est finie après gentilhomme ordinaire du roi ; il n'y a plus de place pour les autres titres -Ah çà ! Monsieur Perdriau, avec votre figure de mouton, vous êtes un malin... Touchez là et dînez avec nous. » -- M. Perdriau refusa et se retira. Le lendemain il vit arriver chez lui Vagnières porteur d'une pile de piastres que Voltaire lui envoyait pour les pauvres de sa paroisse. « Remerciez M. de Voltaire, lui dit-il, et dites-lui qu'il vaut mieux pour lui de faire bénir Dieu avec son argent que de le faire maudire avec ses écrits ! » Vagnières osa-t-il rapporter ces mots à son maître ? Je ne sais, mais dès lors Voltaire fit remettre souvent de fortes sommes pour les pauvres du Petit-Saconnex.

Un autre ecclésiastique genevois, $\mathrm{M}$. Roustan, soutint avec Voltaire une discussion des plus vives, et ses écrits lui firent passer de mauvais moments, si l'on en juge parle torrent d'injures qu'il lui prodigue en maintes occasions.

Voici comment Antoine Mouchon décrit cette lutte : « La majorité des citoyens flottent encore indécis entre la foi de leurs pères et l'incrédulité des philosophes. Ils ont peur de Voltaire et de ses satellites. Honneur donc à ceux qui se mettent au-dessus des polissonneries du vieux diable de Ferney. Notre bon Roustan est de ce nombre : il ne craint pas de saisir le taureau par les cornes. Il vient de publier une série de lettres sur le christianisme, ouvrage rempli de traits lumineux et de réflexions victorieuses qui font honneur à la touche mâle et hardie de l'auteur. -- Ces lettres ont fait éclore une lettre de Voltaire, où il raille $\mathrm{M}$. Roustan d'une manière assez plate : « M. Roustan, enlevons une lettre de votre nom, vous devenez Rustan, ce qui peint votre caractère.... Votre style ressemble beaucoup, pour la grâce, aux vieux souliers que fabriquait votre père... vous n'auriez pas dû sortir de son échoppe de savetier. » -- Roustan a répliqué par deux nouveaux traités, intitulés : Réponse aux difficultés d'un théiste, et : l'Impie démasqué. Dans la préface de ce dernier, il s'honore de devoir le jour à un 
honnête homme, et prie M. de Voltaire de laisser en paix les cendres de son père ; il l'assure qu'il ne voit rien de si plaisant dans l'état de cordonnier ; il lui affirme qu'il n'achètera pas le moindre petit domaine pour ajouter un nom de terre au nom paternel. et lui demande si, par hasard, il trouverait que lui, Roustan, ferait un bien beau trait d'esprit en lui ôtant son $T$, au lieu d'Arouet le laissant Aroué de Voltaire. »

Ce qui vexa le plus Voltaire, ce fut cette apostrophe de Roustan : «Monsieur, vos paroles sont dignes de la société qui se rassemble autour de votre table. Quand nous aurons prouvé la vérité du christianisme, nous savons qu'il est impossible de demander à vos jolis messieurs et à vos élégantes dames d'interrompre la lecture de vos petites oeuvres et leurs petits soupers pour s'occuper de leur Créateur, de leur âme, de leurs fautes, et de Celui qui peut seul les pardonner. En effet, il n'y a pas là le moindre mot pour rire, et c'est surtout pour rire que nous sommes en ce monde. Passe encore qu'on se désespère quand un acteur parfait, une actrice délicate sont attaqués d'un rhume qui les empêche de jouer! Mais dans ce siècle philosophe, tout honnête homme doit être ravi qu'on lui prouve qu'il est le frère aîné de la brute, et qu'il finira sa brillante existence entre quatre planches de sapin. Cela importe peu, pourvu qu'on puisse se plonger dans toutes sortes de débauches, enlever l'honneur à son meilleur ami, ou faire des épigrammes sur Jésus-Christ entre la poire et le fromage. C'est ainsi que, dans les cours de Charles II et du régent de France, on a su jouir de la vie, et vous, les descendants de ces messieurs, vous êtes dignes de ces maîtres. » -- Dans une autre lettre, Roustan, examinant les sources de l'incrédulité, dénonce comme la principale les abus de la religion romaine ; il lui demande un compte sévère de toutes les idées fausses dont elle a revêtu le christianisme, et de toutes les horreurs dont elle l'a rendu responsable aux yeux des hommes ; mais, toujours équitable dans ses jugements, il supplie ses lecteurs de ne pas confondre les catholiques avec le papisme, "parce que, dit-il, beaucoup d'entre eux valent mieux que leur religion, comme beaucoup de protestants sont au-dessous de la leur. »

Le professeur Claparède porta la lutte sur un autre terrain, et chercha surtout à parler au cœur des Genevois, à faire vibrer leur patriotisme en leur rappelant tout ce qu'ils devaient à cette foi chrétienne que Voltaire poursuivait de ses sarcasmes. On peut citer comme 
exemple de sa prédication cette rapide péroraison d'un de ses discours : " Je vous retracerai brièvement les fléaux qui désolent l'Europe. Des armées innombrables descendent du nord au midi; une flotte formidable, après un circuit de mille lieues, presse la capitale du plus vaste empire ; les couronnes s'ébranlent de tous côtés ; la famine, la peste exercent en divers lieux leur cruelle influence ; la terre est un théâtre de révolutions qui s'enchaînent les unes aux autres, et Genève, la petite Genève, subsiste encore. Pourquoi les souverains la laissent-ils debout ? C'est qu'elle est un foyer de religion qui a éclairé plusieurs peuples, c'est qu'elle doit à la religion son crédit, sa splendeur, son existence. -- Vous donc, citoyens genevois, en abandonnant cette religion, n'abandonnez-vous pas votre pays ? -- Les Juifs disaient : Peut-il sortir quelque chose de bon de Nazareth ?...Que sont devenus les Juifs ? Et pensez-vous que si Genève éteint volontairement les rayons du soleil de justice qui brille encore sur sa couronne, elle ne descendra pas, comme les nations d'autrefois, dans les sombres demeures des ténèbres et de l'oubli ? »

Toutes ces prédications immédiatement imprimées et répandues à profusion dans le pays ainsi que les diverses brochures que nous avons mentionnées, irritaient d'autant plus la cour de Ferney que l'on se servait contre Voltaire des mêmes armes dont lui-même avait enseigné l'usage. Des colporteurs zélés et adroits répandaient partout ces écrits chrétiens, dans les maisons, les boutiques et les ateliers. On alla même plus loin et l'on rendit exactement au philosophe la monnaie de sa pièce. -- J'ai parlé d'un pamphlet intitulé : Lettre d'un proposant à $M$. le professeur de Roches, dans lequel Voltaire avait condensé toutes ses railleries contre Moïse et l'Évangile. M. Vernes et M. Claparède, profitant de ce que l'attention publique était fixée sur ce sujet, répondirent à Voltaire par une lettre qui concentre en quelques mots les principaux arguments relatifs à la divinité du christianisme. -- « Vous placez mal vos sympathies... " écrivaient ces Messieurs, car les Egyptiens, pères de la science, adoraient les serpents et les légumes. -Athènes et Rome, mères de la philosophie et des arts, adoraient tous les vices et toutes les passions. -- Vos Chinois, que vous aimez par-dessus tout, immolent leurs enfants et abrégent les jours de leurs vieillards. -- A notre tour, nous voulons vous poser quelques brèves questions, vous priant d'y répondre aussi longuement qu'il vous plaira. -- Comment douze bateliers et péagers juifs eurent-ils l'idée de chan- 
ger la face du monde ? -- Comment, s'ils étaient d'ambitieux fourbes, eurent-ils la bêtise de consigner par écrit tous leurs torts envers Jésus-Christ ? -- Comment, sans être fous ou visionnaires, ont-ils pu se tromper sur les miracles de leur Maître ? -- Comment des insensés et des visionnaires inventèrent-ils la doctrine et la morale qu'ils enseignèrent à l'univers ? -- Comment des ouvriers et des idiots exécutèrent-ils ce que les Socrate et les Platon n'ont pas su faire, à savoir le renversement de l'idolâtrie et la destruction des faux dieux ?

"C'est une grande affaire, Monsieur, que la conversion de l'univers. Voyons, Monsieur de Voltaire, vous qui n'êtes pas comme les apôtres, batelier ou visiteur d'octroi, mais le plus grand esprit et le plus vaste génie de ce siècle, entreprenez une mission, prêchez partout le monde le culte de ce qui est pur, de tout ce qui est honnête et digne de louange, sans offrir aux hommes d'autre motif que l'amour du beau et du bon, et dans trente ans venez nous raconter vos conquêtes, les Églises que vous aurez fondées et les nations que vous aurez converties! » Cette petite brochure, contenant, comme on le voit, à peine une page d'impression, mit Voltaire en fureur, voici comment. Un domestique de son château fut gagné par des étudiants en théologie, et un jour que Voltaire avait quarante-cinq personnes à dîner, chaque convive trouva la Réponse de M. de Roches dans sa serviette. On la lut, mais la figure du maître exprimant une rage concentrée, et ses yeux lançant des éclairs, ses hôtes gardèrent un prudent silence.

Nous pourrions prolonger nos citations, mais les faits précédents suffiront pour donner une idée du caractère de cette lutte où la foi et le bon sens avaient pour adversaire le plus redoutable esprit du siècle. Seulement, pour être justes, nous devons ajouter que quelquefois Voltaire témoigna moins d'hostilité et d'emportement vis-à-vis des pasteurs genevois. Ainsi, un grand vicaire de l'archevêque de Lyon qu'il avait à demeure à Ferney, étant curieux d'assister à un sermon hérétique, se rendit un dimanche au Temple-Neuf, y entendit M. Picot prêcher sur ces paroles de saint Jean : "Travaillons pendant qu'il fait jour. » De retour à Ferney, enchanté de l'éloquence et de la force des paroles de l'orateur, le grand-vicaire le loua sans réserve devant Voltaire ; M. Rieu, de Satigny, paroissien de M. Picot, était présent. "Mon cher Rieu, dit le philosophe, veuillez faire mes compliments à l'abbé Picot et lui dire qu'il a à peu près converti $\mathrm{M}$. le grand-vicaire. - 
- Ces éloges me touchent peu, répondit M. Picot, le lendemain, quand M. Rieu s'acquitta de sa commission, mais dites à votre ami, si vous l'osez, que c'est sa conversion à lui que je voudrais essayer. »

Une autre fois, M. Claparède étant allé à Ferney en compagnie de Vernes, qui connaissait intimement le maître du logis, il le trouva dans son cabinet ayant entre les mains.....une Bible. « Vous le voyez, Monsieur le professeur, dit Voltaire, moi aussi je m'occupe de l'Évangile. - Malheureusement oui, répondit M. Claparède, car je n'ose supposer que ce soit dans un autre dessein que de le travestir comme toujours. - Non pas, s'il vous plaît, non pas! Je lisais le treizième chapitre de la première Epître aux Corinthiens : il faudrait n'avoir ni cœur ni âme pour oser plaisanter sur cette description de la charité, qui contient les plus belles et les plus saintes-paroles qui soient jamais sorties d'une bouche humaine ! » $\mathrm{M}$. Claparède eût bien désiré pouvoir continuer la conversation sur ce ton, mais elle fut interrompue par plusieurs personnes et elle changea aussitôt de cours. Du reste le professeur Claparède, en provoquant une discussion religieuse avec Voltaire, n'avait aucunement la prétention d'agir sur son intelligence, il désirait rendre témoignage à la vérité chrétienne, en face d'un écrivain qui souvent réduisait au silence des hommes amis de leur religion, mais trop timides pour affronter les coups de son impitoyable ironie. 


\section{XV \\ Voltaire et le ministre Jacob Vernes. Mort de Voltaire.}

Relations littéraires de Voltaire et de Vernes, et amitié de Voltaire pour ce jeune ecclésiastique. -- Vernes aux dîners de Voltaire -- Les objections à la Bible. -- Le figuier stérile, le massacré des innocents, les vases d'or des Égyptiens, les prisonniers des Juifs torturés. -- Confidence philosophique de Vernes. -- Jugement du publiciste Linguet touchant ce livre. -- Vernes et les vieux incrédules. -- Désintéressement de ce pasteur. -- Dernier voyage de Voltaire à Paris. -- Ses derniers jours et sa mort décrits par les correspondants genevois. -- Lettres de Beauchâteau, de Tronchin et de d'Alembert. -- Situation de l'Église de Genève après la mort de Voltaire.

Les détails dans lesquels nous sommes entré jusqu'ici montrent que Voltaire aimait peu les Genevois : ne pouvant supporter la contradiction, surtout en matière de discussions religieuses, il ne témoignait de la sympathie et n'ouvrait son intimité qu'aux hommes qui applaudissaient à ses bons mots. Cependant nous avons déjà constaté une exception à ce fait en parlant de Moultou, et maintenant nous allons voir cette exception s'étendre à un autre Genevois ; le ministre Jacob Vernes. Jusqu'en 1772, Voltaire lui conserva en effet, une amitié sincère, et même après l'avoir fort maltraité, il regretta vivement la rupture de leur ancienne liaison, puisque, quelques mois avant sa mort, il le faisait solliciter de revenir à Ferney. 
Cette amitié de Voltaire s'explique : Vernes avait des talents littéraires distingués. A l'âge de vingt-deux ans, il parcourait déjà l'Europe, et, de même que Moultou, il était admis auprès des hommes les plus marquants de l'époque ; les encyclopédistes eux-mêmes ne se défendirent pas du charme de sa conversation, et lui surent bon gré de la douceur pleine de fermeté avec laquelle il savait prendre sa place sur le terrain difficile de la lutte entamée autour des convictions chrétiennes. Il fallait que Voltaire lui-même tînt bien à l'estime de Vernes pour que, ce ministre n'étant encore âgé que de vingt-six ans, le vieux philosophe crut devoir se disculper à ses yeux, avec une grande énergie, de toute participation aux deux productions de Candide et de Jeanne d'Arc.

Nous devons dire, du reste, que Vernes avait mieux compris que la plupart de ses collègues l'esprit du temps, et la nécessité de ne pas mettre la défense dans des conditions trop défavorables vis-à-vis de l'attaque. Désirant par-dessus tout conserver dans Genève les grands principes chrétiens et la morale évangélique, il n'attachait pas beaucoup d'importance à des pratiques usées, et qui tenaient plus du domaine des formes extérieures que de celui des convictions internes. Les choses nouvelles ne lui paraissaient pas mauvaises par ce seul fait qu'elles ne portaient point le caractère d'une antiquité qui rend fort respectables certaines institutions, mais dont le culte ne doit pas être poussé jusqu'à exclure des modifications conseillées par l'expérience et imposées par la marche des temps. Il trouvait les lois somptuaires inexécutables avec le développement de la prospérité contemporaine. La prohibition absolue des fêtes et des spectacles, aisée dans les temps de guerres continuelles et au milieu des périls extérieurs de la République, lui paraissait exagérée, fâcheuse même en pleine paix, et il ne concevait pas quel mal pouvaient causer à l'État, ou même à la religion, la tragédie et la haute comédie.

Ces idées larges, tout en suscitant à Vernes de violents adversaires, lui avaient valu l'estime et la sympathie des hommes qui ne croyaient pas que le XVIIIe siècle pût être contraint à endosser, bon gré mal gré, l'habit du XVIe. L'espèce de popularité dont il jouissait rendit sa position, comme défenseur du christianisme, plus favorable que celle de beaucoup d'autres, et lui permit de défendre la divinité des Ecritures avec plus de succès peut-être que ses collègues. 
Vernes se trouvait souvent à Ferney, et les commensaux de Voltaire observaient avec surprise qu'en présence du jeune ministre genevois, le maître du logis s'abstenait de ses plaisanteries habituelles sur la religion, et que, si la discussion venait à tourner sur ce sujet, elle affectait toujours une forme sérieuse à laquelle ils étaient peu habitués. Un jour, un nouveau venu dînait à Ferney ; l'entretien se portant sur des brochures récentes dirigées contre les incrédules par des écrivains hollandais : " Je voudrais bien, s'écria-t-il, être chargé de travailler ces chrétiens d'Amsterdam! Quel silence accueillerait mes objections ! Elles sont si fortes, que je défierais bien le théologien le plus consommé d'y pouvoir répondre un seul mot ! -- Monsieur, lui répondit M. Vernes en souriant, je ne suis pas théologien consommé, mais avec la permission de $\mathrm{M}$. de Voltaire, je me chargerais volontiers de répondre séance tenante à toutes vos assertions. » Un murmure de satisfaction prouva que les convives ne seraient pas fâchés d'assister à ce tournoi, et le docteur étranger commença par une proposition qui se trouve au moins trente fois répétée dans les brochures de Voltaire : « N'est-ce pas, Monsieur, une chose absurde que Jésus ait maudit un figuier parce qu'il ne portait pas des fruits dans la saison où il n'y a pas de figues ? -- Rétablissons le texte, répliqua Vernes; l'Evangéliste dit : Il n'y trouva que des feuilles, et ce n'était pas la saison des figues. Or, la saison des figues, des blés, des raisins ne signifiait pas le temps où ces fruits mûrissent, mais bien le moment où l'on fait la récolte ; le sens des paroles citées est donc celui-ci : le figuier devait porter des fruits, puisque la saison où on les cueille n'était pas encore venue. L'acte de Jésus devient dès lors une parabole en action très-facile à comprendre. -- Ah ! fort bien... passons à l'Ancien Testament. J'ai lu au chapitre XX des Chroniques que David, ayant battu les Ammonites, fit scier en deux tous les habitants des villes dont il s'empara... L'esprit de Dieu put-il approuver une pareille cruauté ? -- La Bible, Monsieur, n'est pas responsable des fautes de ses traducteurs ; le véritable sens de ce passage est que David employa ses prisonniers à fabriquer des scies, etc., ce qui n'est pas tout à fait la même chose. En ce cas, pourriez-vous me dire si le traducteur est aussi pour quelque chose dans la sanction donnée au vol, par le fait que Jéhovah ordonna aux Hébreux d'emporter les vases d'or et d'argent des Egyptiens ? -Ce procédé me paraît tenir de l'échange ou de la compensation beaucoup plus que du vol ; d'autant plus que les payements ne se faisaient 
guère autrement à cette époque. Les Israélites étaient forcés par la précipitation de leur départ de laisser aux Egyptiens un matériel immense et des troupeaux considérables dans le pays de Goscen : les vases d'or emportés par eux n'étaient qu'une indemnité. -- C'est possible ; mais je désirerais encore être éclairé sur le massacre des enfants de Bethléem. Des milliers d'enfants égorgés de sang-froid !!.... une aussi horrible action devrait être inscrite dans les annales du temps; cependant ni Josèphe, ni les écrivains romains n'en disent mot. N'est-ce pas bien singulier ?... -- Puisque vous avez lu la Bible, vous savez sans doute, Monsieur, que Bethléem est appelée une des petites ville de Juda : c'était une bourgade de mille à douze cents âmes ; sur une population semblable, il existe à peine à la fois une trentaine d'enfants au-dessous de deux ans : le massacre ne dépassa pas ce nombre, et ce fait peut bien rester inaperçu dans un règne aussi cruel que celui d'Hérode. Du reste, Monsieur, il se passe de nos jours des choses qui expliquent entièrement le silence des auteurs romains sur plusieurs faits de l'histoire évangélique. Pendant que, dans cette heureuse province, nous sommes en paix, à 80 lieues de nous, au fond des Cévennes, de par l'ordre du roi, on persécute les protestants qui se rassemblent dans les déserts de leurs montagnes pour y prier selon leur foi, on a égorge des enfants, on fait subir aux femmes les derniers outrages, ou pend les ministres. Nous avons bien d'autres moyens de publicité que les Romains, nous lisons les gazettes, et cependant la génération présente et la postérité ignoreront toujours la plus grande partie de ces horreurs commises dans un temps qui s'appelle le siècle de la civilisation, du goût et des lumières.....» Le docteur, un peu abasourdi, ne fit pas d'autre question, et Voltaire détourna l'entretien. Toutefois, les réponses de Vernes lui avaient causé une certaine irritation, car à quelques jours de là, se trouvant à dîner dans une maison genevoise, lorsqu'il entra dans la salle à manger : «Eh! que de plats ! que de plats ! s'écria-t-il ; mais il en manque pourtant un. -- Et lequel ? -C'est le plat Vernes. »

Ce ne fut pas cette plaisanterie, ni d'autres du même aloi qui refroidirent la liaison de Vernes et de Voltaire ; mais le poëte s'éloigna du ministre lorsque celui-ci publia sa Confidence philosophique (1770). Vernes, s'apercevant que la forme sérieuse des brochures par lesquelles les Genevois répondaient à celles de Voltaire, nuisait à leur succès auprès de lecteurs fascinés par le brillant de l'esprit et la finesse 
des railleries du philosophe de Ferney, voulut retourner contre lui ses propres armes, en mettant en scène des philosophes matérialistes appliquant leur morale à la vie pratique et se faisant confidence des résultats de cette expérience. Dans ce roman se trouvent reproduites toutes les objections élevées contre l'existence de la divinité et contre la réalité des faits évangéliques, avec des réponses brèves, claires et énergiques ; l'auteur, pour amener même les incrédules à les lire, ne les offre jamais directement, mais il les enchâsse avec adresse dans un récit animé, de telle sorte que le lecteur, entraîné par l'intérêt de l'action, soit forcé à venir de lui-même se placer sous les traits de lumière qui en jaillissent. M. Vernes y flagelle les travers et les ridicules de ses adversaires, tout en montrant la faiblesse de leur logique, en dirigeant contre eux cette arme puissante de l'ironie dont ils avaient si bien les premiers usé et abusé. Du reste, cet ouvrage, dont nous souhaitons vivement la réimpression, attaque sans distinction tous les ennemis du christianisme : la superstition qui ajoute y est aussi maltraitée que l'incrédulité qui retranche.

Un éclatant succès suivit la publication de la Confidence philosophique: elle eut dès l'abord cinq éditions françaises, trois allemandes, deux anglaises et une hollandaise. Les chefs du journalisme en France manifestèrent hautement leur approbation ; nous citerons entre autres une lettre de Linguet, datée du 25 juillet 1772 :

« J'ai reçu, Monsieur, avec le plus grand plaisir la Confidence philosophique. L'idée de mettre en action la morale des incrédules est en effet très-heureuse ; elle est exécutée comme elle devait l'être, sans sarcasme, sans malignité, mais avec la décence, la force et l'adresse qui pouvaient rendre ce roman aussi agréable qu'utile. La dixième lettre est de la meilleure plaisanterie : c'est dans ce genre-là ce que j'ai vu de mieux depuis les Provinciales. Je me rappelle que vous m'avez dit que cet ouvrage avait trouvé de la difficulté à s'introduire dans Paris et que vous en étiez surpris, attendu que les circonstances vous paraissaient peu favorables aux incrédules Mais ne serait-ce pas votre neuvième lettre qui en serait cause ? Nos prêtres ne seraient-ils pas choqués de la proposition que vous faites d'écarter le billon théologique pour ne conserver que l'or de l'Évangile ? Cette opération-là ferait évanouir toute leur opulence, et ils y tiennent au moins autant qu'à leur religion. L'Évangile purifié, comme vous dites, ne donne ni croix 
pectorales, ni abbayes, ni commanderies, ni chapeaux de pourpre, et nous trouvons tout cela fort bon. Aussi nos prêtres s'accommoderaient peut-être encore plus des philosophes qui se contentent de rire du culte que de vous qui, en bon protestant, proposez tout d'un coup une réforme. Dans notre état de choses, des gens qui se moquent de l'Évangile ne sont dangereux que pour les mœurs et ne le sont guère pour les dignités ecclésiastiques. Prétendre que le christianisme est absurde, ce n'est pas prouver la nécessité de renverser notre clergé. Mais vous qui rendez ce christianisme raisonnable, vous qui en simplifiez la pratique et la règle, vous portez les plus grands coups aux loups déguisés en pasteurs qui le prêchent pour leurs intérêts. -- Au reste, Monsieur, vous devez vous consoler de ces traverses : votre ouvrage vous conciliera dans tous les temps l'estime des âmes honnêtes, et c'est le payement le plus satisfaisant pour un écrivain qui en est digne. »

Le brillant succès littéraire qui accueillit la Confidence philosophique éloigna pour longtemps Vernes de Voltaire : " Il se forme, dit à ce sujet la correspondance de $\mathrm{M}$. Mouchon, il se forme contre M. Vernes une ligue de la part de Messieurs les Genevois qui fréquentent le château de Ferney ; ils se vantent d'avoir engagé l'ermite de Ferney à une lutte qui ne peut manquer d'être curieuse entre deux champions dont l'un, prime en tout lieu par son esprit, mais dont l'autre ne manque ni de fermeté, ni de mordant, ni de science. On a demandé à M. Vernes comment il se conduirait lorsque Voltaire lui déclarerait la guerre. Il a répondu : « Tant qu'il ne m'opposera que des bavardages, des brocards et des plaisanteries sur mon ouvrage, je le laisserai se soulager ; mais s'il attaque sérieusement mes principes et qu'il mette en doute ma sincérité, je lui ferai voir que, si je n'ai pas un grand génie comme lui, du moins je sais me défendre et je lui tomberai sur le corps de la belle manière. » Une circonstance imprévue empêcha cette polémique: $M$. Vernes fut brisé dans ses plus chères affections de famille, et Voltaire, respectant le malheur d'un ancien ami, ne songea plus à déchirer ses ouvrages.

Un fait particulier qui se passa à cette époque fut peut-être plus sensible encore à Voltaire que le succès de la Confidence. Un vieux magistrat genevois, commensal assidu de Ferney, avait plusieurs fois été témoin des franches et solides réponses faites par Vernes à Vol- 
taire. Bien que fervent admirateur de ce dernier, il n'avait pu échapper à l'impression produite sur lui par la présence d'esprit et le courage chrétien de Vernes. Un jour, se sentant malade, il fit appeler ce ministre ; et, après de longues et amicales conférences. Vernes eut le bonheur de voir le vieillard revenir à la foi de ses jeunes années, et se préparer, par une repentance sérieuse et pratique, à la mort qui l'enleva en 1778. Il ne laissait que des parents fort éloignés : à l'ouverture de son testament on trouva qu'il avait institué $\mathrm{M}$. Jacob Vernes comme son législataire universel. $M$. Vernes réunit immédiatement la famille du défunt et lui déclara qu'il refusait d'accepter le legs, mais qu'il désirait qu'on lui permit seulement de conserver une pièce d'argenterie en souvenir de son ami. -- Ce vieillard était du même âge que Voltaire, et sa mort l'impressionna plus vivement qu'il ne voulut l'avouer; ce fut sous l'influence de cet événement qu'il écrivit sa déclaration : «Je meurs tranquille, croyant en Dieu, aimant mes amis, ne haïssant pas mes ennemis et détestant le fanatisme. »

Ce fut donc en 1778 que Voltaire quitta sa retraite de Ferney pour se replonger dans le mouvement de la capitale ; en réalité il y allait mourir. Il semble donc qu'ici se termine logiquement notre œuvre, puisque, dans la vaste carrière du philosophe, nous n'avons voulu que détacher un tableau dont le peu d'étendue n'excédât pas les dimensions du cadre restreint qu'indique le titre de cet ouvrage. Néanmoins, à un double point de vue, nous ne pouvons nous dispenser d'y joindre encore, à traits rapides, une esquisse de la mort de Voltaire, tracée d'après des documents genevois. En effet, cette mort touche chronologiquement de si près aux derniers faits que nous avons eu à examiner, qu'il serait difficile de n'en pas dire ici deux mots ; et du reste, nous ne sortirons pas en cela de notre sujet, puisque nous nous bornerons à citer les documents genevois relatifs aux derniers moments de l'existence de Voltaire. Ces documents peuvent jeter quelque jour sur cette question encore très-controversée : mourut-il comme un philosophe paisible, comme un sage sublime, ainsi que l'affirment Condorcet et son secrétaire ? ou bien fut-il tourmenté par les remords, torturé par les plus horribles visions, selon la version adoptée par les écrivains ultramontains?

M. Beauchâteau, parent de Jean-Jacque Rousseau, écrivant à M. Mouchon (Paris, mai 1778), lui disait : «A 84 ans faire des tragé- 
dies, courir 120 lieues de poste ; le lendemain de son arrivée, ouvrir sa maison, recevoir un monde de visitants, faire lui-même diverses visites, lire son Irène à des gens de goût, et sur leurs observations, changer totalement un acte et faire beaucoup de corrections aux deux autres, écrire pendant ce temps-là une foule de lettres en prose et en vers, tout cela, ce me semble, n'est pas mal singulier ; aussi court-il le risque de payer cher le tout. A la suite de toutes ces choses, qui accableraient un jeune homme dans sa vigueur, Voltaire a fait une répétition de sa pièce chez lui, et, les acteurs saisissant en général de travers l'esprit de leurs rôles, il s'est donné autour d'eux une peine incroyable et s'est extraordinairement échauffé. -- Se sentant mal et crachant du sang, il a demandé $M$. Tronchin et un prêtre ; voyant ce dernier, il dit au docteur : " Faites-moi le plaisir d'avertir cet homme qu'il est indispensable que je parle peu. » $M$. Tronchin espère le tirer d'affaire, mais c'est douteux... »

Voici maintenant ce que mandait Tronchin lui-même à son frère (Manuscrits de M. le colonel Tronchin) : «Voltaire est très-malade. S'il meurt gaiement, comme il l'a promis, j'en serai bien trompé ; il ne se gênera pas pour ses intimes, il se laissera aller à son humeur, à sa poltronnerie, à la peur qu'il aura de quitter le certain pour l'incertain. Le ciel de la vie à venir n'est pas aussi clair que celui des îles d'Hyères ou de Montauban pour un octogénaire né poltron et tant soit peu brouillé avec l'existence éternelle. Je le crois fort affligé de sa fin prochaine ; je parie qu'il n'en plaisante point. La fin sera pour Voltaire un fichu moment; s'il conserve sa tête jusqu'au bout, ce sera un plat mourant...»

D'Alembert subit la même impression, et sachant que Tronchin vient de dire à Voltaire la vérité sur son danger, il lui écrit : "Mon cher et illustre confrère, vous avez fait ce que la prudence et l'humanité exigent ; maintenant tranquillisez-le, si possible, sur sa position : je passai hier quelque temps avec lui; il me parut fort effrayé non-seulement de son état, mais des suites désagréables pour lui qu'il pourrait entraîner ${ }^{14}$.»

14 L'original de cette lettre est dans les manuscrits de M. le colonel Tronchin, à Genève. 
Enfin, peu de jours après la mort de Voltaire, voici ce que Tronchin écrit à Charles Bonnet (manuscrits de la Bibl. publ. de Genève) : "Si mes principes avaient besoin que j'en resserrasse le noeud, l'homme que j'ai vu dépérir, agoniser et mourir sous mes yeux, en aurait fait un noeud gordien; et en comparant la mort de l'homme de bien, qui n'est que le soir d'un beau jour, à celle de Voltaire, j'ai vu bien sensiblement la différence qu'il y a entre un beau jour et une tempête. Ces derniers temps, exaspéré par des contrariétés littéraires, il a pris tant de drogues et fait tant de folies qu'il s'est jeté dans l'état de désespoir et de démence le plus affreux. Je ne me le rappelle pas sans horreur. Dès qu'il vit que tout ce qu'il avait tenté pour augmenter ses forces avait produit un effet contraire, la mort fut toujours devant ses yeux ; dès ce moment la rage s'est emparée de son âme. Rappelez-vous les fureurs d'Oreste ; ainsi est mort Voltaire : furiis agitatus obiit. »

Il nous reste, pour compléter cette conclusion, à dire quelques mots de Genève après la mort de Voltaire. Son existence morale en devint aussitôt beaucoup plus calme, et son Église, en particulier, eut des jours plus tranquilles. Les écrits impies ne se multipliant plus avec la même abondance, les pasteurs purent s'attacher à neutraliser les fâcheuses influences des luttes récentes, et à détruire les germes d'incrédulité et d'immoralité jetés par le philosophe de Ferney, sans avoir en même temps la continuelle inquiétude de surveiller des ouvrages nouveaux et de repousser des attaques sans cesse renouvelées. Pour donner une idée approximative de l'état religieux dans lequel se trouva notre ville durant les vingt dernières années de ce siècle, dont Voltaire avait accaparé le centre et le cœur, nous citerons seulement encore quelques lignes d'un rapport du Consistoire. On sait que ce corps n'a jamais cherché, dans ses comptes rendus, à déguiser la vérité : « Si nous avons, dit-il, la douleur de voir des gens en grand nombre subir l'influence de la fausse philosophie et vivre sans Dieu et sans espérance en ce monde, nous bénissons Dieu de compter, dans tous les rangs de la société, des maisons où la piété est héréditaire et où l'instruction domestique répond à l'instruction publique. Dans ces demeures l'union règne, chacun se sent dans l'ordre chacun emploie utilement sa journée. On la commence en priant Dieu. Le jour du dimanche en partie en actes de dévotion et de charité, en partie en délassements honnêtes. Nous sommes heureux de rencontrer souvent, dans ce 
jour du Seigneur, la jeune mère de famille, accompagnée d'un enfant, qui porte le secours et la joie dans une pauvre demeure, et fait aimer à son fils et à sa fille les premiers devoirs du chrétien. Le lendemain on se remet gaiement au travail, et l'on est plus content dans la médiocrité que d'autres ne le sont dans l'abondance. L'aliment spirituel qu'on prend chaque jour entretient la santé des âmes chrétiennes. Survient-il quelque revers, quelque maladie, on s'entraide, on se console, on se fortifie mutuellement, on prie Dieu. Les paroles du mourant restent gravées dans le souvenir de ceux qui l'entourent; on pleure un tel homme, on le suit dans la demeure céleste où la foi, manifestée par ses oeuvres, lui assure la bonne place... »

La richesse, la renommée, l'esprit et le génie, sont de grands moyens pour diriger le monde, et, ce qui n'est pas à l'honneur de notre pauvre humanité, jamais leur action n'est plus puissante que lorsqu'ils prennent comme point d'appui quelqu'une des mauvaises passions dont fourmille cette terre. Mais si l'expérience nous révèle ce triste fait, elle nous donne aussi la preuve consolante qu'il est un autre pouvoir, plus lent peut-être dans son action et plus difficile à mettre en œuvre, mais, en revanche, plus fécond encore en effets durables. C'est la foi ferme et patiente des hommes résolus à faire prévaloir, avec l'aide de la protection divine, les principes éternellement vrais de la justice, de la sagesse et de la moralité. 